\title{
Design and Development of a Novel Nanoparticle Aerosol Generation System for Research Applications
}

Justin R. Chambers

Follow this and additional works at: https://researchrepository.wvu.edu/etd

\section{Recommended Citation}

Chambers, Justin R., "Design and Development of a Novel Nanoparticle Aerosol Generation System for Research Applications" (2017). Graduate Theses, Dissertations, and Problem Reports. 5335.

https://researchrepository.wvu.edu/etd/5335

This Dissertation is protected by copyright and/or related rights. It has been brought to you by the The Research Repository @ WVU with permission from the rights-holder(s). You are free to use this Dissertation in any way that is permitted by the copyright and related rights legislation that applies to your use. For other uses you must obtain permission from the rights-holder(s) directly, unless additional rights are indicated by a Creative Commons license in the record and/ or on the work itself. This Dissertation has been accepted for inclusion in WVU Graduate Theses, Dissertations, and Problem Reports collection by an authorized administrator of The Research Repository @ WVU.

For more information, please contact researchrepository@mail.wvu.edu. 


\title{
Design and Development of a Novel Nanoparticle Aerosol Generation System for Research Applications
}

\author{
Justin R. Chambers \\ Dissertation Submitted to the \\ Benjamin M. Statler College of Engineering and Mineral Resources \\ at West Virginia University \\ in partial fulfillment for the Degree of \\ Doctorate of Philosophy in Mechanical Engineering
}

\author{
James E. Smith, Ph.D., Chairman \\ Timothy Nurkiewicz, Ph.D. \\ Patrick Browning, Ph.D. \\ Edward Sabolsky, Ph.D. \\ Andrew Lowery, Ph.D.
}
Department of Mechanical and Aerospace Engineering
Morgantown, West Virginia
2016

Keywords: Nano-Particle, Generator, Aerosol, Dry Powder

Copyright 2016 Justin R. Chambers 


\section{Abstract \\ Design and Development of a Novel Nanoparticle Aerosol Generation System for Research Applications \\ Justin R. Chambers}

Nanoparticles have become of great interest within the scientific community for their use in diverse applications. With this rapidly evolving field, new nano-sized compounds are being developed and used for a variety of reasons. Nanoparticle aerosol technology, aerosolization and dispersion of nano-compounds, has many novel applications and can be used to support current research efforts. This may include anything from drug delivery techniques to industrial processes. To aid these processes, new methods of aerosol generation and dispersion are needed to meet these future needs. This research and development is being conducted to expand upon a novel nanoparticle aerosol generator as a research device, as well as, future applications such as biomedical, pharmaceutical and industrial manufacturing.

This investigation involves the analysis of a fully developed nanoparticle aerosol generation system. It was hypothesized that the particle size and concentration (output) of the device can be varied by precise manipulation of the input parameters. Moreover, the output of a sample compound can be set to a desired value based on a predictive mathematical model constructed experimentally. This hypothesis was tested through the completion of this work.

While a fundamental analysis of the aerosol generator represented an important first step, the resulting work demonstrates the valuable use of a controllable nano particle aerosol generation system and a predictive tool to allow the device to operate with a broad range of output characteristics and compounds. This allows the device to be used for multiple and diverse research efforts in the future.

The resulting outcome of this dissertation is a controllable system capable of varying both concentration and mean particle size by precise manipulation of the input parameters. The results demonstrate a single peak distribution with a geometric mean particle size $<200 \mathrm{~nm}$, standard deviation under 2.5 and the ability to hold consistent long term concentrations. Additionally, the predictive model allows the user to predict output values for a given range of input settings with an average prediction accuracy of greater than $92 \%$. The developed model also provides valuable information which include factor effects, optimal settings, factor influence and interactions. This information along with the controllable system provides valuable insights for further development of the technology. 


\section{ACKNOWLEDGEMENTS}

Highest regard and appreciation to my advisor, Dr. James Smith; and to my committee members Dr. Timothy Nurkiewicz, Dr. Patrick Browning, Dr. Edward Sabolsky and Dr. Andrew Lowery. Your tutelage has been instrumental in my success and the success of this work.

Further gratitude goes to Dr. Jinghai Yi and Carroll McBride for their support and assistance in the lab. Additionally, Dr. Gary Ganser who provided significant contribution to any and all of my mathematical questions. I would also like to thank all of my family, friends, colleagues, instructors and mentors who have contributed to my personal and professional growth.

Lastly, I would like to thank my parents for their love and support as I pursued my degrees. I would not be where I am today without them. 


\section{TABLE OF CONTENTS}

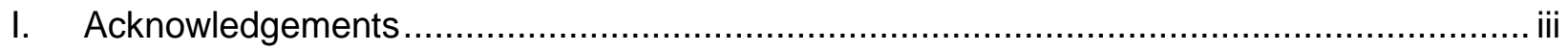

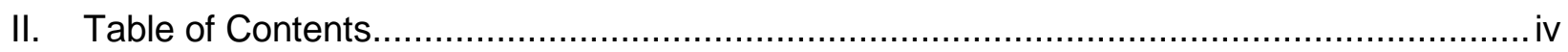

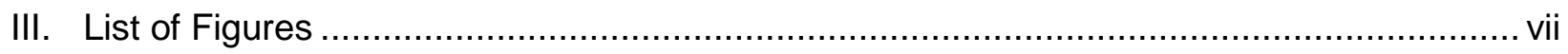

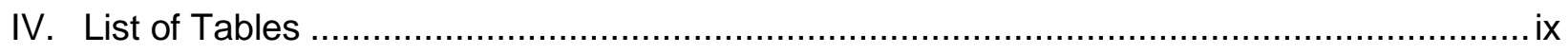

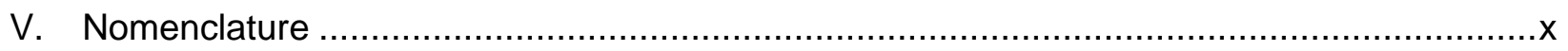

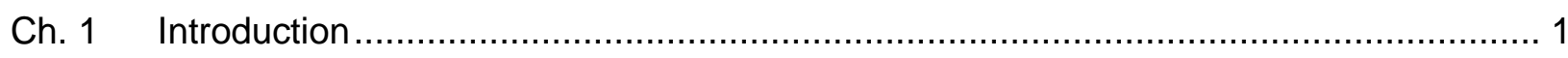

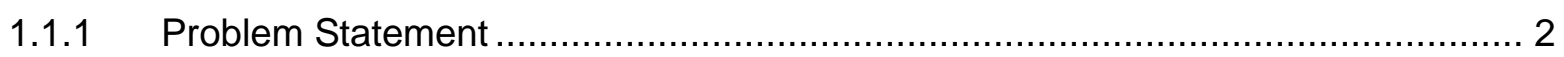

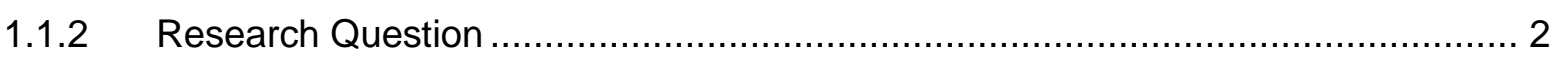

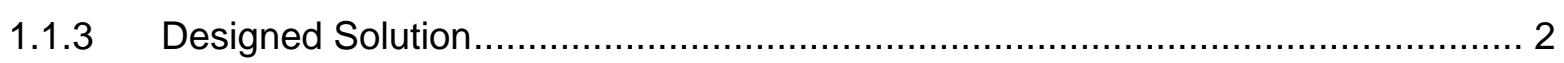

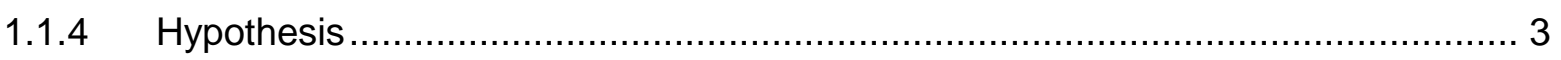

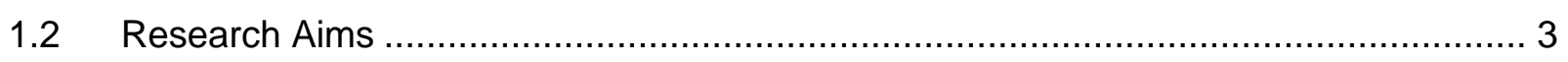

1.2.1 Specific Aim 1: Evaluate the existing technology (Analytical Analysis) ................. 3

1.2.2 Specific Aim 2: Develop a system with control capabilities for characterization

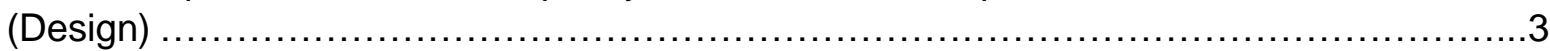

1.2.3 Specific Aim 3: Demonstrate the range of the system using a test matrix to build a predictive tool. (Experimental Testing) .................................................................. 3

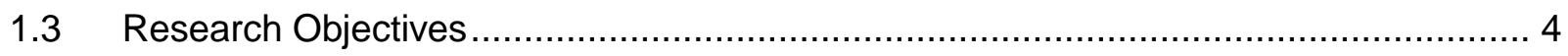

1.3.1 Objective 1: Fundamental Analytical Analysis (Evaluate) ……......................... 4

1.3.2 Objective 2: Design and Build the Controllable System (Develop) ....................... 4

1.3.3 Objective 3: Experimentally test the developed system for characterization (Demonstrate) ............................................................................................ 4

1.4 Research Approach ..................................................................................... 5

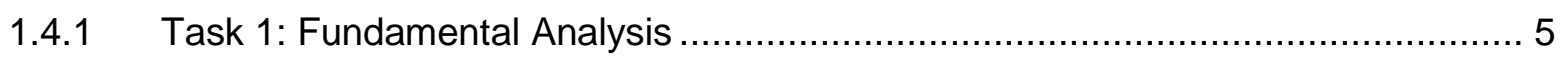

1.4.2 Task 2: Design and Build Controllable System................................................. 5

1.4.3 Task 3: Experimental Design .................................................................... 5

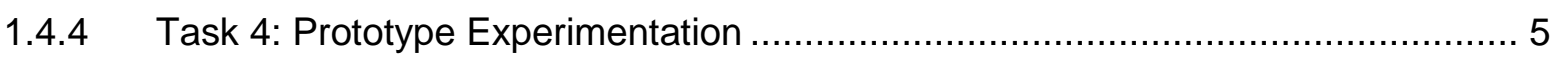

1.4.5 Task 5: Mathematical model based on experimental testing ............................... 5

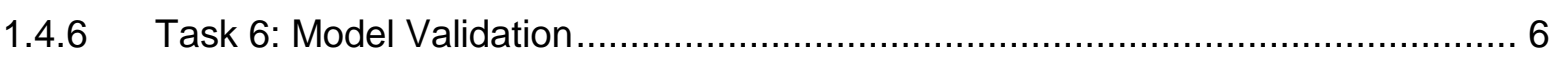

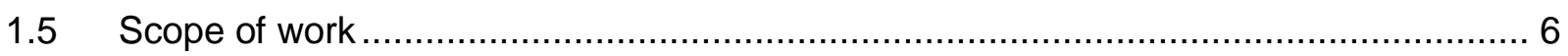

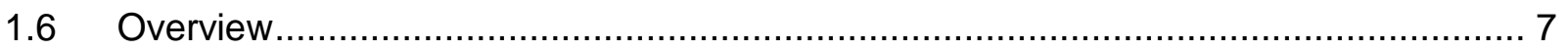

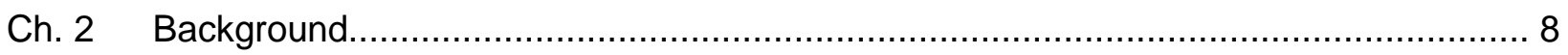

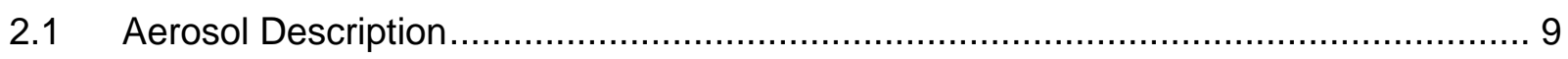

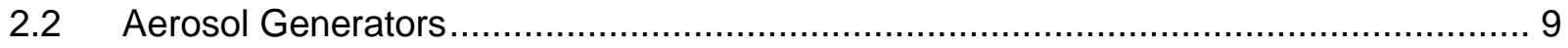

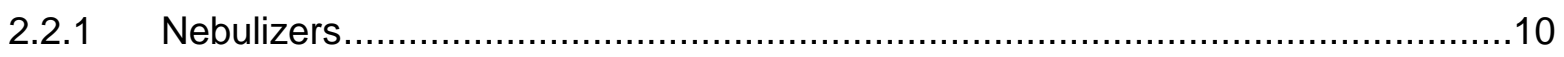

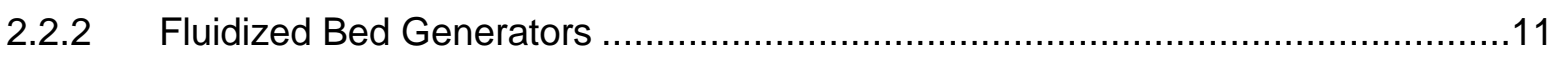




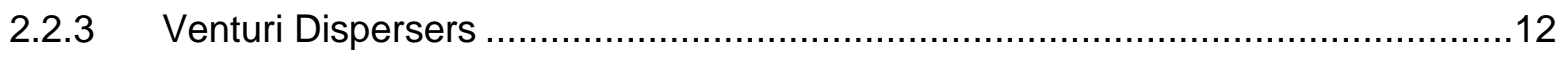

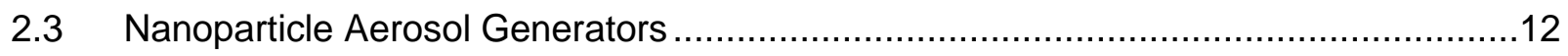

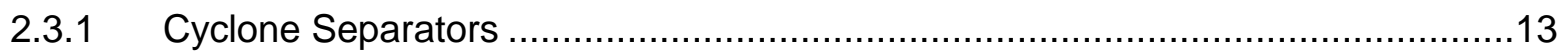

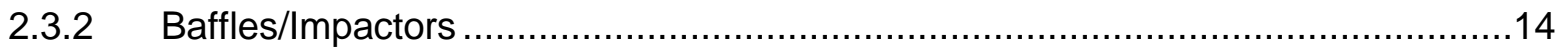

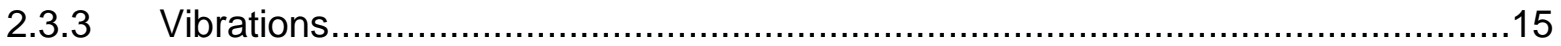

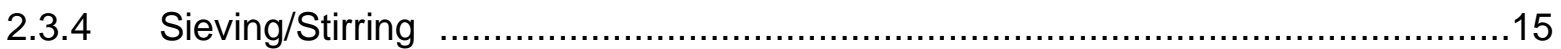

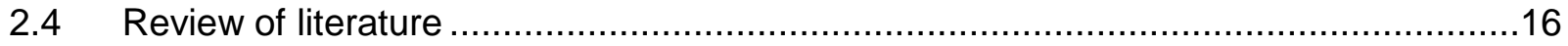

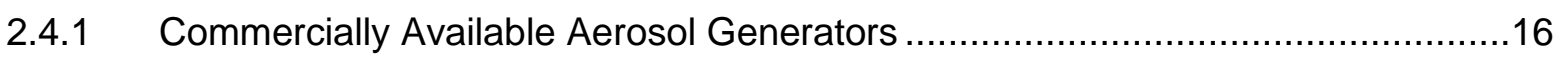

2.4.2 Aerosol Generator Research and Development...........................................23

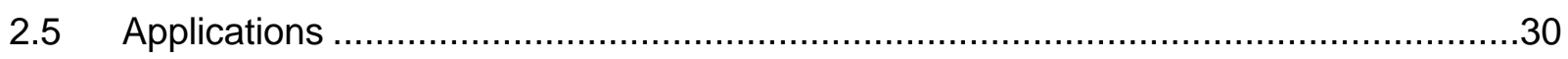

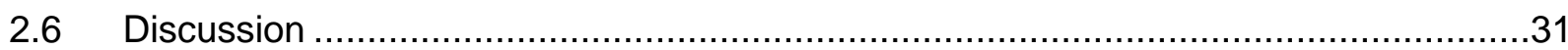

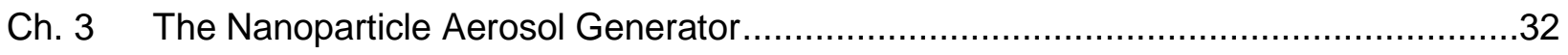

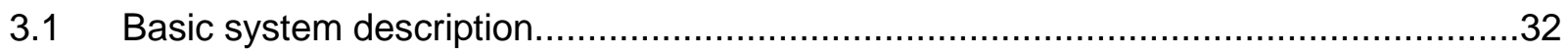

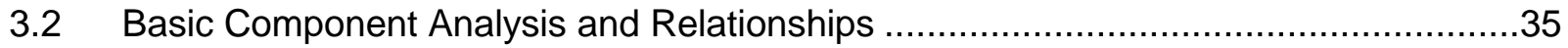

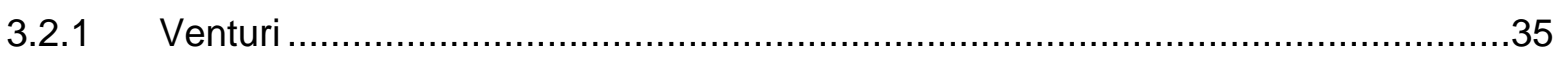

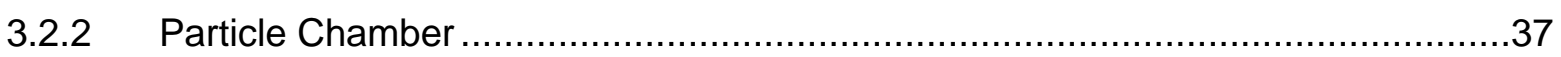

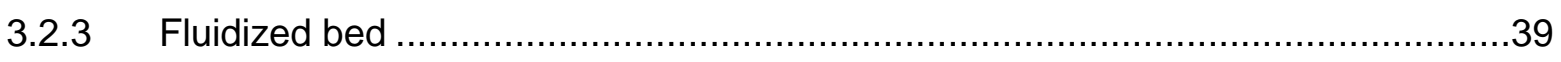

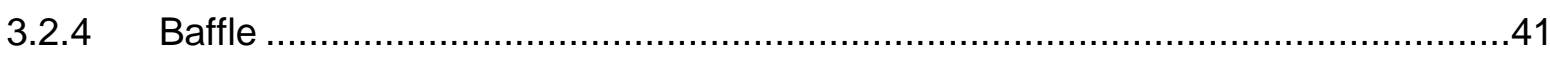

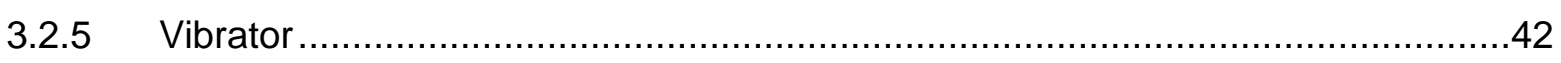

3.3 Combined Component Flow Analysis.................................................................

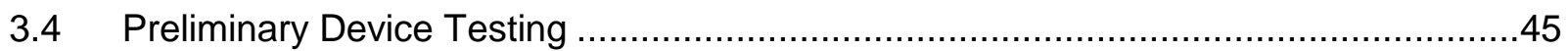

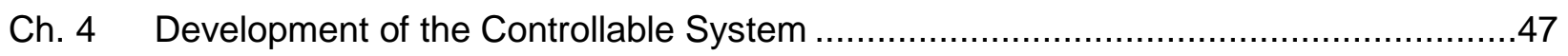

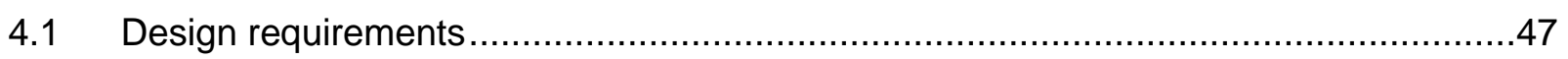

Ch. 5 Modeling the Nanoparticle Aerosol Generation System ….....................................51

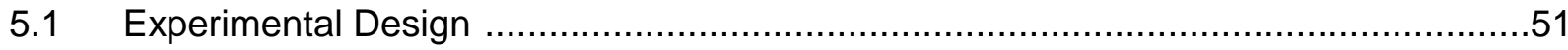

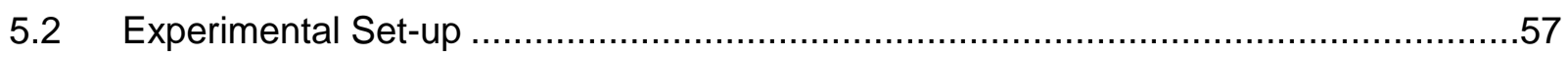

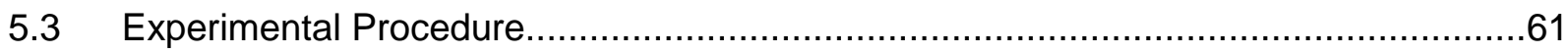

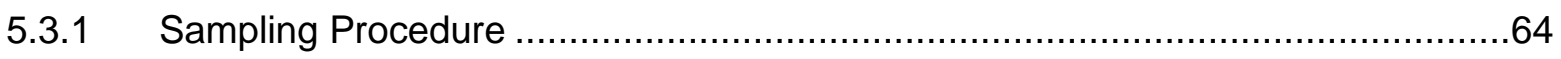

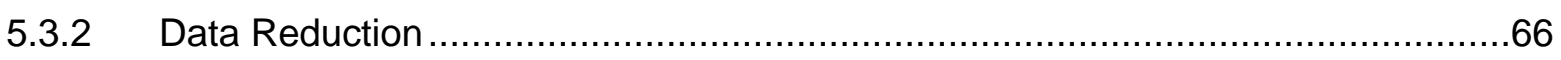

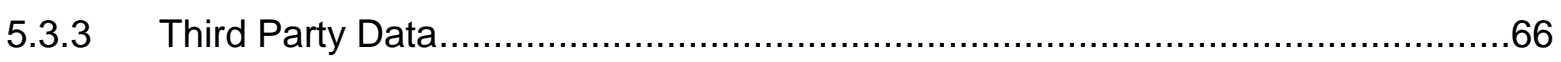

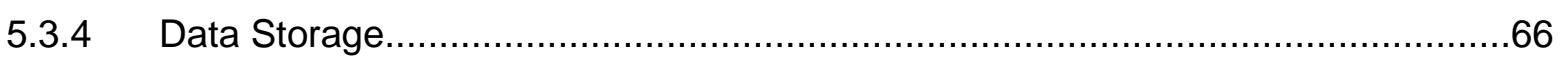

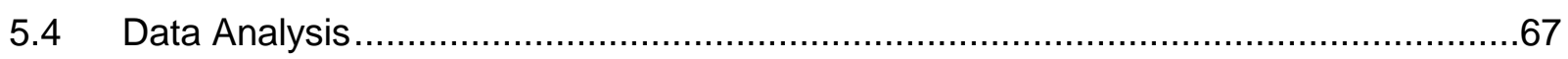

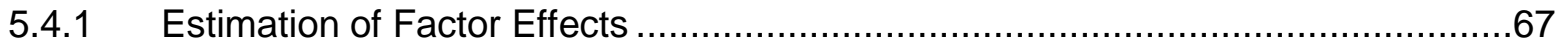

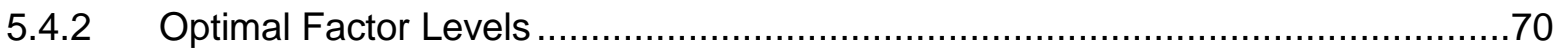

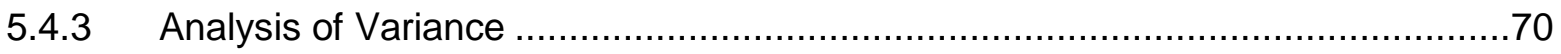

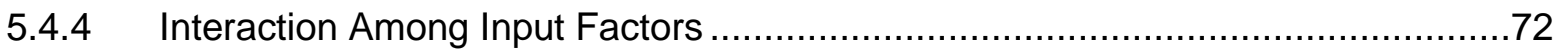

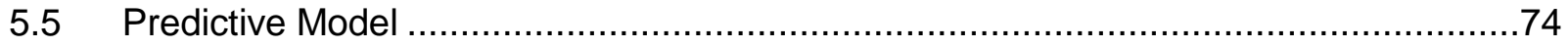




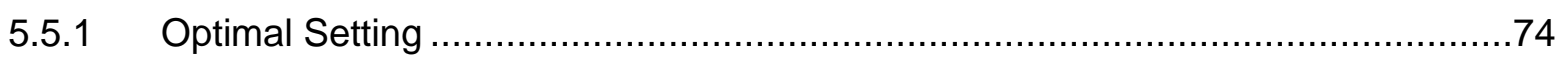

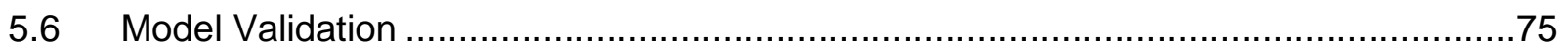

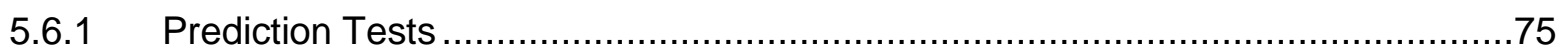

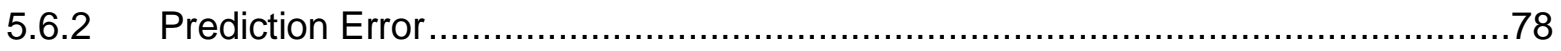

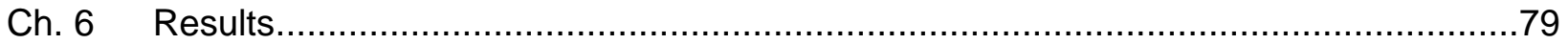

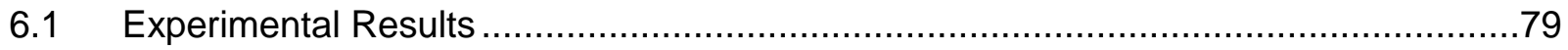

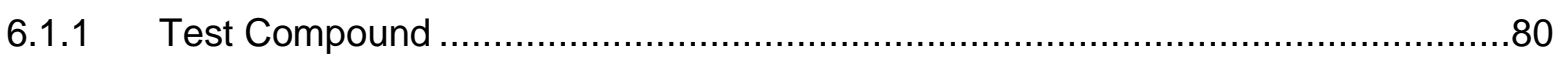

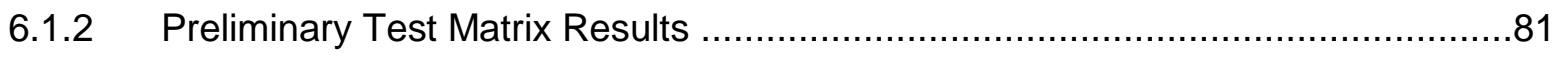

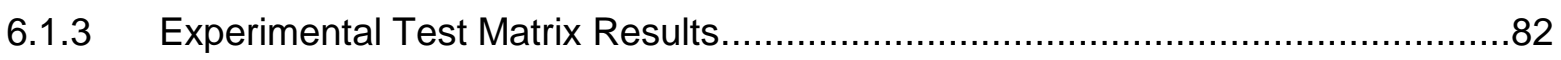

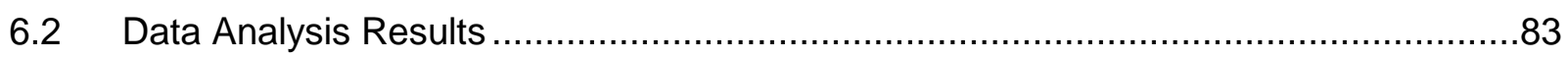

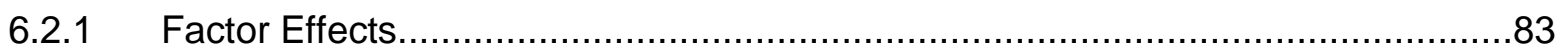

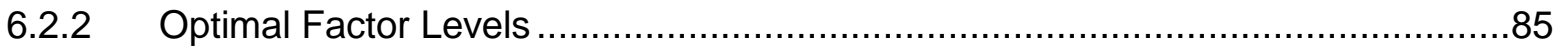

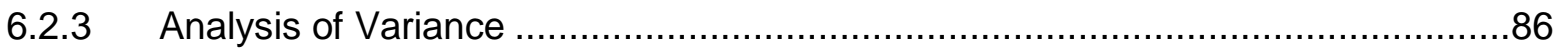

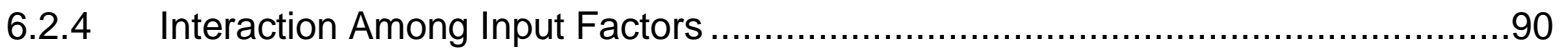

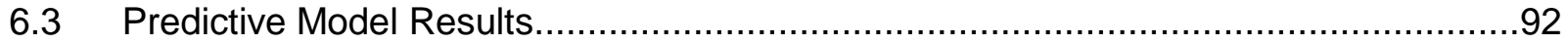

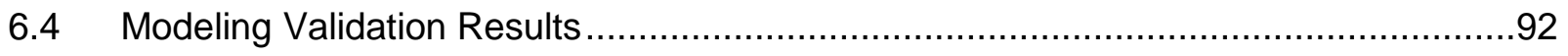

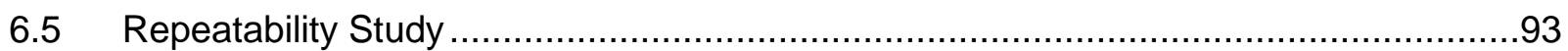

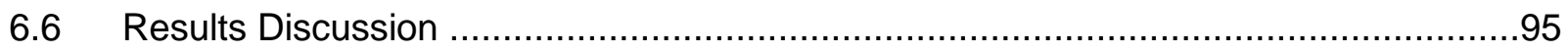

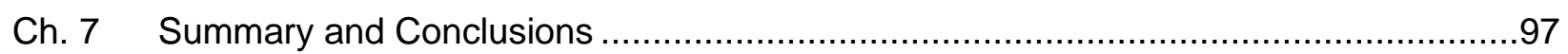

Ch. 8 Recommendations and Continued Work ...........................................................

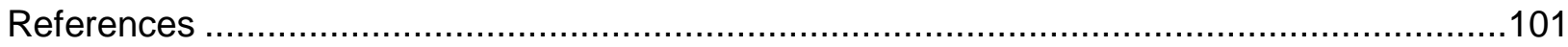

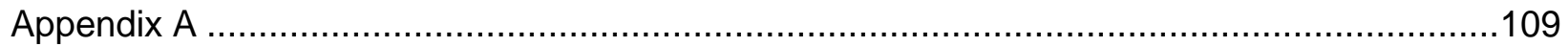

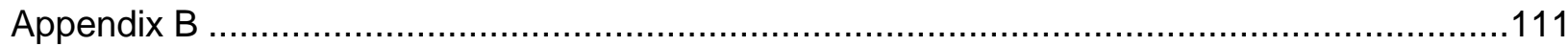




\section{LIST OF FIGURES}

Figure 1- Common Nebulizing Techniques ....................................................................10

Figure 2 - Standard Fluidized Bed ............................................................................

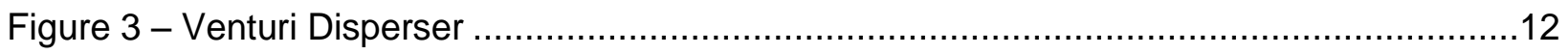

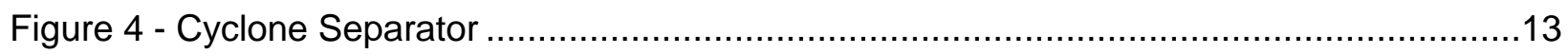

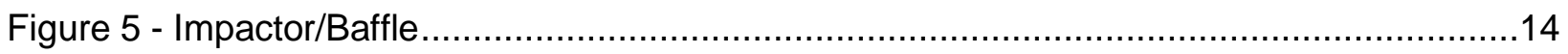

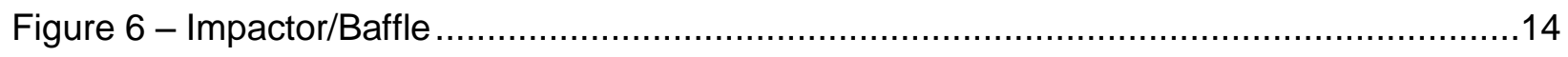

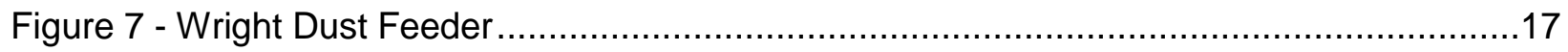

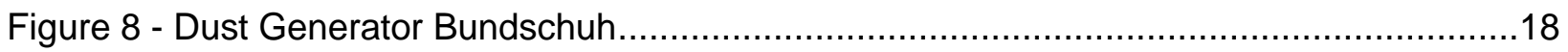

Figure 9 - Small Scale Powder Disperser ..................................................................19

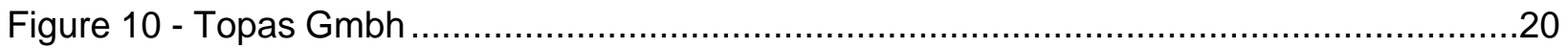

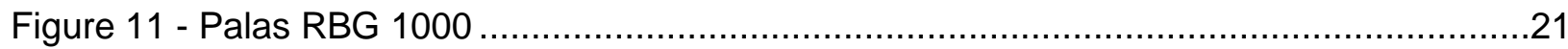

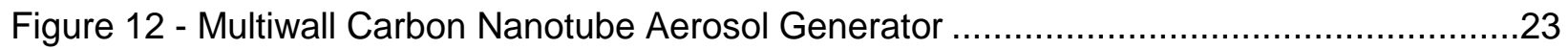

Figure 13 - Layout of aerosol generation and inhalation exposure system ...............................24

Figure 14 - Diagram of acoustic generator and exposure system.........................................25

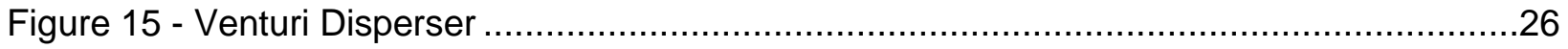

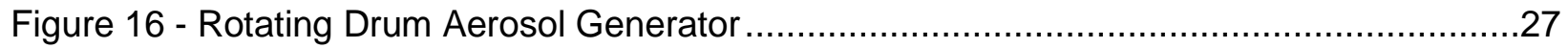

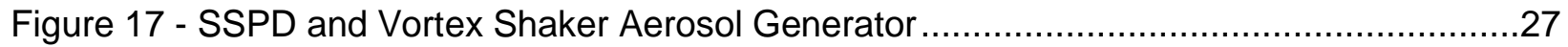

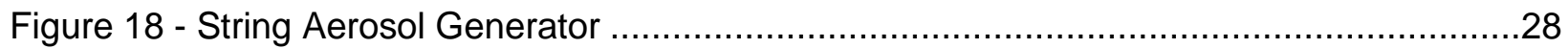

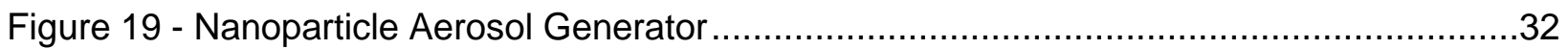

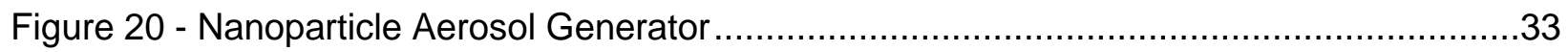

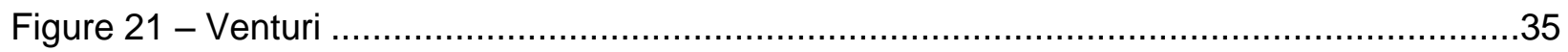

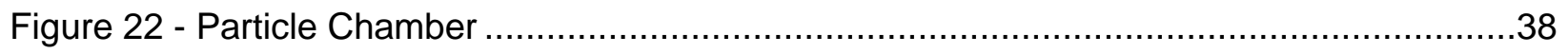

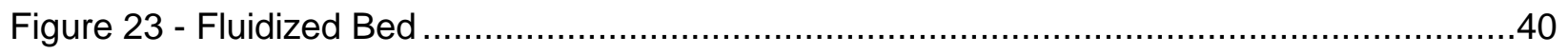

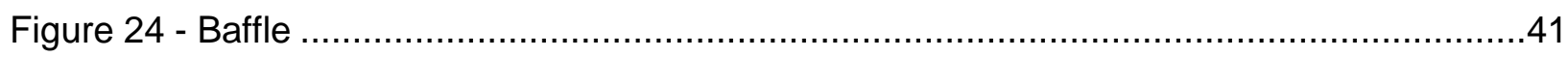

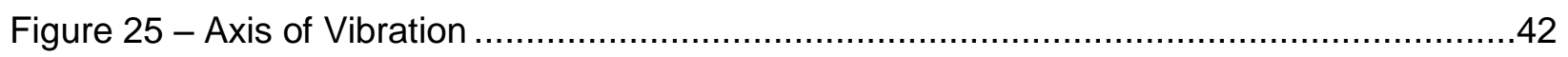

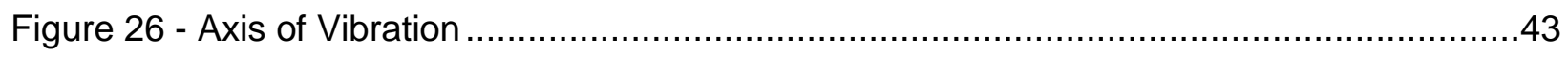

Figure 27 - Nanoparticle Aerosol Generator ................................................................... 44

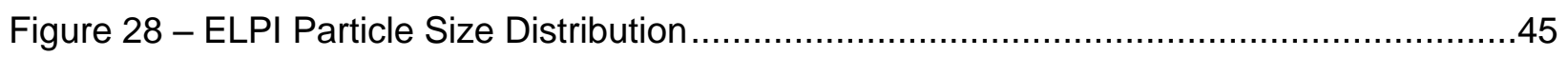

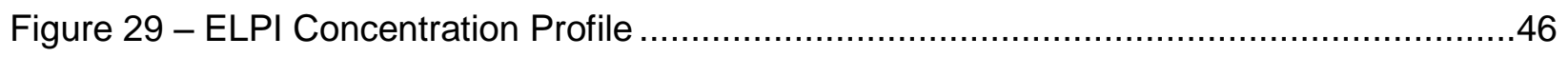

Figure 30 - Nanoparticle Aerosol Generator System Schematic..........................................48

Figure 31 - Nanoparticle Aerosol Generator System Rendering …....................................49

Figure 32 - Nanoparticle Aerosol Generator System Prototype ...........................................50

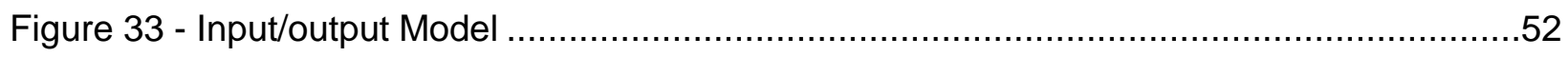


Figure 34 - Lognormal Aerosol Size Distribution Example............................................53

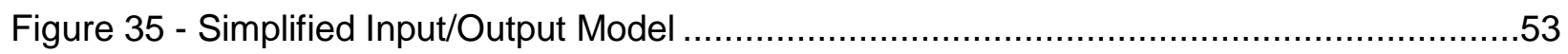

Figure 36 - Sampling Chamber Set-up .................................................................... 57

Figure 37 - Nanoparticle Aerosol Generation System Test Set-up ......................................58

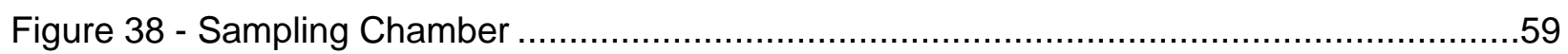

Figure 39 - Scanning Mobility Particle Sizer .........................................................60

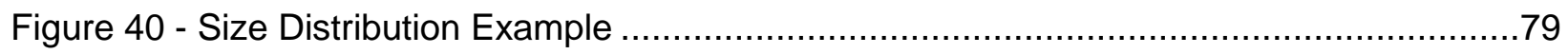

Figure 41 - Statistic Table Example as Displayed by the SMPS .......................................79

Figure 42 - SEM Image of Aerosol Sample ................................................................ 80

Figure 43 - Factor Effect Plot for Particle Concentration.................................................. 83

Figure 44 - Factor Effect Plot for Mean Particle Size ....................................................... 84

Figure 45 - Factor Effect Plot for Geometric Standard Deviation ....................................... 84

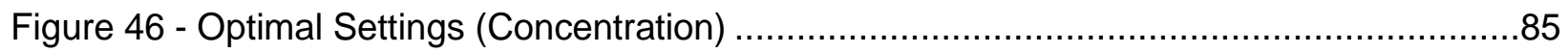

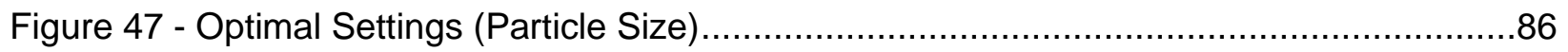

Figure 48 - Optimal Settings (Standard Deviation) ….................................................... 86

Figure 49 - Influence of each factor on Concentration .................................................... 88

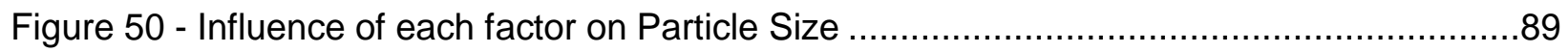

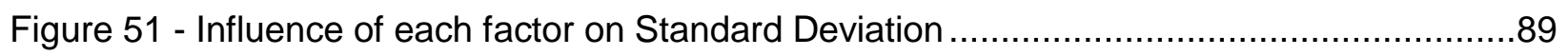

Figure 52 - Interaction Plot for Factors B and C on Concentration.....................................90

Figure 53 - Main Effects Plot for Factors B and C on Concentration .....................................

Figure 54 - Interaction Surface Plot for Factors B and C on Concentration.............................91

Figure 55 - Concentration Accumulation Factor Plot ......................................................94

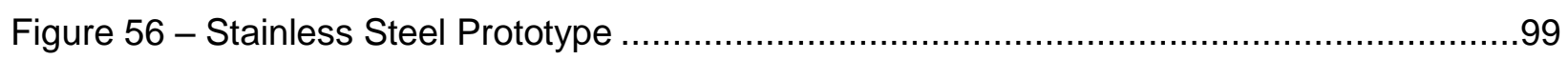




\section{LIST OF TABLES}

Table 1 - Comparison of Select Commercially Available Aerosol Generators..........................22

Table 2 - Comparison Table of Technology in Research and Development ...........................29

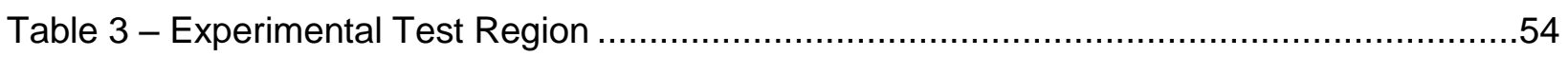

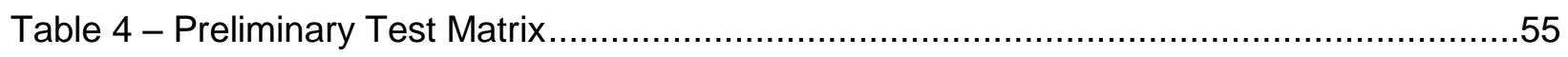

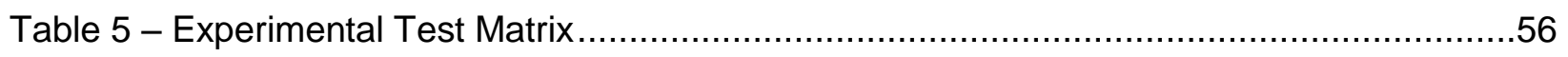

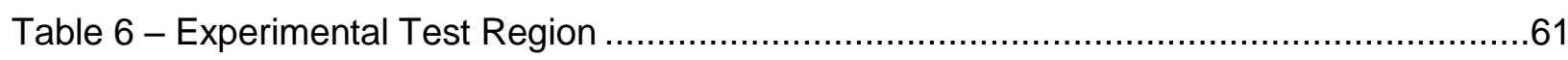

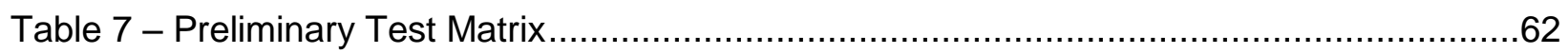

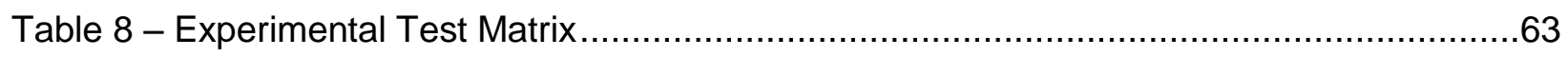

Table 9 - Preliminary Test Matrix with Output Particle Characteristics ...................................64

Table 10 - Experimental Test Matrix with Output Particle Characteristics .............................65

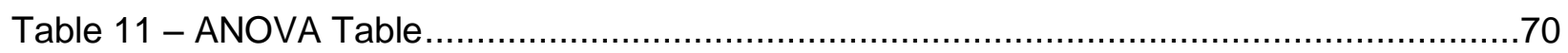

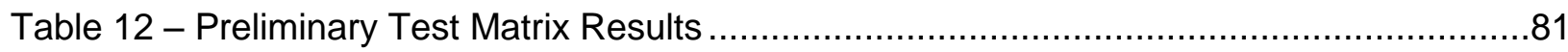

Table 13 - Experimental Test Matrix Results .......................................................... 82

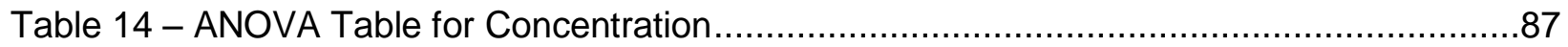

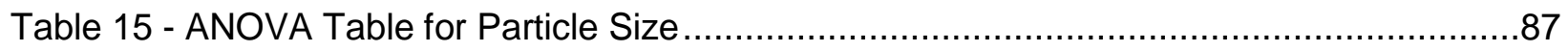

Table 16 - ANOVA Table for Standard Deviation ............................................................ 88

Table 17 - Interaction Values for Factors B and C on Concentration ...................................90

Table 18 - Prediction Results for Optimal Settings ..............................................................92

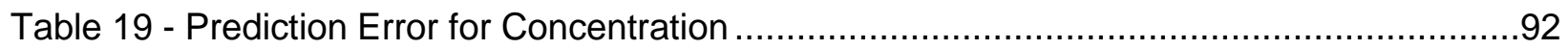

Table 20 - Prediction Error for Geometric Particle Size ....................................................93

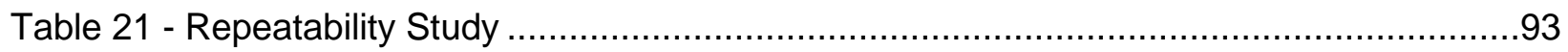




\section{NOMENCLATURE}

Symbol

Description

Units

Mathematical Terms and Abbreviations

\begin{tabular}{ccc}
\hline$N$ & Number of Particles & - \\
$D$ & Geometric Diameter & $\mathrm{nm}$ \\
$D_{p}$ & Aerodynamic Diameter & $\mathrm{nm}$ \\
$Q$ & Volumetric Flow Rate & $\mathrm{L} / \mathrm{min}$ \\
$A$ & Area & $\mathrm{m}$ \\
$P$ & Pressure & $\mathrm{kPa}$ \\
$v$ & Fluid Velocity & $\mathrm{m} / \mathrm{s}$ \\
$Z$ & Distance from the Datum & $\mathrm{m}$ \\
$V$ & Volume & $\mathrm{m}^{3}$ \\
$\Delta P$ & Differential Pressure & $\mathrm{kPa}$ \\
$g$ & Gravity & $\mathrm{m} / \mathrm{s}^{2}$ \\
$F_{0}$ & Force & $\mathrm{N}$ \\
$t$ & Time & $\mathrm{s}$ \\
$\mathrm{SiO}_{2}$ & Silicon Dioxide & - \\
$\mathrm{TiO}_{2}$ & Titanium Dioxide & - \\
$\mathrm{ZnO}$ & Zinc Oxide & - \\
\hline
\end{tabular}

\begin{tabular}{ccc}
\hline \multicolumn{3}{c}{ Greek Variables } \\
\hline$\gamma$ & Specific Weight & $\mathrm{kN} / \mathrm{m}^{3}$ \\
$\epsilon$ & Fluidized Bed Void Fraction & - \\
$\rho_{p}$ & Powder Density & $\mathrm{kg} / \mathrm{m}^{3}$ \\
$\rho_{f}$ & Fluid Density & $\mathrm{kg} / \mathrm{m}^{3}$ \\
$\omega$ & Frequency & $\mathrm{Hertz}$ \\
$\sigma_{g}$ & Geometric Standard Deviation & - \\
$\eta$ & Summary Statistic & - \\
$\mu$ & Overall Mean & - \\
\hline
\end{tabular}

\section{Acronyms}

APS

CAD

CFD

CPC

ELPI

ENM
Aerodynamic Particle Sizer

Computer Aided Design

Computational Fluid Dynamics

Condensation Particle Counter

Electric Low Pressure Impactor

Engineered Nano Materials 


\begin{tabular}{|c|c|c|}
\hline EPA & Environmental Protection Agency & - \\
\hline DOE & Design of Experiments & - \\
\hline GSD & Geometric Standard Deviation & - \\
\hline HEPA & High-efficiency Particulate Arrestance & - \\
\hline MMAD & Mean Mobility Aerodynamic Diameter & $\mathrm{nm}$ \\
\hline MOUDI & Micro-Orifice Uniform Deposition Impactors & - \\
\hline MWCNT & Multiwall Carbon Nanotubes & - \\
\hline NSAM & Nanoparticle Surface Area Monitor & - \\
\hline $\mathrm{NIH}$ & National Institute of Health & - \\
\hline $\mathrm{NIOSH}$ & National Institute of Occupational Safety and Health & - \\
\hline NPAG & Nano-Particle Aerosol Generator & - \\
\hline PM & Particulate Matter & - \\
\hline SMPS & Scanning Mobility Particle Sizer & - \\
\hline SSPD & Small Scale Powder Disperser & - \\
\hline WBP & Whole-body Plethysmography & - \\
\hline \multicolumn{3}{|c|}{ Subscripts and Superscripts } \\
\hline $\mathbf{\square}_{\text {in }}$ & Indicates entering the system & - \\
\hline $\mathbf{\square}_{\text {out }}$ & Indicates exiting the system & - \\
\hline $\mathbf{\square}_{m p}$ & Referring to the midpoint & - \\
\hline $\mathbf{\square}_{i}$ & Referring to the current step in time or space & - \\
\hline $\mathbf{a}_{1}, \mathbf{m}_{2}$ & Referring to the state (first or second) & - \\
\hline
\end{tabular}




\section{CH. 1 INTRODUCTION}

Nanotechnology has gained great interest within the scientific community for its use in diverse applications. Within this rapidly expanding research area new nano-sized compounds and materials are being developed and used in a variety of fields for both research and commercial applications. Aerosolization and dispersion of these nanomaterials has novel applications and can be used to support current research efforts as well as reinventing nanoparticle utilization techniques within the research community and industry. The design and development of novel ways to generate nanoparticle aerosols (<200 $\mathrm{nm}$ ) specifically from dry powder formulas has a significant role in the future of nanotechnology [1]. Currently, this plays a significant role in testing the toxicity of new nanomaterials for public health and environmental exposure when nanomaterials are manufactured and used. Additionally, uniformly sized particles are needed for various industrial applications such as the calibration of aerosol measurement instruments, testing filter efficiencies as well as a wide range of other research applications.

The generation of nanoparticle aerosols, specifically from dry powders, is difficult because of how easily these engineered nanomaterials agglomerate [2]. This is due to the strong intermolecular forces that primarily consist of van der walls attraction, capillary and electrostatic forces [3, 4]. This leads to the formation of larger agglomerated structures in the tens or hundreds of microns in size [4], which are difficult to break up, especially for more cohesive dry powders such as nano-titanium dioxide (nanoTiO2). Additionally, the generation of nanoparticle aerosols with consistent long term concentrations and a high level of repeatability is very difficult [5]. Therefore, to generate and disperse aerosols with a mean particle size $<200 \mathrm{~nm}$ over extend periods of time requires the development of novel methods and devices.

To address this need, a nanoparticle aerosol generator was invented by Dr. Jinghai Yi and Dr. Timothy Nurkiewicz within the Toxicology Research Lab at West Virginia University [6] [7]. It consists of a vibrating fluidized bed within a negative pressure particle chamber, a baffle and a venturi. The device utilizes vibration, high speed shear flow and multiple impaction sections to break up larger agglomerates for dispersion. The initial purpose of this technology was to create a device for toxicology research that facilitated the ability to identify safe nanomaterials for use in diverse human applications and to establish safe pulmonary nanomaterial exposure limits.

The study of biological health effects using aerosolized nanoparticles is particularly complex and timeconsuming [2]. These studies require the aerosolized particles delivered to the exposure chamber to have stable concentrations maintained at a target level for extended periods; a homogeneous 
composition free of contaminants; and lastly, a stable size distribution with a geometric mean diameter < $200 \mathrm{~nm}$ and a geometric standard deviation $\sigma_{\mathrm{g}}<2.5[5]$.

Commercially available aerosol generators include nebulizers, fluidized beds, venturi aspirators and dust feeders. However, the majority of these commercially available aerosol generators cannot generate aerosols with a size distribution (mean diameter) $<1 \mu \mathrm{m}$ [5]. There is an immediate need for a nanoparticle aerosol generator with these increased capabilities due to the fact that currently available technology cannot create aerosols in the size range, concentration and duration that are necessary to conduct nanoparticle inhalation toxicology assessments that simulate human exposures.

Failure to address this problem for toxicology assessments will result in the continued and increasing use of untested nanomaterials in industry and a delay in the identification of safe nanomaterials for diverse uses that will ultimately benefit human and environmental health. The efforts of this research also support the Toxic Substance Control Act-section 10 (TSCA) and the Clean Air Act-Section 103 (CAA) established by the EPA. [8]

\subsubsection{Problem Statement}

The nanoparticle aerosol generator currently provides one distribution and one concentration of nanoparticle aerosols from a dry powder formula. The operational range and device characterization of the current technology is still unknown. This includes the bounds in particle size, size distribution and concentration as well as its use with diverse compounds. It is also unknown how the input parameters of the current technology effect the output and what degree of influence each one has on that output as well as which are the dominating parameters. This makes it challenging to determine and set the optimal input parameters for a desired output. This also makes it difficult to predict how to aerosolize various other compounds and regulate or control the particle size and concentration. Therefore, the proposed effort will be to characterize the technology for a range above and below the currently known operational parameters of the device. This characterization currently does not exist for this technology. This provides the basis for the research question:

\subsubsection{Research Question}

How can the current state of the technology be evaluated and improved to provide a fully controllable system and then characterized to develop a predictive tool for operation?

\subsubsection{Designed Solution}

A mathematical modeling approach using designed experiments will allow various parameters to be better understood. These parameters include:

- Input Factor Effects 
- Optimal Settings

- Dominant Factors

- Factor Interactions

- Predictive Model

This approach will provide the ability to vary the input parameters based on a predictive model to create a desired output, one that can go above and below the current devices operational range (i.e. higher concentrations, lower particle sizes). This will be significant for future applications such as industrial, medical and additional research applications. It will establish the foundation needed to automate the system and apply feedback control to the technology. This will also provide a platform for the testing of new compounds of interest in the future.

\subsubsection{Hypothesis}

The central hypothesis of this work is that the particle size and concentration (output) can be varied by precise manipulation of the input parameters. Moreover, the output (size distribution and concentration) of a known compound can be set to a desired value based on a predictive mathematical model constructed experimentally. This hypothesis is tested through the completion of the set research aims and objectives.

\subsection{Research Aims}

The proposed investigation seeks to characterize the current state of the technology and to build a controllable unit with a predictive tool for the device's performance. More specifically, the purpose of this study is to generate and disperse nanoparticle aerosols from dry powder formulas over extended periods of time with the ability to vary particle size, size distribution and concentration for a desired application and compound. To achieve these goals, the following aims have been identified.

1.2.1 Specific Aim 1: Evaluate the existing technology (Analytical Analysis)

Aim 1A: Describe fundamental operation of the technology

Aim 1B: Conduct fundamental analytical analysis

1.2.2 Specific Aim 2: Develop a system with control capabilities for characterization (Design) Aim 2A: Design controllable system

Aim 2B: Spec components based on fundamental analytical analysis

1.2.3 Specific Aim 3: Demonstrate the range of the system using a test matrix to build a predictive tool (Experimental Testing)

Aim 3A: Design and Conduct Experiments 
Aim 3B: Analyze Data

Aim 3C: Develop Predictive Model

\subsection{Research Objectives}

The objective of this research is to take the current technology and characterize it to build a controllable system and a predictive tool to ultimately provide the ability to expand its output to a wider range of particle sizes, concentrations and compounds to be aerosolized. In order to reach the aims presented above the following objectives have been identified.

\subsubsection{Objective 1: Fundamental Analytical Analysis (Evaluate)}

A fundamental analytical analysis will be conducted on the various components and subsystems of the technology separately. This will then be combined for an overall system description to provide a fundamental understanding of the device's operation. This will be used to evaluate the current device and size the components for the design and development of the controllable system.

\subsubsection{Objective 2: Design and Build the Controllable System (Develop)}

This system will provide the ability to control the output of the device and the compounds that can be aerosolized. This system will also help to standardize the technology to allow it to be used in other labs and for diverse applications.

The design of the controllable unit has the following requirements:

I. Full enclosure which includes all of the necessary components needed to generate particles

i. The enclosure must retain a slightly negative relative pressure to capture rogue particles providing containment of fugitive particles

ii. The enclosure must dampen any vibrations from the device

iii. The enclosure must reduce the noise of the device

II. The system must allow for the manifold of multiple generators for higher concentrations and longer experiment durations (phasing in additional generators or using the automatic material feed to the fluidized bed)

III. The system must allow full control of each controllable input parameter which include: vibration frequency, amplitude and orientation; venturi pressure and flowrate; fluidized bed flowrate and differential pressure; and dilution port flowrate.

\subsubsection{Objective 3: Experimentally test the developed system for characterization} (Demonstrate)

Experimental testing will be conducted to quantify the range of the developed system. Validation of the system will be done with state-of-the-art particle aerosol characterization techniques within the inhalation 
facility at West Virginia University. A test matrix will be built to run a set of tests to build out the predictive tool. Statistical analysis will be used to describe the collected data received from the experiments. This will provide the necessary information to characterize the technology, refine the analysis and find the critical parameters that influence the output.

\subsection{Research Approach}

To accomplish the set objectives, tasks have been identified and outlined below. Details of the tasks and subtasks presents the completion of the research.

\subsubsection{Task 1: Fundamental Analysis}

A fundamental analytical analysis was conducted to evaluate the current device design, explain the basic operation and size components for the controllable system. Initially, simple models were chosen to characterize each piece individually and then combined to describe the overall system.

\subsubsection{Task 2: Design and Build Controllable System}

An experimental apparatus (research prototype) was constructed to use for experimental testing and verification. This apparatus allows for each of the input parameters to be adjusted and controlled independently. This will provide the ability to run a range of experiments for the test matrix and build the predictive tool to characterize the device.

\subsubsection{Task 3: Experimental Design}

A design of experiments approach was used to develop the test matrix needed to provide the appropriate data to construct the predictive models. This approach also provides exploration of the design space which will reveal trends and relationships advancing the overall understanding of operation.

\subsubsection{Task 4: Prototype Experimentation}

The controllable system will be tested using a designed experiment approach utilizing a test matrix which will be built based on the information gained from previous tasks and preliminary device testing. The outputs of the device, the real-time particle size distribution, will be measured and monitored with a Scanning Mobility Particle Sizer (SMPS).

\subsubsection{Task 5: Mathematical model based on experimental testing}

With the experimental data available, a mathematical model will be used to build a predictive tool. This will be used to predict system performance based on selected input parameters or desired outputs. Additionally, this will provide other critical information about performance such as which inputs have the greatest influence on the output and to what degree. In the future, this will allow for smooth incorporation of control architecture and the characterization foundation needed to provide automation and feedback control to the technology. 


\subsubsection{Task 6: Model Validation}

The developed model will be validated by comparing the model's prediction estimations to the experimental results obtained from a preliminary test matrix independent of the experimental test matrix used to build the model. Validation tests at various input levels and combinations will be conducted to compute the prediction error for each test. The prediction error of the model for both particle size and concentration will be evaluated.

\subsection{Scope of work}

The scope of this work has been reduced to aerodynamic models and design of experiments models. Additional models that will be considered to be outside the scope of this work include thermodynamic models, electrical and magnetism models, particle to particle interaction models, flow/aerosol properties of nanoparticles, and compound specific models. The scope of this work is bound by the following assumptions:

I. Constant temperature - The temperature of the control chamber will be measured and held constant at 23 degrees Celsius.

II. Constant humidity - The humidity of the control chamber will be measured and held constant for the duration of the experiments. The target humidity for experimentation will be $<10 \%$.

III. Grounded components - All components of the device are grounded to reduce the influence of charge build up.

Although it is understood that the charge on the particles and devices has a significant influence on the aerosol behavior, it is unclear to what charge or charge level they exhibit and if the influence of charge is beneficial or degrading to the desired aerosol state. Literature has shown that aerosolized particles will develop a charge but it is unclear as to what charge they develop when at the nano scale. Some methods that have previously been used to control the charge on micron size particles, for example, include [9]:

I. Field charging by passing the particles through an electrical field

II. Diffusion charging which is due to thermal collisions between particles and ions

III. Photoelectron charging in which electrons are emitted from particles by UV irradiation

The analysis of formation and transfer of the charge on a particle is very theoretically intensive and partially unknown at the nano scale. For these reasons it will remain out of the scope of this work but will remain an area of interest for future work once the aerosol generator is characterized using the proposed methods. 


\subsection{Overview}

The proposed approach provides for an overall characterization of the system to create a technology that can be used in various research or commercial settings. This characterization provides new insights to the function of the technology and a novel method to predict performance. This approach also provides the most value for the current state of the technology and overall contribution to this research field and its future applications.

The results of this work are contained in the following chapters which will consist of a background and literature review to help put the technology, proposed aims, objectives and tasks into context with current research and available technology in Ch. 2. A system description and fundamental analysis of the technology and its components is reported in Ch. 3. Stemming from this analysis the design and development of the controllable system is reported in $\mathrm{Ch}$. 4 . The developed system is then modelled and characterized in Ch.5 using a designed experiment to develop the predictive model. This model is then validated and the results are reported. The final chapters conclude the work with recommendations and looks at the future of the technology with regard to potential applications and impacts. 


\section{CH. 2 BACKGROUND}

In the last decade nanotechnology has forged a path to new electronic components, optical coatings, pharmaceuticals, medical technologies and more. Nanotechnology, which is defined as the science of working with materials on the nanometer scale [10], is anticipated to continue growing in prevalence within these fields. This growth has already been demonstrated with the increased use of nanotechnology in consumer products, research initiatives and technology development. These new nanotechnology innovations are, in one way or another, composed of or manufactured using engineered nanomaterials. Engineered nanomaterials (ENMs) are materials with at least one dimension in the size range of 1-100 nm [11]. While these new materials are being implemented in several fields, studies are showing that engineered nanomaterials can be toxic to humans and the environment when handled or exposed to the air [12]. With the increased utilization of nanotechnology today, engineered nanomaterials will only become more prevalent in the manufacturing setting as well as other aspects of the environment. This exposure of engineered nanomaterials to workers, consumers and the environments has led to the need for regulation, safe levels of exposure and proper handling procedures. These regulations are set by the Environmental Protection Agency (EPA) and are defined as Particulate Matter Levels [13].

Particulate Matter (PM) is defined as a mixture of airborne particles ranging from $5 \mathrm{~nm}$ to $100 \mu \mathrm{m}$ in aerodynamic diameter [14]. The EPA has set standards for what are considered safe levels of PM in the environment. $\mathrm{PM}_{10}$ was first established in 1987 to limit particles below $10 \mu \mathrm{m}$ in the air. As concern grew the EPA updated this regulation in 1997 introducing $\mathrm{PM}_{2.5}$ limiting the number of particles below 2.5 $\mu \mathrm{m}$ which are considered as "fine particles". Studies have shown that $\mathrm{PM}_{2.5}$ exposure is known to cause a number of undesirable cardiac, vascular and pulmonary responses [15]. As nanotechnology and the use of nanomaterials continued to progress, particles less than $100 \mathrm{~nm}$ became of interest for regulation. Early research has suggested that particles in this size range may be more damaging to such biological systems [15]. The EPA responded to this with new standards for what they define as "ultrafine particles", $\mathrm{PM}_{0.1}$ in light of these new findings. $\mathrm{PM}_{0.1}$ has since been shown to have a more toxic effect on biological systems than the larger $\mathrm{PM}_{2.5}$ confirming the need for such regulation [14].

To help establish these standards government agencies rely on labs that conduct exposure studies known as inhalation nanotoxicology assessments. Nanotoxicolgy, the branch of toxicology research concerned with the toxicity of nanomaterials, has since become a specific area of interest and research. Currently, nanotoxicology research using nanoparticle aerosols is being conducted to evaluate the toxicity of engineered nanomaterials that may be used in the future and exposed to the environment. 


\subsection{Aerosol Description}

An aerosol is defined as a colloidal system of particles suspended in dry air or another gas [16]. The term aerosol was presumably first established during World War I with the discovery of clouds of microscopic particles in the air. Aerosol research has since progressed significantly and today it is being used for a variety of applications. There are various types of aerosols and several established parameters used to help characterize aerosols including mass concentration, number concentration and size distribution of the particles suspended in the gas. Particle size and shape have a significant role in characterization. Since most particles are actually agglomerations of smaller particles and often irregular in shape, the aerodynamic diameter is typically used. The aerodynamic diameter of a particle is defined as the diameter of a hypothetical sphere of density $1 \mathrm{~g} / \mathrm{cm}^{3}$ having the same terminal settling velocity in calm air as the particle in question, regardless of its geometric size, shape and true density [17]. Lastly, aerosols can vary in how they are dispersed. For example, particle size distribution can be bimodal meaning there are two dominant particle size concentrations in the aerosol. Typically, unimodal distributions are sought after when generating aerosols.

\subsection{Aerosol Generators}

Aerosol generators were used as early as 1858 with the invention of nebulizers and vapor generators for inhalation therapy [18]. Aerosol generators have since been developed for a number of applications using both wet and dry approaches where both techniques have limitations. Wet aerosol generation methods can alter particle chemistry, while dry methods often cannot produce truly nanoscale aerosols [3]. Wet devices, such as nebulizers, electrospray and ultrasonic techniques generate evaporated aerosol particles from solutions. Wet devices have been shown to generate particles on the sub-micron level but have also been shown to be unsuitable for nanoparticle toxicology testing as it pertains to this research work [5]. 


\subsubsection{Nebulizers}

For years nebulizers were the primary method to aerosolize solutions. Common nebulizing techniques, as seen in Figure 1, include: ultrasonic nebulizers, jet nebulizers and other novel nebulizing techniques [19].
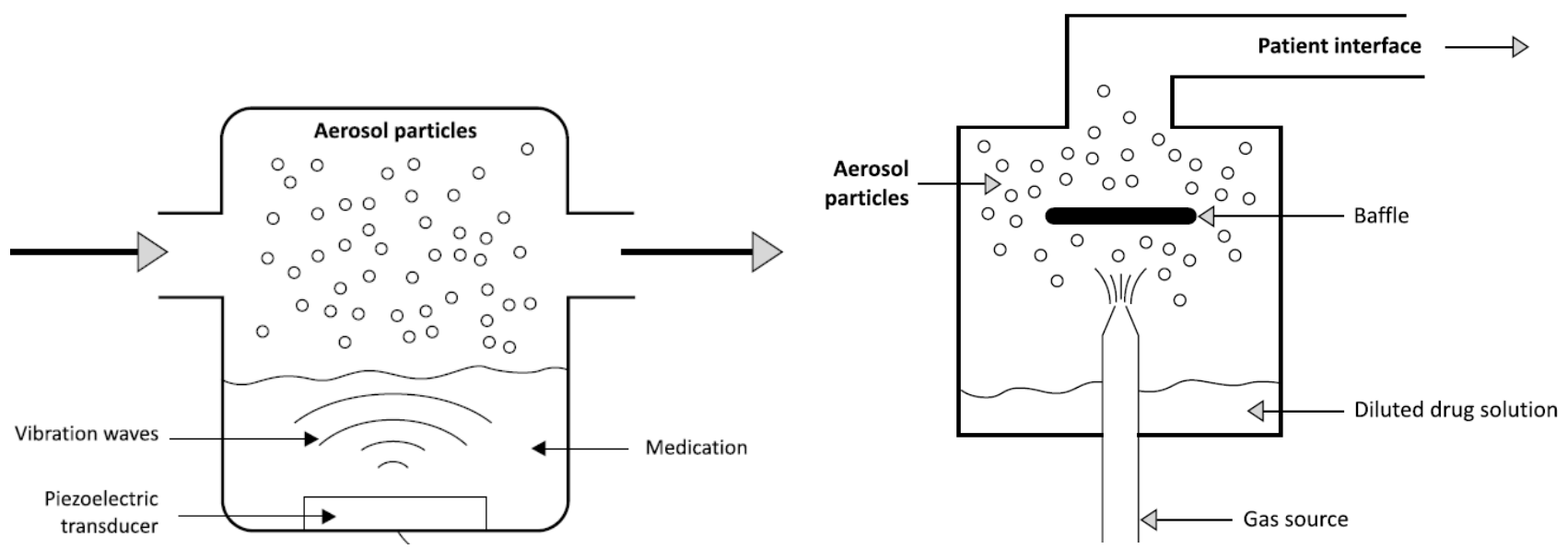

Figure 1- Common Nebulizing Techniques [19]

Dry techniques, such as ejectors, dust feeders and fluidized beds are used to aerosolize dry powders but achieving particles $<1 \mu \mathrm{m}$ has been shown to be difficult [3]. Dry powder aerosols have been shown to present many desirable advantages including: 1) No excipients needed to carry or evaporate from the sample leading to higher purity in the experiments and applications. 2) Production of higher concentrations of a sample or compound can be achieved. 3) Dry powders provide a more stable sample with longer shelf lives that are easier to ship/store [20]. 


\subsubsection{Fluidized Bed Generators}

Fluidized beds have been used for many years in research and industry to aerosolize dry compounds and are well characterized [21]. A traditional fluidized bed, seen in Figure 2, is created by having a gas pass through a dry powder layer at a flowrate which will separate the particles and support them with the gas to create a fluid-like state. Fine particles are entrained into the gas flow upward and carried as an aerosol while larger particles fall back to the bed. Typical fluidized beds can efficiently aerosolize particles with a mean aerodynamic diameter of around $100 \mu \mathrm{m}$ [21]. Although, fine and cohesive powders have been known to be difficult to fluidize, this may be overcome if vibrations are applied to the bed.

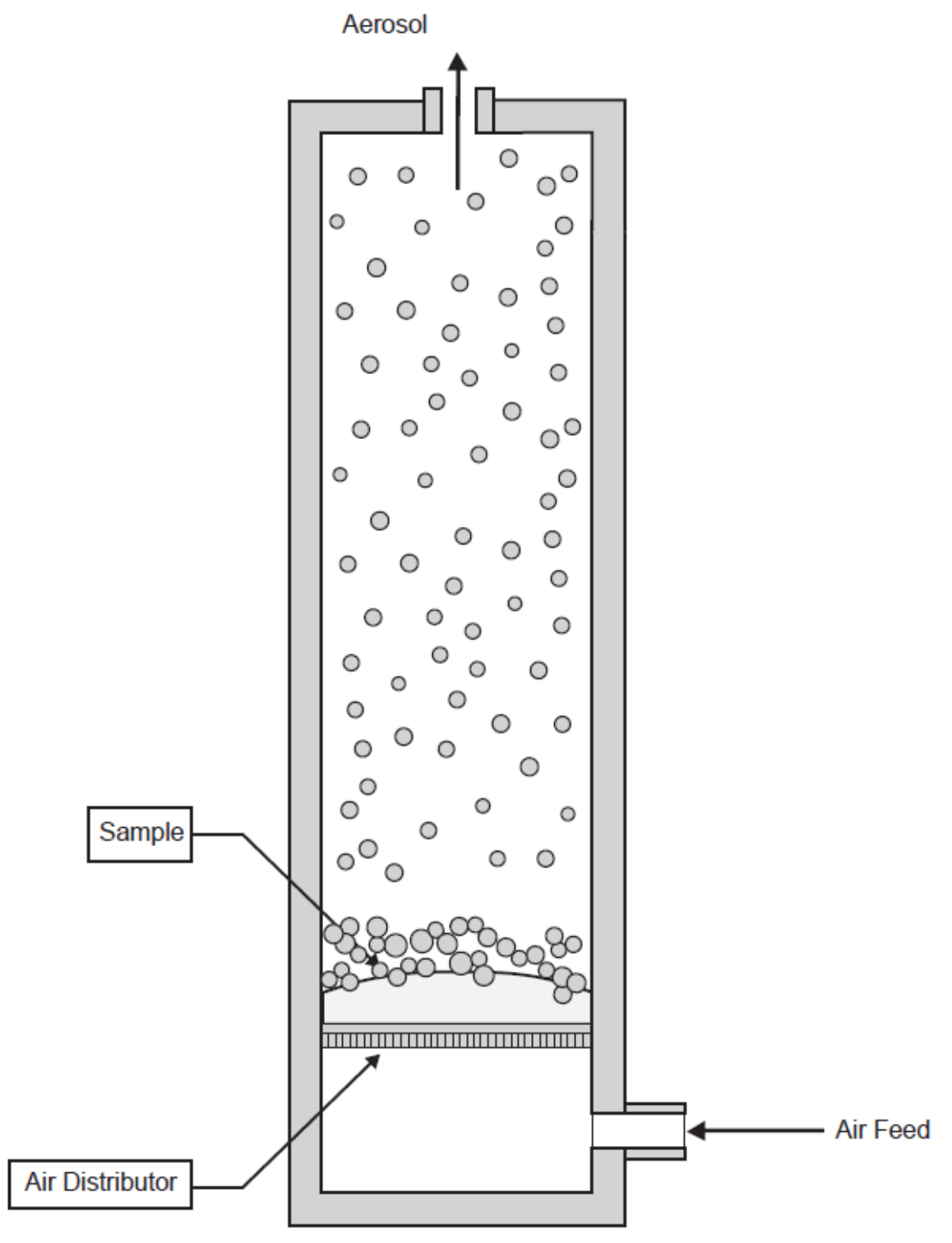

Figure 2 - Standard Fluidized Bed 


\subsubsection{Venturi Dispersers}

Venturi Dispersers are also a common approach to aerosolize dry powders. The venturi disperser, as seen in Figure 3, is a converging/diverging device that creates a low pressure section in the throat. This low pressure section, due to the increase in velocity of the gas as a result of the converging geometry, creates a vacuum in the secondary inlet. This vacuum draws particles through the secondary inlet and into the throat while the high shear flow breaks up the agglomerates and disperses the particles into an aerosol as the flow expands in the diverging section. Cheng et al. has demonstrated that the venturi dispersers can support long term exposures ( $>20$ days with material feed mechanism) and aerosolize cohesive compounds such as $\mathrm{TiO}_{2}$ as well as free flowing compounds such as quartz [22].

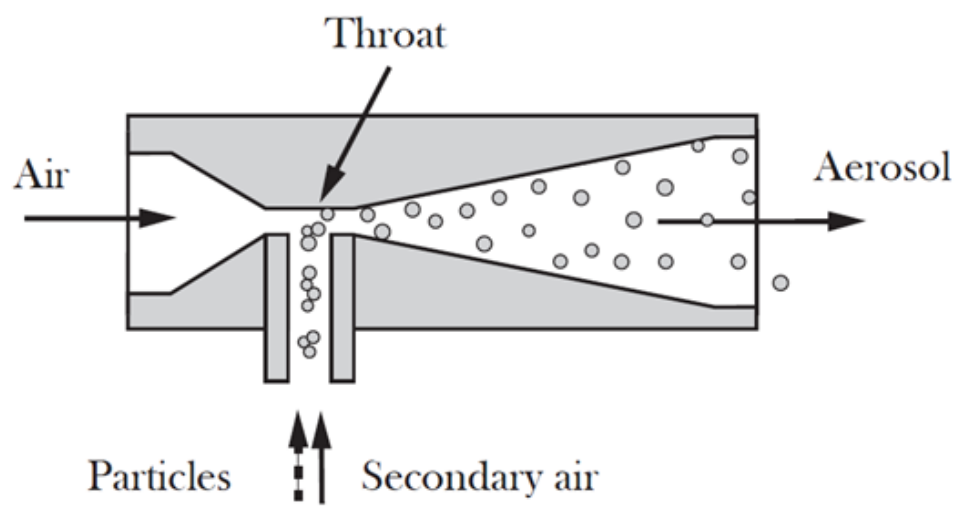

Figure 3 - Venturi Disperser [21]

\subsection{Nanoparticle Aerosol Generators}

Nanoparticle aerosols have recently became of interest due to their unique properties. These unique properties, namely high surface area to volume ratio, have been known to behave differently than their micro counterparts [23]. Nanoparticles, also referred to as ultrafine particles, are defined as ambient or engineered particles with at least one dimension below $100 \mathrm{~nm}$ [24]. Nanoparticle aerosol generators are used to generate and disperse particles with mean aerodynamic diameters $\sim 100 \mathrm{~nm}$. Some common techniques used to generate nanoparticle aerosols are to use existing aerosol generation techniques with devices used to separate out the larger particles $(>1 \mu \mathrm{m})$ from the overall particle distribution to reduce the overall mean size distribution. Some of these additional devices to reduce overall particle size distribution include cyclone separators, baffles and cascade impactors which are covered in the following sections. 


\subsubsection{Cyclone Separators}

Cyclone separators are commonly used to separate particles in an aerosol based on the size of the particles. This is often used to assist in reaching the desired mean particle size. The primary mode of operation for a cyclone separator is the use of centrifugal force and turbulent flow to separate particles. This allows the larger particles to migrate to the edge and be captured as the smaller particles remain in the center and gets entrained in the exit flow which typically exits at the top of the cyclone [25]. Cyclone separators are characterized by the particle cut-off diameter and the separation yield or collection efficiency [26]. A typical cyclone separator is shown in Figure 4.

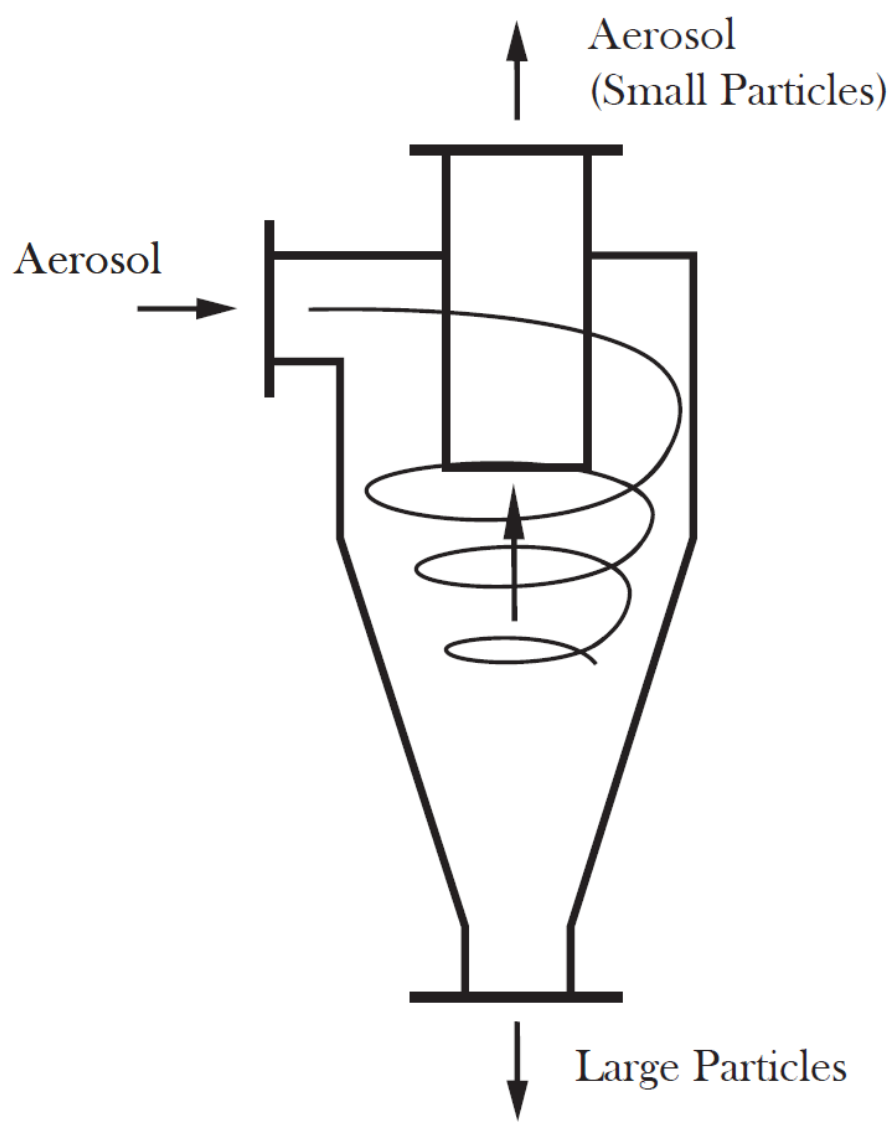

Figure 4 - Cyclone Separator 


\subsubsection{Baffles/Impactors}

Baffles and impactors are also used to separate out larger particles in an aerosol. These devices typically work on the same principle by applying barriers in the flow stream for which an aerosol is required to flow around. Larger particles with higher inertias will impact on the baffle in the areas call "impaction zones" while the smaller particles remain entrained in the flow and are carried through. In some cases to increase the effectiveness of these techniques several baffles or impaction sections are placed in series, also referred to as cascade impactors. These techniques can be used to help reduce the overall mean particle size of the aerosol [27] [28]. This principle can be seen in Figure 5 and Figure 6.

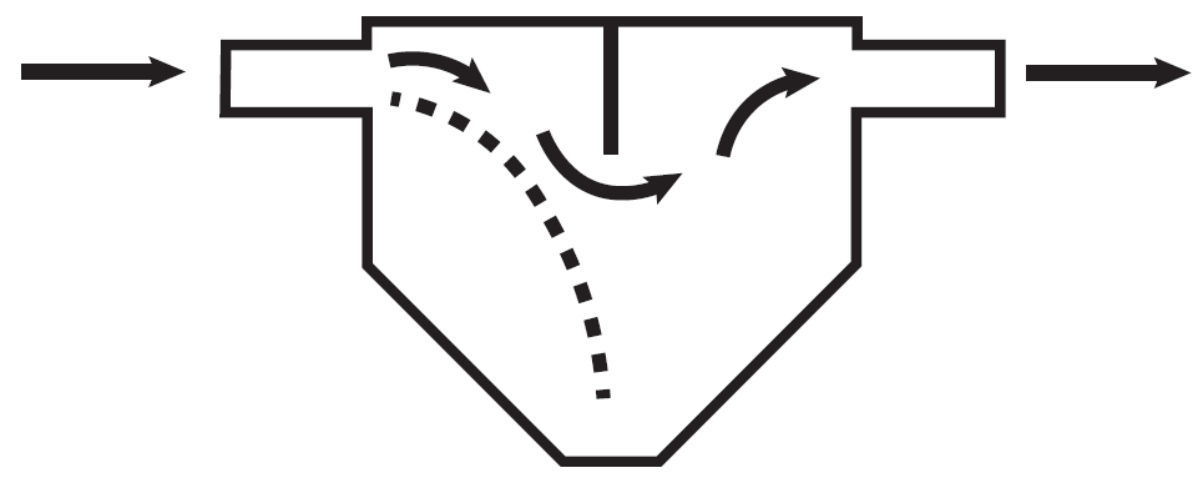

Figure 5 - Impactor/Baffle

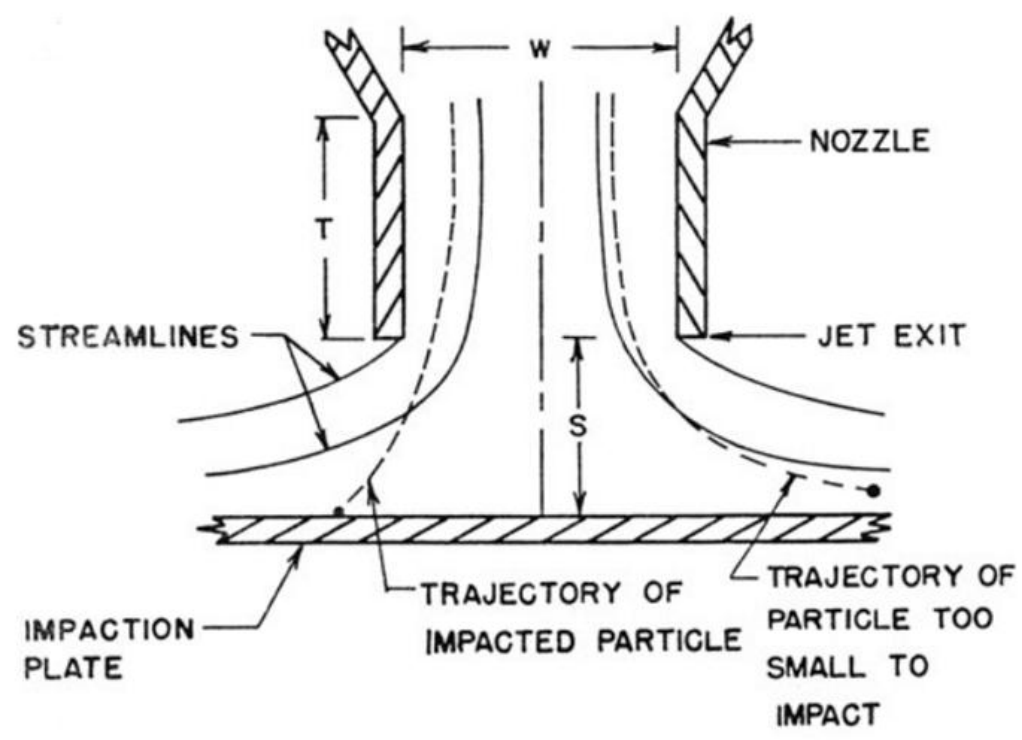

Figure 6 - Impactor/Baffle [27] 


\subsubsection{Vibrations}

Mechanical vibration is another method to influence particle dispersion. Vibrations for the treatment of powders in industry is commonly used to assist with fine powder transport characteristics [21] [29]. It is also commonly applied to fluidized beds and often referred to as the vibrating fluidized bed (VFB). Vibration energy introduced to a bed allows for a lower gas velocity and pressure drop compared to conventional fluidized beds [30]. Therefore, vibrational energy can be an important part of powder aerosolization.

\subsubsection{Sieving/Stirring}

Lastly, the stirring and sieving of powders and powder beds is a common method for the treatment of powders during a process. Typically this is used in the feeding process to help break up larger agglomerates and influence fluidization of the powder during its dynamic state. This ultimately prepares the powder for its next stage which, for the interest of this work, is aerosolization. 


\subsection{Review of literature}

A literature review was conducted for aerosol generation devices and techniques with a special interest in nanoparticle aerosols generated from dry powder formulas. The search was conducted by first evaluating commercially available particle aerosol generators as well as a literature search of such technology that may be in research and development stages. The search criteria consisted of: Nanoparticle, Dry Powder, Aerosol, Generator and Generation in various combinations. The objectives of this review are to evaluate the current state of the art, past approaches that have been taken and to establish the relevance of the novel device currently being developed. For this review the primary interest is in dry powder platforms that can aerosolize particles with an aerodynamic diameter of $<1 \mu \mathrm{m}$. The important literature related to this work is summarized below.

\subsubsection{Commercially Available Aerosol Generators}

Documentation for aerosol generators that are commercially available and said to generate aerosol in the nano range were collected and evaluated. There are many commercially available aerosol generators in various types, sizes and combinations. From these a list of units were identified to generator fine particle aerosols with many of the units being wet devices. Roughly 20 devices (see Appendix A for complete list) were identified as dry powder units with the majority of the devices only applicable for particle sizes $>1 \mu \mathrm{m}$ which are unsuitable for the interest of this review. The few remaining units were identified to generator nanoparticle aerosol specifically from dry powders. However, based on further examination it was found that these units were unable to either; generate particles with a mean size in the range needed, generate particles at the required concentrations or generate consistently over extended periods of time ( 4 hours).

To confirm this, independent reviews have been conducted that evaluated commercially available technology to generate fine particle aerosols. Tang et al. [31] provides an extensive review of commercially available particle generators to show that none exist for this need and furthermore can be extremely expensive. Tiwari et al. [3] also conducted an extensive review of current systems which concluded that nanoparticle aerosol generation from dry powders is very difficult for exposure studies with the currently available technology. Schmoll et al. [5] conducted an in-depth study that evaluated 5 different methods to produce test aerosols for inhalation toxicology assessments with the goal of producing an acceptable aerosol that is homogenous, has a consistent concentration over time and has a size distribution that is both unimodal and has a small geometric mean diameter $(<200 \mathrm{~nm})$. Four different nano-powders were evaluated. Wet based units were capable of producing fine particles but did not provide a homogenous compositions or extended run times. The dry methods tested included a small-scale powder disperser (SSPD), an acoustic dry aerosol generator/elutriator (ADAGE) and fluidized 
bed aerosol generator (FBG). The SSPD and FBG from TSI Inc. was suggested for particle diameters between 0.5-5 $\mu \mathrm{m}$ and 0.5-40 $\mu \mathrm{m}$ respectfully. The ADAGE system, which uses sonic energy to disperse particles, produced bimodal distributions for all ENPs tested. It was able to produce aerosols with particles $<100 \mathrm{~nm}$ from $\mathrm{SiO}_{2}$ and single walled carbon nanotubes. Although, this system was not able to aerosolize $\mathrm{TiO}_{2}$. The ADAGE system is similar to the system used by W. McKinney et al. [32]. Overall, it was found that none of the methods evaluated met the established requirements.

The following are the identified commercially available units:

\subsubsection{The Wright Dust Feeder}

The Wright Dust Feeder [33] as seen in Figure 7 is a common device used in industry as well as the research setting for a variety of applications.

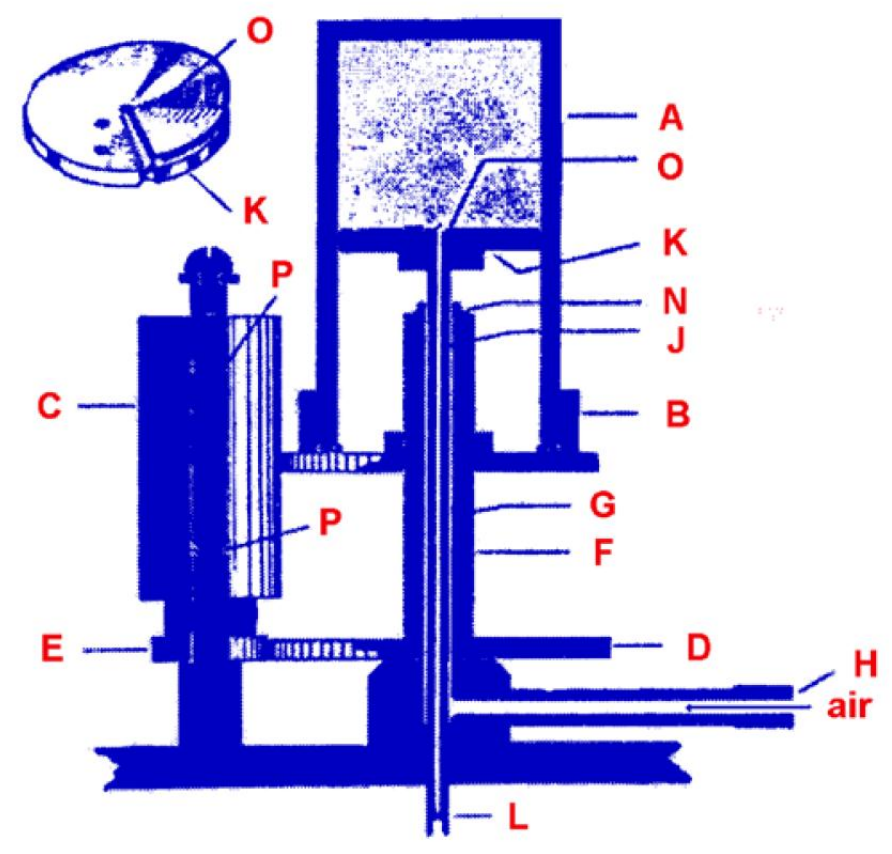

Figure 7 - Wright Dust Feeder [33]

The Wright Dust Feeder works as follows: Dust is contained within the cylindrical holder $(A)$ where it is lightly packed. The packed dust is scraped into a groove in the surface of a scraper head (K). Along this groove a stream of air is passed through $(H)$ so the dust is carried down the inner tube $(J)$. At $(L)$ it is passed through the jet which breaks up any remaining aggregates and delivered to the desired location. Although this technique is popular it does not work well with sticky material such as $\mathrm{TiO}_{2}$ or particles $<1 \mu \mathrm{m}[2]$. 


\subsubsection{Dust Generator Bundschuh}

The Dust Generator Bundschuh [34] is a commercially available device used for inhalation studies as seen in Figure 8.

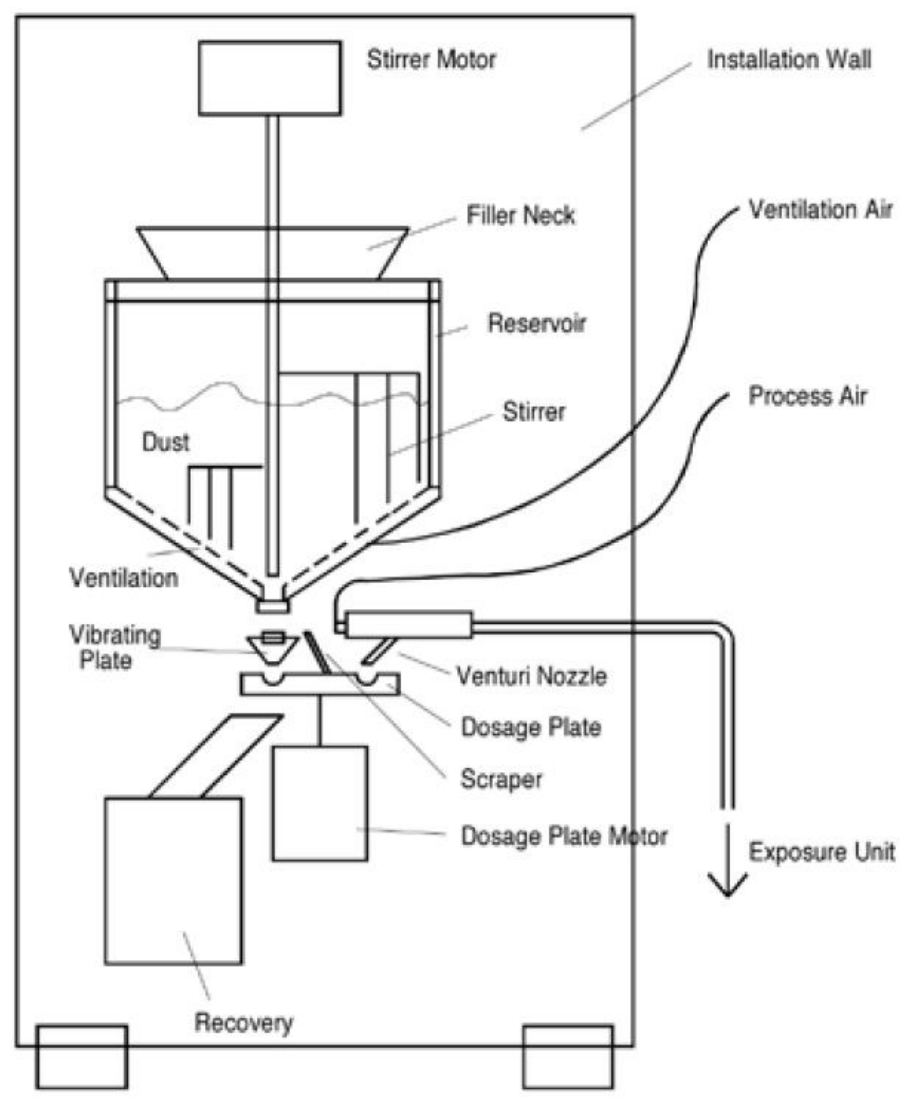

Figure 8 - Dust Generator Bundschuh [34]

The dust generator works by first having the sample compound contained within the reservoir and mixed by the stirrer with variable speed and ventilated air. By means of a vibrating dosage unit the sample is forced out of the reservoir onto the dosage plate which is driven by a motor. The dosage plate is equipped with holes or grooves along its periphery. The choice of the specific plate and the setting of the rotation speed enables control of the aerosol. A scraper removes all the dust particles from the dosage plate which have not fallen into either the dosage holes or grooves. These removed dust particles are collected in a recovery container. Particles which fall into the dosage holes or grooves are sucked up by a venturi nozzle activated by the process flow. A control unit is used to regulate the process to manage the output. This system is not suitable for the generation of nanoparticle aerosols based on the criteria set forth in Table 1. 


\subsubsection{Small Scale Powder Disperser}

The Small Scale Powder Disperser [35] is a commercially available device used for inhalation studies as seen in Figure 9.

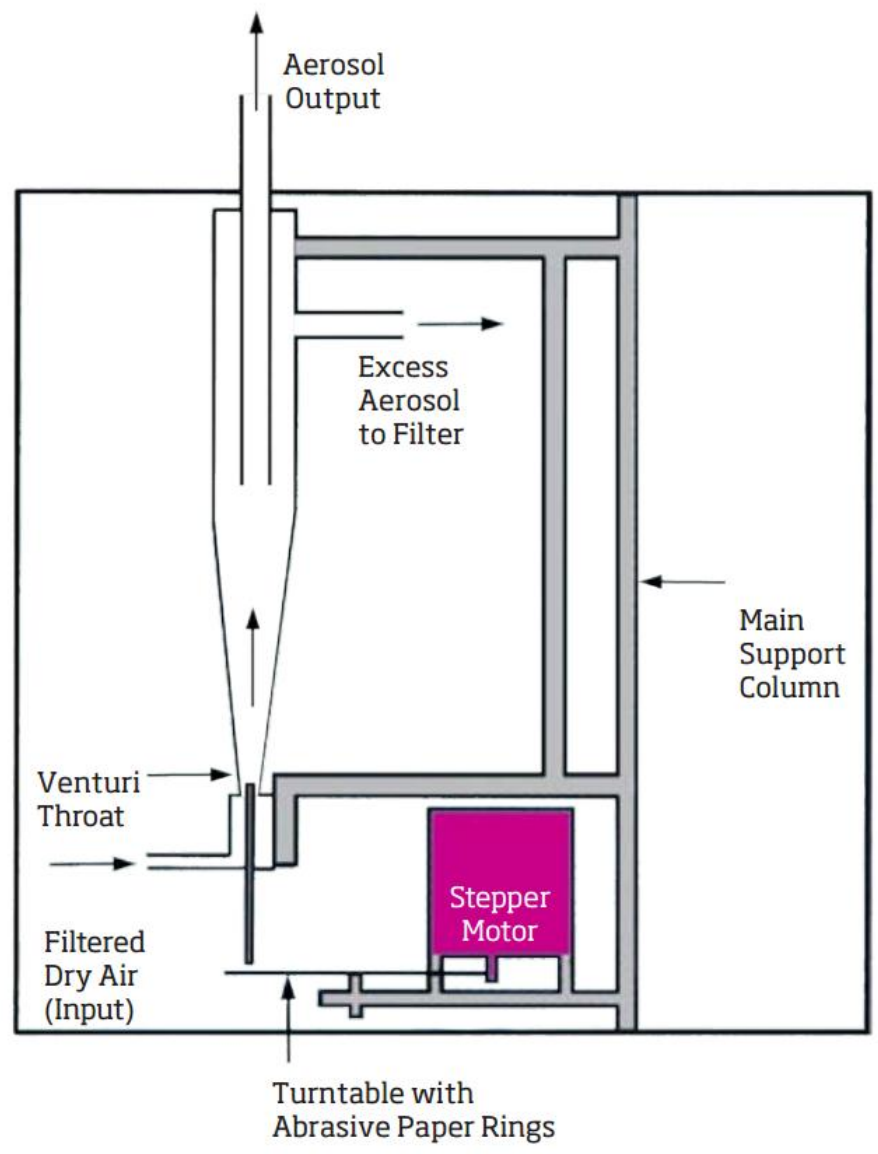

Figure 9 - Small Scale Powder Disperser (SSPD) [35]

This unit works by having the operator gently brush the powder to be dispersed across one of three annular rings of abrasive paper glued to the top of a turntable. One end of a stainless-steel capillary is positioned just above the turntable, the other in a venturi throat. A suction transmitted through the capillary tube removes the powder from the surface of the turntable. Because the air velocity in the venturi throat greatly exceeds that in the capillary tube, shear forces are created where the two flows meet, causing the powder to deagglomerate. The powder then enters an expansion cone, from which it exhausts from the unit.

The Small Scale Powder Disperser (SSPD) as tested by Tsai et al. [36] produced unimodal, but very broad, size distributions (with "peaks" that plateau over several hundred nanometers) for all three engineered nanoparticles (ENPs) tested. It is best suited for micro particles for shorter duration studies. 


\subsubsection{Topas Gmbh}

The Topas Gmbh SAG 410 [37] as seen in Figure 10 is a commercially available aerosol generator that works by feeding the powder to an ejector by way of a feeding belt. The feeding belt segments are supplied by the scraper where the sample is located. The defined segments warrant a constant and reproducible supply of the powder even in small quantities. The resulting particle number concentration of the output aerosol can be adjusted by setting the feeding belt speed. Its design enables a constant dosing of the powder that is nearly independent of the powder reservoir filling level. The reservoir can be refilled during operation without any effects on the aerosol concentration. The dispersing unit consists of a dual-stream ejector nozzle and a tube connection to the housing for compressed air supply. Shear forces created in this ejector disperse and deagglomerate the powder to form an aerosol. This unit is good for long duration experiments but only applicable for particles $>1 \mu \mathrm{m}$.

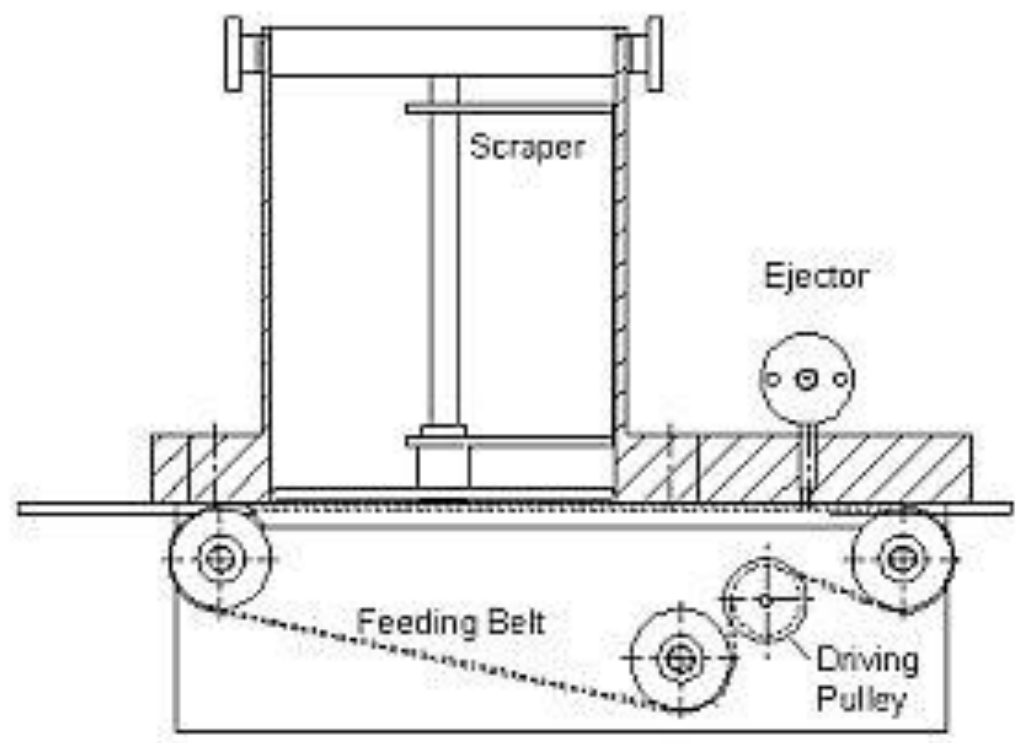

Figure 10 - Topas Gmbh [37] 


\subsubsection{Palas RBG 1000}

The Palas RBG 1000 [38] is a commercially available rotating brush powder feed system as seen in Figure 11. The system works by feeding a sample into a rotating brush. The rotating brush carries the sample into the airstream where it is aerosolized and dispersed. This unit is good for long duration experiments but only applicable for particles $>1 \mu \mathrm{m}$.

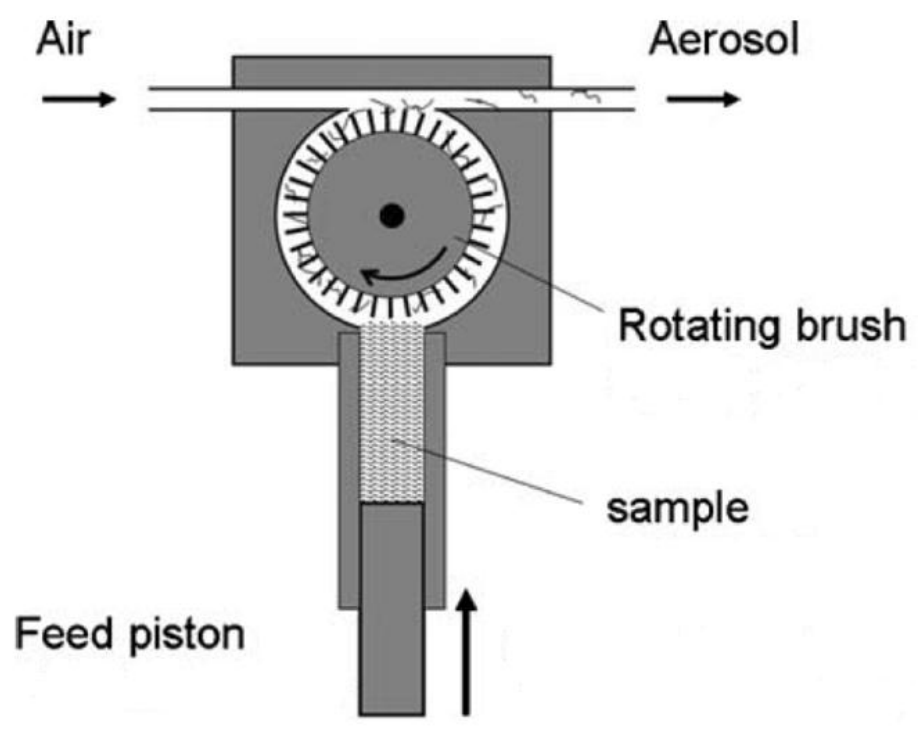

Figure 11 - Palas RBG 1000 [38]

\subsubsection{Summary}

It can be seen from this review of commercial units that no available devices can meet the set criteria of generating particles with a mean diameter $<200 \mathrm{~nm}$, generating particles at the required concentrations or generating aerosols consistently over extended periods of time ( $\sim 4$ hours), especially for cohesive powder such as $\mathrm{TiO}_{2}$. Table 1 below is presented to summarize these findings. It can be noted after reviewing the selected aerosol generators for comparison that all have difficulty generating mean aerosol sizes $<1 \mu \mathrm{m}$. 
Table 1 - Comparison of Select Commercially Available Aerosol Generators

\begin{tabular}{|c|c|c|c|c|}
\hline Aerosol Generator & Dry vs. Wet & $\begin{array}{c}\text { Stable Concentrations } \\
\mathbf{2} \mathbf{4 h s}\end{array}$ & $\begin{array}{c}\text { Homogeneous } \\
\text { Composition }\end{array}$ & $\begin{array}{c}\text { Mean Particle } \\
\text { Size }\end{array}$ \\
\hline $\begin{array}{c}\text { Nanoparticle Aerosol } \\
\text { Generator }\end{array}$ & Dry & Yes & Yes & $<200 \mathrm{~nm}$ \\
\hline Nebulizers & Wet & Yes & Nos & $>1 \mu \mathrm{m}$ \\
\hline Fluidized Beds & Dry & Yes & Yes & $>1 \mu \mathrm{m}$ \\
\hline $\begin{array}{c}\text { Venturi Dispersers } \\
\text { Wright Dust Feeder }\end{array}$ & Dry & Yes & Yes & $>1 \mu \mathrm{m}$ \\
\hline Dust Generator & Dry & Yes & Yes & $>1 \mu \mathrm{m}$ \\
Bundschuh & & Yes & Yes & $>1 \mu \mathrm{m}$ \\
\hline $\begin{array}{c}\text { Small Scale Powder } \\
\text { Disperser }\end{array}$ & Dry & No & Yes & $>1 \mu \mathrm{m}$ \\
\hline Topas Gmbh & Dry & Yes & & $>1 \mu \mathrm{m}$ \\
\hline Palas RBG 1000 & Dry & Yes & & \\
\hline
\end{tabular}

${ }^{*}$ Mean Particle Size may vary slightly based on measurement technique used. Values above are used for comparison purposes only. 


\subsubsection{Aerosol Generator Research and Development}

T. Myojo et al. [39] presented a method for generating multiwall carbon nanotubes (MWCNT) for inhalation studies. This unique approach utilized a Palas RBG-1000 (evaluated in section 2.4.1) aerosol generator feeding into a two-component fluidized bed as seen in Figure 12.

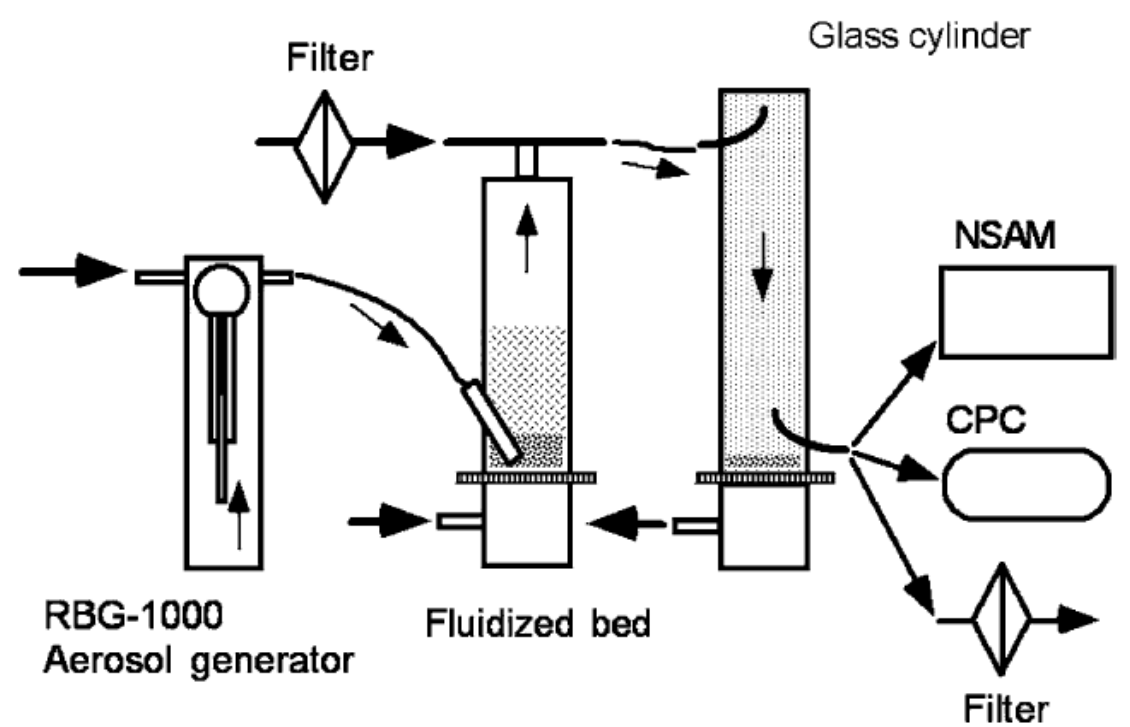

Figure 12 - Multiwall Carbon Nanotube Aerosol Generator [39]

Although this device was able to aerosolize multiwall carbon nanotubes, it was limited in its functionality for whole body experiments. It must be noted for the aerosolization of fibrous compounds such as MWCNTs that it does not directly correlate with spherical particles that this study is interested in. This provides an idea of how the aerosolization was approached. Particle size and concentrations between fibrous compounds and spherical compounds cannot be directly compared.

T. Kasai et al. [40] created an original aerosol generator for MWCNT for whole body exposures as seen in Figure 13. In addition, a control system with feedback control was developed to manage long term exposure periods. The generator used a dust feed, cyclone and sieve to disperse MWCNT to the exposure chamber. Ionizers were used to control the charge of the system which helps to prevent the MWCNT from depositing on the inner walls of the system. The generation method was termed the “Cyclone Sieve Method" by the authors' institution. 


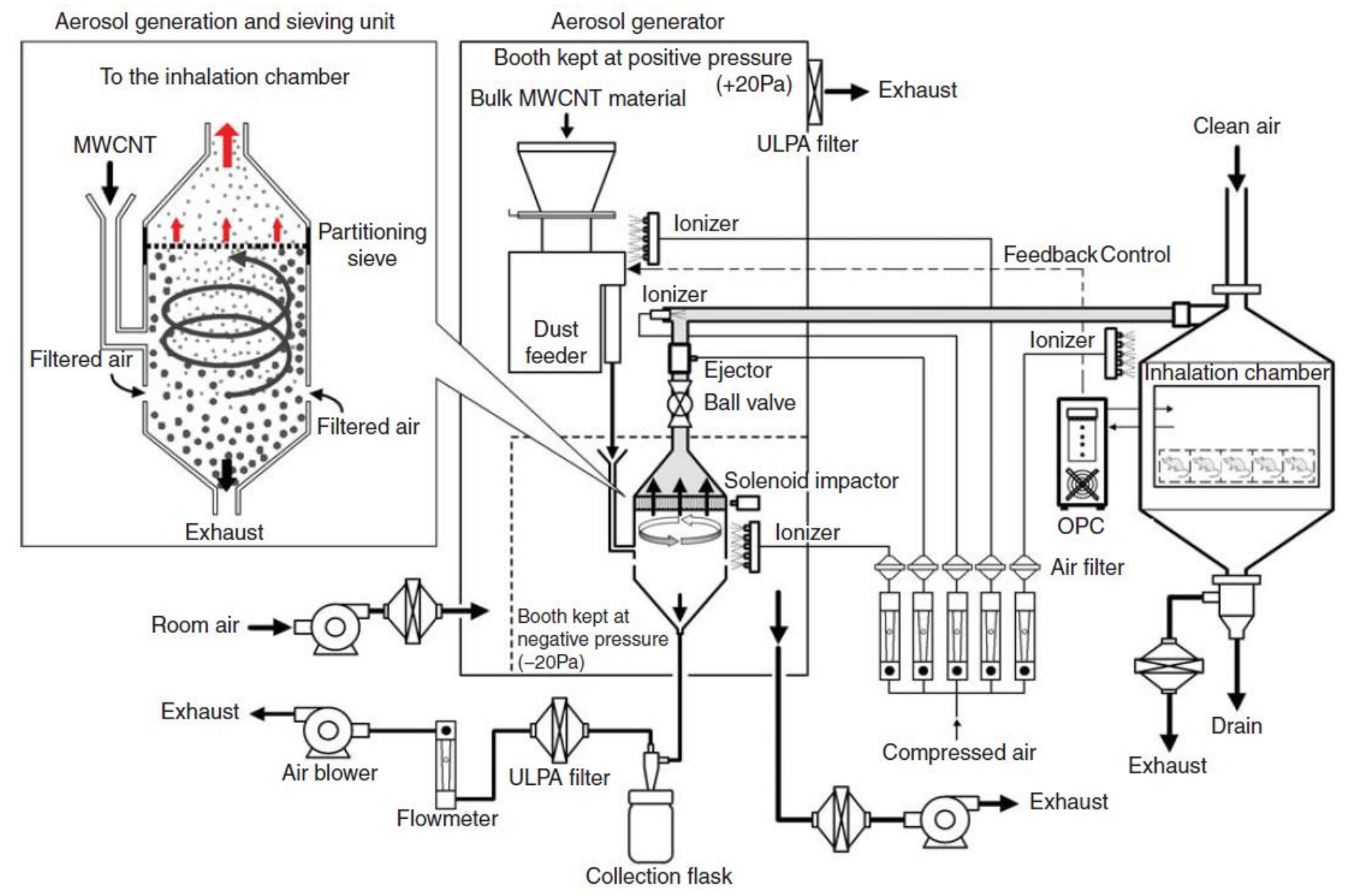

Figure 13 - Layout of aerosol generation and inhalation exposure system [40]

This system proved to hold consistent concentrations over extended periods of time with the median aerodynamic diameter $>1 \mu \mathrm{m}$.

W. McKinney et al. [32], who are colleagues of the Nurkiewicz lab at West Virginia University, have developed an acoustic dry powder aerosol generator for animal exposures with a unique control automation system as seen in Figure 14. This system monitors and controls the desired output during exposures using feedback control and custom software. This unit is capable of generating aerosols up to $20 \mathrm{mg} / \mathrm{m}^{3}$ for durations lasting up to $8 \mathrm{hrs}$. The inhalation exposure system utilizes a combination of airflow controllers, particle monitors, data acquisition devices and custom software with automatic feedback control to achieve constant and repeatable exposure environments. 


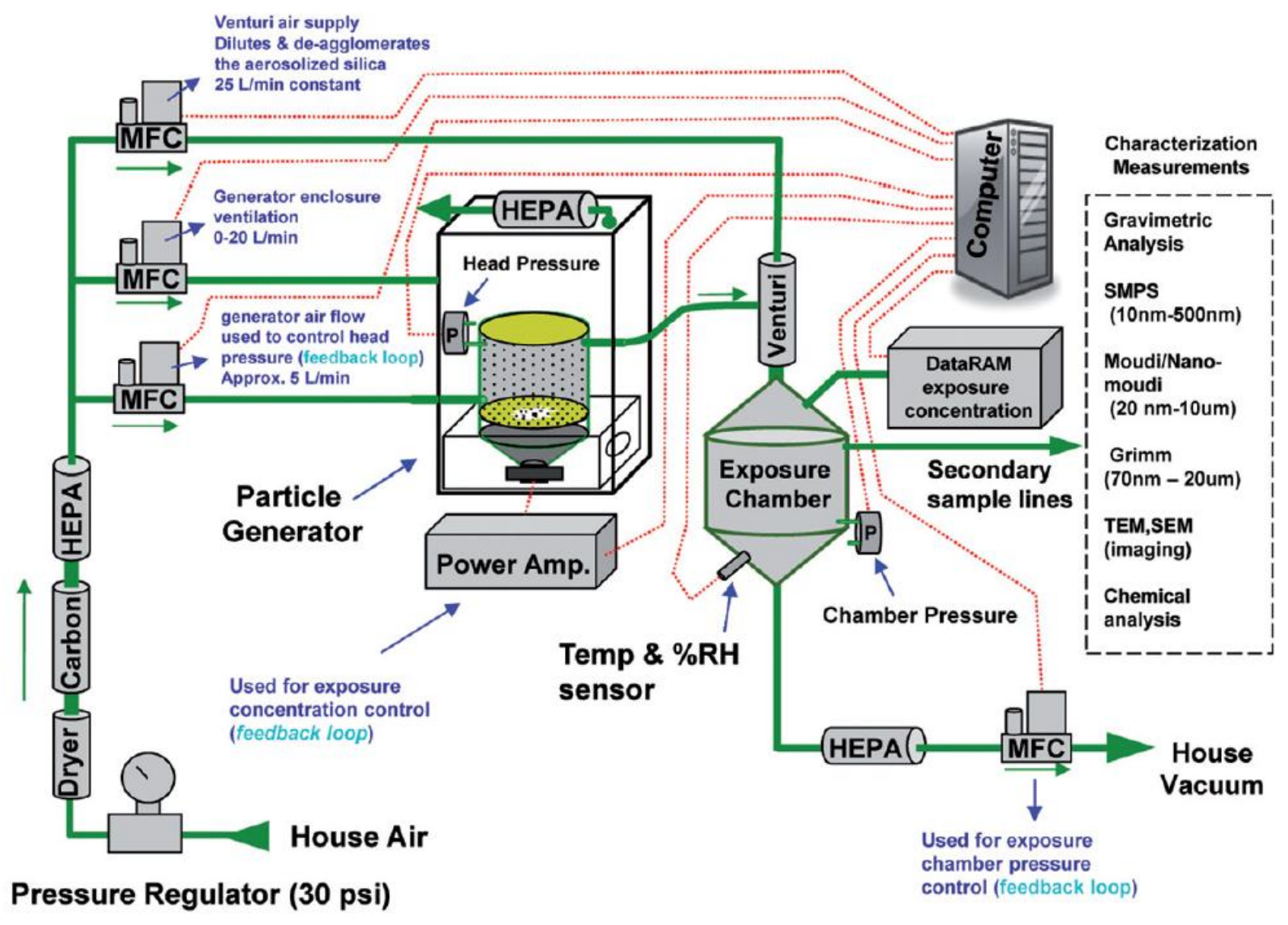

Figure 14 - Diagram of acoustic generator and exposure system [32]

The primary components of the generator are a large cylindrical acrylic chamber with flexible latex diaphragms at the top and bottom. A speaker is placed below the bottom diaphragm with the sample placed in the chamber on the lower diaphragm. The speaker is used to precisely vibrate the diaphragm to aerosolize the particles in the chamber. Air is then passed through the top of the chamber to carry the smaller particles to a venturi which further breaks up agglomerates and helps to dilute the aerosol. The aerosol leaves the venturi and enters the exposure chamber. Using the unique control mechanisms, this technology is capable of generating aerosols with high concentrations that are consistent over long periods of time. Moreover, this technology has been shown to be capable of generating particles $<1 \mu \mathrm{m}$. Tang et al. [31] utilized a simple ejector nozzle to conduct CFD to analyze the effects of introducing swirling into the system. The goal of this study was to improve the ejector's performance by simulating various swirl techniques. The fluid was treated as an ideal gas with the molecular weight of air. It was clear in this study that CFD could be used to help optimize parameters for experimentation. Although 
this aerosolization approach is only applicable for short durations it demonstrates how simulation can be utilized for process improvement.

Tiwari et al. [3] produced a device based on a modification of the work reported by Tang et al. [31] which consisted of a commercially available vacuum generator and during continued use this produces large particles $>1 \mu \mathrm{m}$. Tiwari et al. modified the vacuum generator, as seen in Figure 15, by utilizing a hopper and ejector setup after the vacuum which produced nanoparticles with mode diameters of around $65 \mathrm{~nm}$ for $\mathrm{TiO}_{2}$. The major drawback of this unit is that it can only operate for a few minutes due to its design.

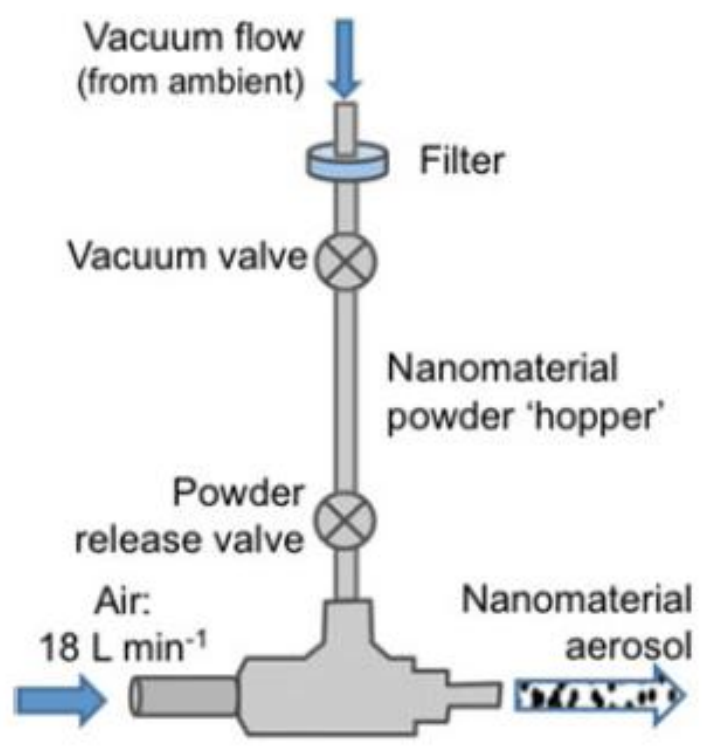

Figure 15 - Venturi Disperser [3]

Tsai et al. [36] proposed three different methods for generating particles for three different nanomaterials. They included the rotating drum dustiness tester, the vortex shaker and the small scale powder disperser. These three techniques were used to investigate the emission characteristics of nano-titanium dioxide (nano - $\mathrm{TiO}_{2}$, primary diameter: $21 \mathrm{~nm}$ ), nano-zinc oxide (nano - $\mathrm{ZnO}$, primary diameter: $30-50 \mathrm{~nm}$ ), and nano-silicon dioxide (nano - $\mathrm{SiO}_{2}$, primary diameter: $10-30 \mathrm{~nm}$ ) over an average of 30 min run time. The rotating drum test, as seen in Figure 16, produced bimodal distributions with very large particles > $5 \mu \mathrm{m}$ (MMAD: $5.2-11.2 \mu \mathrm{m}$ ) for all three compounds tested. 


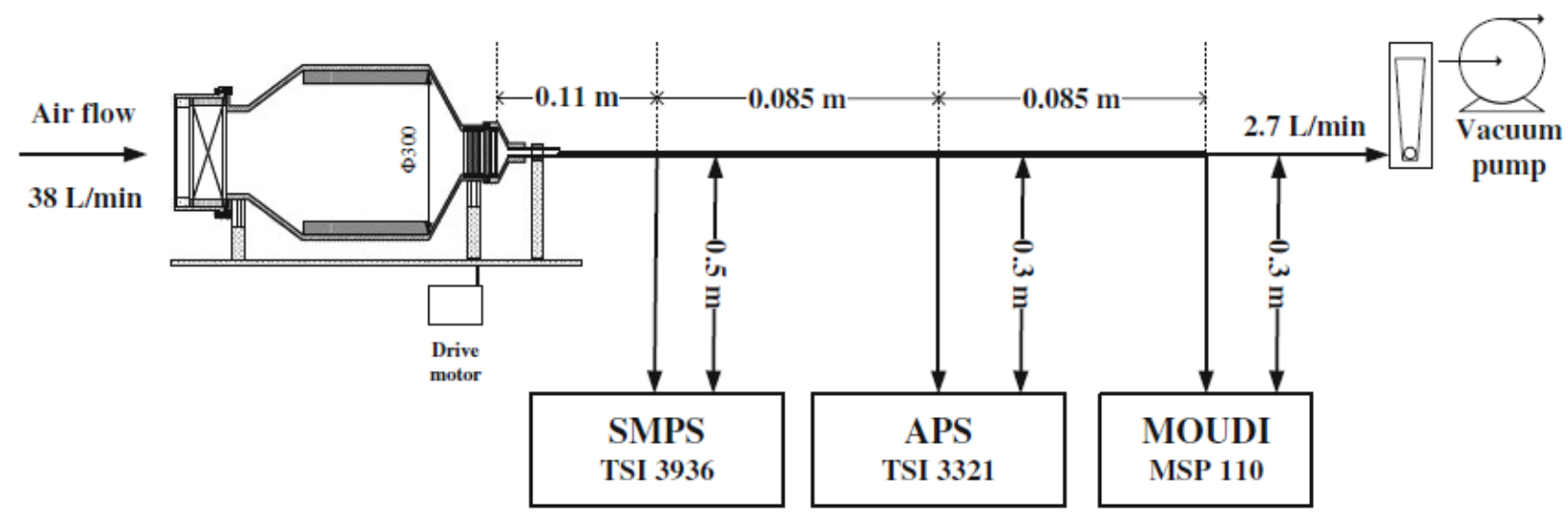

Figure 16 - Rotating Drum Aerosol Generator [36]

The vortex shaker test also produced bimodal distributions with particles $>1 \mu \mathrm{m}$ (MMAD: $3.3-6.0 \mu \mathrm{m}$ ) for all three compounds tested while the SSPD produced unimodal distribution with particles $>1 \mu \mathrm{m}$ (MMAD $1.1-2.1 \mu \mathrm{m}$ ) for all three nano-powders.

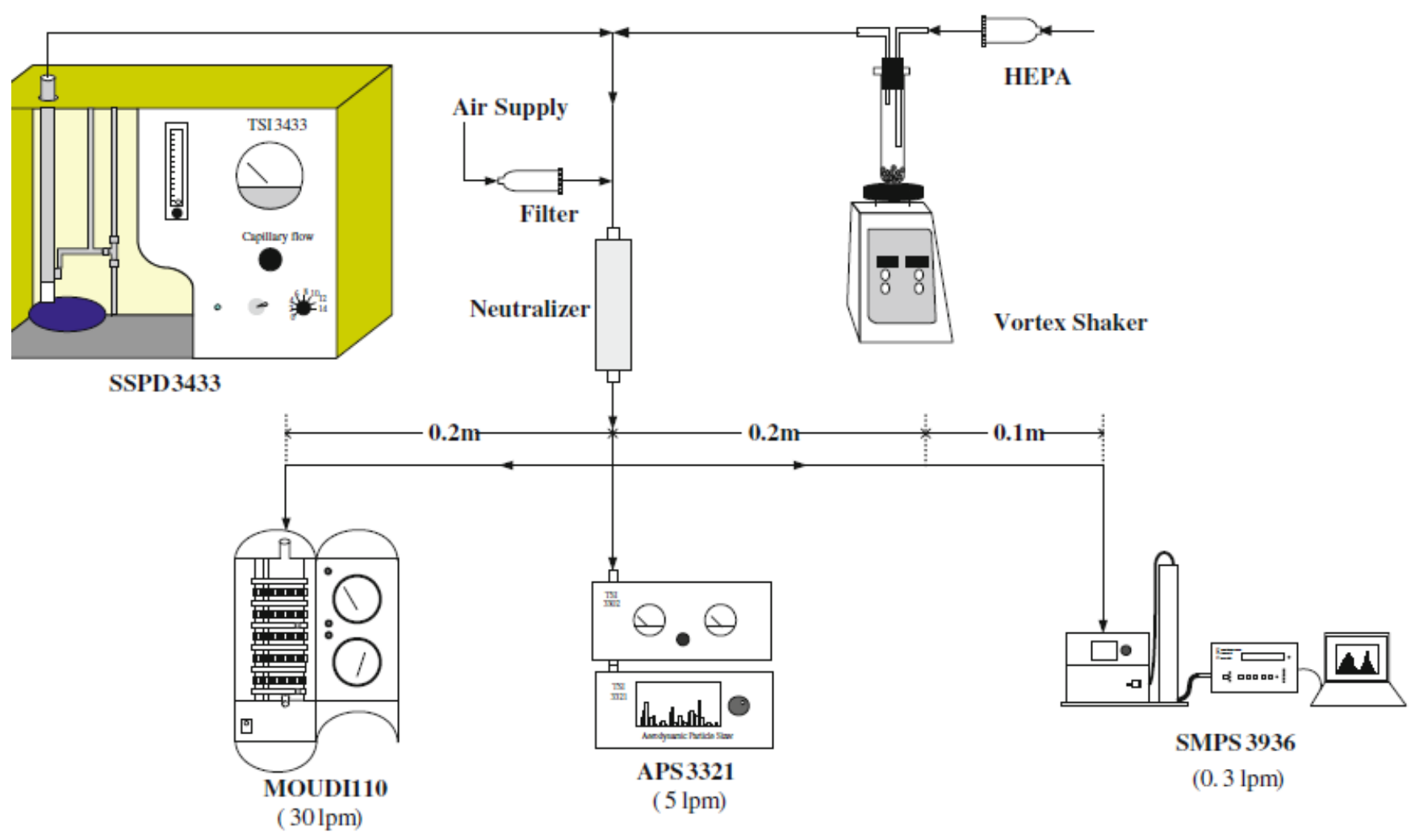

Figure 17 - SSPD and Vortex Shaker Aerosol Generator [36] 
The String Aerosol Generator was originally developed by the National Health and Environmental Effects Research Laboratory, U.S. Environmental Protection Agency. The String Aerosol Generator as described by Ledbetter et al. [41] was based on the principle of a carpenters chalk line to pick up particles from a small reservoir and carry them out through an orifice, past an air jet, where the particles are blown off the string. This method was capable of generating particles $<2.5 \mu \mathrm{m}$ with the use of a $2.5 \mu \mathrm{m}$ cutoff cyclone separator and concentrations at $10-15 \mathrm{mg} / \mathrm{m}^{3}$ with a continuous delivery. Although, it was not capable of producing particles with mean aerodynamic diameters $<1 \mu \mathrm{m}$.

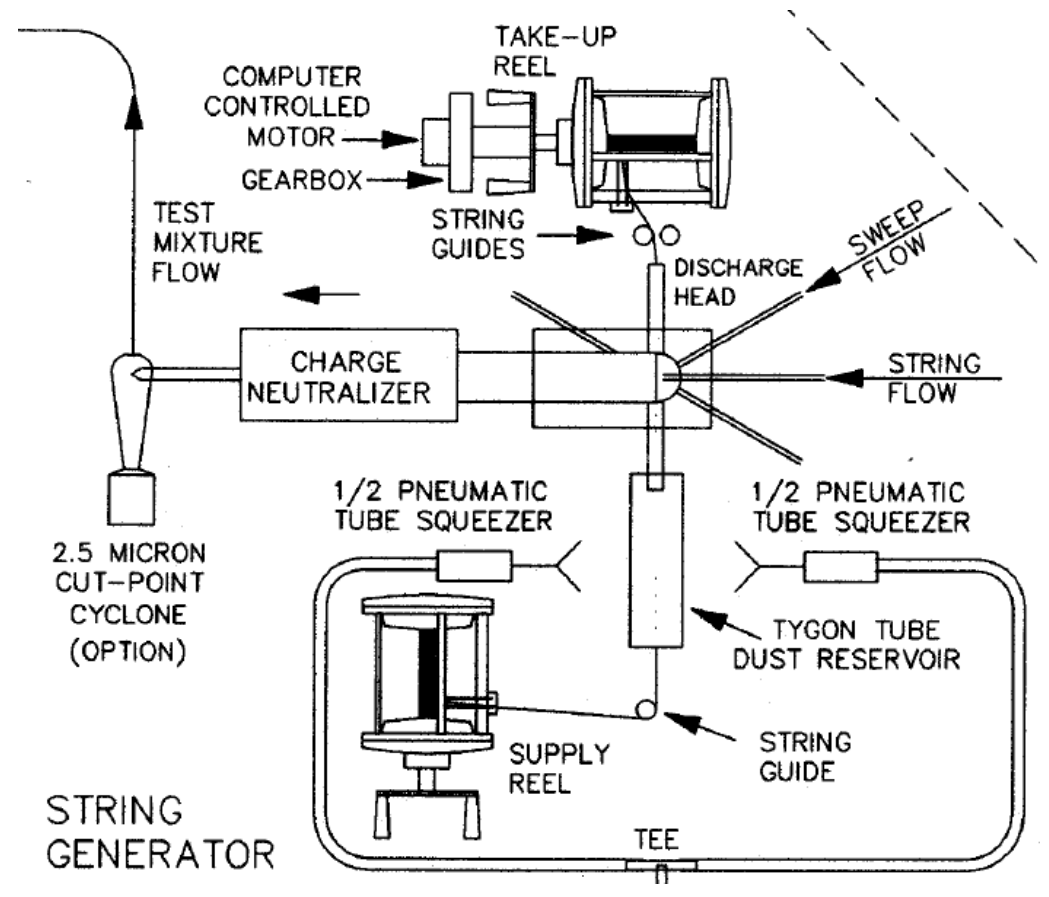

Figure 18 - String Aerosol Generator [41]

Winchers et al. [42] used the string generator to develop a dry aerosol inhalation exposure system for whole-body plethysmography (WBP). This system produced concentrations at $\sim 13 \mathrm{mg} / \mathrm{m}^{3}$ of an oil combustion-derived particle (HP12) with particle with a MMAD of $1.19-1.95 \mu \mathrm{m}$ and a GSD of $2.66-$ 3.49 .

Arc generators have been demonstrated to generate nanoparticle aerosols. Chen et al. [43] who developed a novel method for the continuous generation of titanium dioxide nanoparticles by dielectric barrier discharge process is presented using titanium tetraisopropoxide (TTIP) and water as precursors. The aerosol generator employs an atmospheric pressure plasma enhanced nanoparticle synthesis (APPENS) process of alternative current (AC). The demonstrated approach is unsuitable for whole body experiments. Other methods such as flame-made engineered nanoparticles generated using a versatile engineered nanomaterial generation system (VENGES) from Harvard University [44] and ceramic-based 
heating unit to generate metal and metal oxide nanoparticle aerosols [45] have been demonstrated but are also unsuitable for this review based on the guidelines for toxicology testing set out by Schmoll et al. [5] for acceptable characteristics for inhalation studies.

\subsubsection{Summary}

It can be seen from this review of technologies being researched or developed that, again, no available approaches found in literature can meet the set criteria of generating particles with a mean diameter < $200 \mathrm{~nm}$ at the required concentrations and generating aerosols consistently over extended periods of time ( $\sim$ hours), especially for cohesive powder such as $\mathrm{TiO}_{2}$. Table 2 below is presented to summarize these findings. It can be noted after reviewing the select aerosol generators for comparison that many have difficulty generating mean aerosol sizes $<1 \mu \mathrm{m}$ with one capable of generating $<100 \mathrm{~nm}$ but for short periods of time only. Although, McKinney et al. has shown promise at generating sub-micron aerosols and is anticipated to advance as the technology matures.

Table 2 - Comparison Table of Technology in Research and Development

\begin{tabular}{|c|c|c|c|c|}
\hline $\begin{array}{c}\text { Aerosol } \\
\text { Generator }\end{array}$ & Dry vs. Wet & $\begin{array}{c}\text { Stable Concentrations } \\
\mathbf{4} \mathbf{h r s}\end{array}$ & $\begin{array}{c}\text { Homogeneous } \\
\text { Composition }\end{array}$ & $\begin{array}{c}\text { Mean Particle } \\
\text { Size }\end{array}$ \\
\hline $\begin{array}{c}\text { Nanoparticle } \\
\text { Aerosol Generator }\end{array}$ & Dry & Yes & Yes & $<200 \mathrm{~nm}$ \\
\hline Myojo et al. & Dry & Not Tested & Yes & MWCNT $^{\star *}$ \\
\hline Kasai et al. & Dry & Yes & Yes & MWCNT $>1 \mu \mathrm{m}^{\star *}$ \\
\hline McKinney et al. & Dry & Yes & Yes & $<1 \mu \mathrm{m}$ \\
\hline Tiwari et al. & Dry & No & Yes & $<100 \mathrm{~nm}$ \\
\hline Tsai et al. & Dry & Unknown & Yes & $>1 \mu \mathrm{m}$ \\
\hline String Generator & Dry & Yes & Yes & $>1 \mu \mathrm{m}$ \\
\hline Arc Generator & Both & Unknown & No & Unknown \\
\hline
\end{tabular}

${ }^{*}$ Mean Particle Size may vary slightly based on measurement technique used. Values above are used for comparison purposes only.

** Test with Multi-Walled Carbon Nanotubes (MWCNTs). These materials are fibrous and do not directly compare with spherical particles for which this study is interested in. Therefore, it cannot be directly compared but only used for general comparison of technology approaches. 


\subsection{Applications}

The proposed device in this research program will allow researchers to use the nanoparticle aerosol generator for diverse research purpose. There are a variety of fields and applications not only in the toxicology research setting but other research fields including: biomedical, pharmaceuticals, industrial processes, materials science, physics, chemistry and others working in the nano-technology space.

Pulmonary drug delivery techniques have been used successfully for many years through aerosol inhalation. Although pulmonary drug delivery presents many advantages over other techniques; limitations such as consistency, efficiency and convenience are still in need of improvement [46]. With the emerging field of nanotechnology and the insight to drug interaction and behavior at this scale, new methods of drug delivery are being evaluated. Drug delivery on the nano-scale can be effective at addressing the problems and limitations of early inhalation drug delivery techniques [47]. By using a nanoparticle aerosol generator for pulmonary inhalation therapy; better delivery efficiencies, more consistent dosages, and shorter inhalation periods can be achieved.

Nanoparticle aerosol generation technology has applications for new manufacturing methods of composite pharmaceuticals and composite aerosols. Currently, traditional fluidized beds are used to coat composite particles for encapsulation of a carrier particle for reasons such as thermo-active compounds for targeted drug delivery. Unfortunately, conventional methods for mixing powders are only applicable down to the micron scale because they fail to break the primary aggregates [4]. By using nanoparticle aerosols, it is believed that it will be possible to coat particles on the nano-scale to capitalize on the advantageous properties for drug delivery.

Aerosol deposition of thin films can be achieved using a nanoparticle aerosol generator. This could be useful in the manufacturing of electronics and electronic components. Also, in interfaces where thin films are used such as solid oxide fuel cells or electrically conductive materials [48]. Optical coatings, ones that may influence energy efficient windows or the new generation of solar cells, can also provide opportunities. M. Habibi has shown that $\mathrm{Nano}^{\mathrm{TiO}} 2$ can be used as a transparent thin film for its UV absorbing properties for nano thin films [49]. 


\subsection{Discussion}

It has been shown that there is a need for a particle generator that can produce nanoparticle aerosol from dry powder formulas with a mean particle diameter $<200 \mathrm{~nm}$, concentrations $>5 \mathrm{mg} / \mathrm{m}^{3}$ and over extended periods of time ( $>4 \mathrm{hrs}$ ). Commercially available aerosol generator technology cannot create aerosols in the size range, concentration and duration needed for successful whole body inhalation toxicology assessments. Additionally, there is little evidence in the literature and marketplace that there is a technology in the research phase that can do this as well. This literature review has shown a need for this technology for its use in toxicology assessments as well as other diverse applications [5].

This review has shed light on common approaches and how well they might work for certain applications. Many approaches have been demonstrated to meet 3 out of the 4 criteria in various combinations but none of which satisfy all at the same time. This criteria being 1) dry powder 2) consistent concentration over extended periods 3) Homogeneous composition free of contaminants 4) Unimodal size distribution with a mean geometric diameter $<200 \mathrm{~nm}$ and a small geometric standard deviation of $\sigma_{g}=2.5$ [5] [2]. The technology being developed for this work meets the 4 criteria and outperforms everything seen in the literature. It is also believed that with the better understanding of the technology after this work is complete that it may be possible to reach levels for whole body toxicology assessment of $<100 \mathrm{~nm}$ mean aerodynamic diameter. This will not only provide a unit to meet the needs of research and industry but set a new standard for this technology as well as new standards for toxicology assessments and exposure limits in the work place. 


\section{CH. 3 THE NANOPARTICLE AEROSOL GENERATOR}

As an initial step, a fundamental analytical analysis is performed to offer important insights to understanding the overall system of this research. This section reviews the fundamental operation and understanding to provide the groundwork to characterize the technology.

\subsection{Basic system description}

The nanoparticle aerosol generator used in this investigation is seen in Figure 19 below.

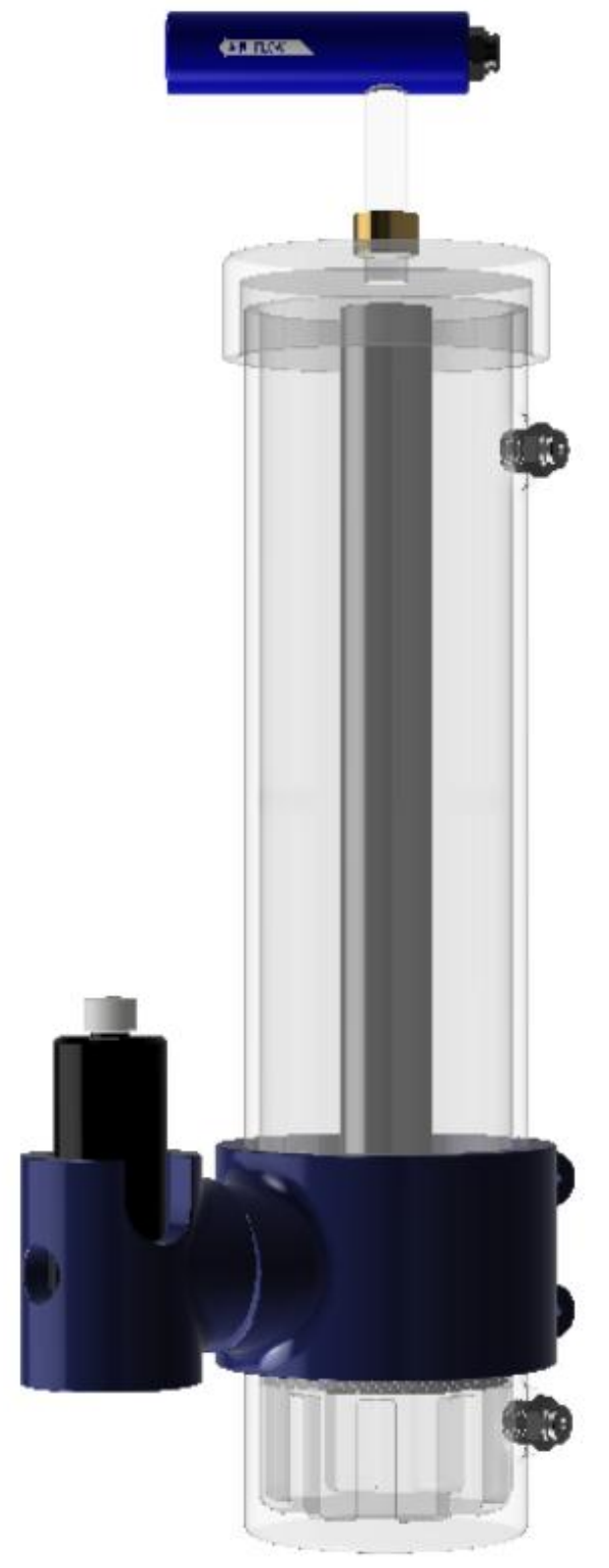

Figure 19 - Nanoparticle Aerosol Generator 
It consists of a vibrating fluidized bed with a baffle inside of a cylindrical particle chamber and a vibrating venturi as shown in Figure 20. The particle chamber is made up of a cylinder that has two air inlet ports, one port is located below the fluidized bed and the other above, and an exit port on the top of the cylinder for which the venturi is connected. The nanoparticle aerosol generator also includes a baffle which is located inside of the particle chamber and connected around the exit port. The vibrator, is attached to the particle chamber producing the mechanical vibrations for the entire unit.

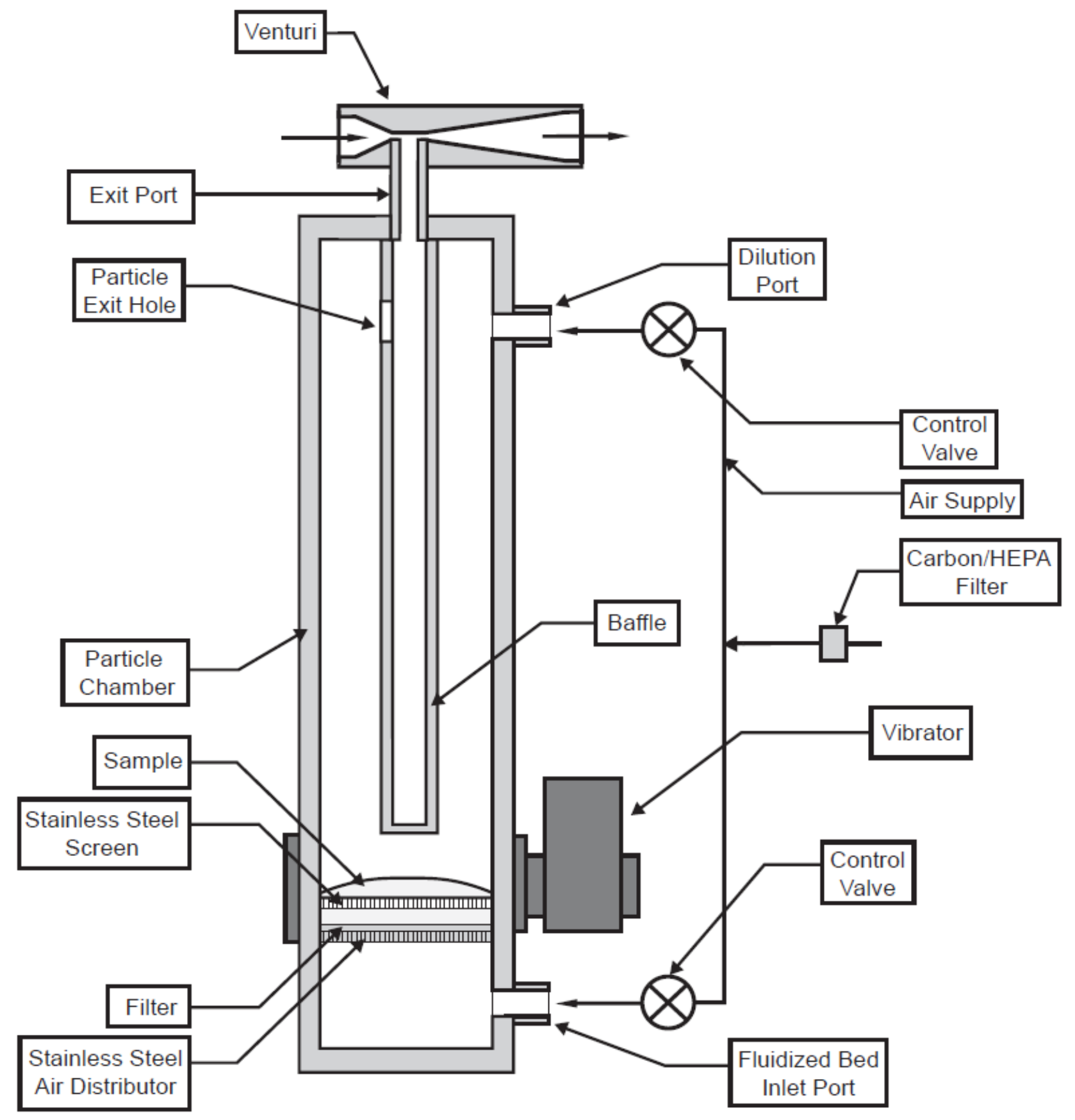

Figure 20 - Nanoparticle Aerosol Generator 
The fluidized bed consists of a filter that is supported by a stainless steel air distributor within the particle chamber. A stainless steel screen with a diameter just smaller than the inner diameter of the particle chamber is placed in the sample to break up larger agglomerates. The sample to be aerosolized is loaded onto the fluidized bed.

The venturi, which vibrates with the particle chamber, is used to create a vacuum in the particle chamber which will draw air into the particle chamber through the air inlet ports. The air inlet ports have control valves and flow meters where air feed tubes are attached so that clean/dry air can be pulled into the particle chamber through an activated carbon and HEPA filter.

The baffle is made from stainless steel tubing with one closed-end and one open-end. The baffle is located in the center of the vibrating particle chamber with the open end connected to the exit port. A hole near the open-end of the baffle is used to allow the aerosols to exit from the particle chamber. The closed-end of the baffle extends to just above the top of the fluidized bed. When the aerosol flows upward, some of the larger agglomerates can be removed from aerosol streams by the baffle. Without the baffle, the size of the output particles can be much larger.

A portion of the air drawn in from the air inlet port will flow through the fluidized bed in the particle chamber to carry small particles upward to form an aerosol stream, and will move towards the exit port, while the rest of air enters the particle chamber through the air inlet port and mixes with the upward flowing aerosol stream. The air flow from the air inlet port will hit the cross flow aerosol stream resulting in some larger particles being removed from the aerosol stream. The aerosol can also be diluted by this cross flow air, which helps reduce the probability of re-agglomeration of the particles.

Once the aerosol enters the venturi, particles will be exposed to high shear stress and impaction. The large particles will be broken up and dispersed, while smaller particles will follow the air flow to mix with the vibrating high speed shear flow in the venturi. The vibrating high speed shear flow will continuously disperse the agglomerates, dilute, and deliver the aerosol.

The vibrator can induce pressure wave/fluctuation in the air which will help distribute the particles, especially nearby the inner surface of the cylinder. The baffle also vibrates with the cylinder transferring the mechanical vibrating energy to the air flow that carries the particles out of the particle chamber. The air flow pressure wave/fluctuations induced by the vibration also helps destroy cohesions between particles and large agglomerates. The mechanical vibrations may also reduce deposition of the particles on the inner surface of the cylinder, the outer surface of baffle and inner surfaces of the venturi and dispersion tubes. 


\subsection{Basic Component Analysis and Relationships}

Modeling complex systems can be simplified by breaking them down into smaller, more manageable sections. A fundamental understanding of these systems will allow for a better understanding of the overall system. Such a review provides a foundation for understanding and a baseline for verification for extended efforts that follow this work. The simplified models can be described by well-known equations such as the Continuity and Bernoulli equations.

\subsubsection{Venturi}

The venturi is a converging/diverging device that uses high shear flow and impaction to break up agglomerates, expand the flow and disperse particles as shown in Figure 21. Low pressure is induced at the throat resulting in a vacuum in the secondary inlet. When agglomerated particles are pulled into the secondary inlet and into the throat the agglomerated particles suffer from the forces induced by the acceleration and shear flow field and are dispersed.

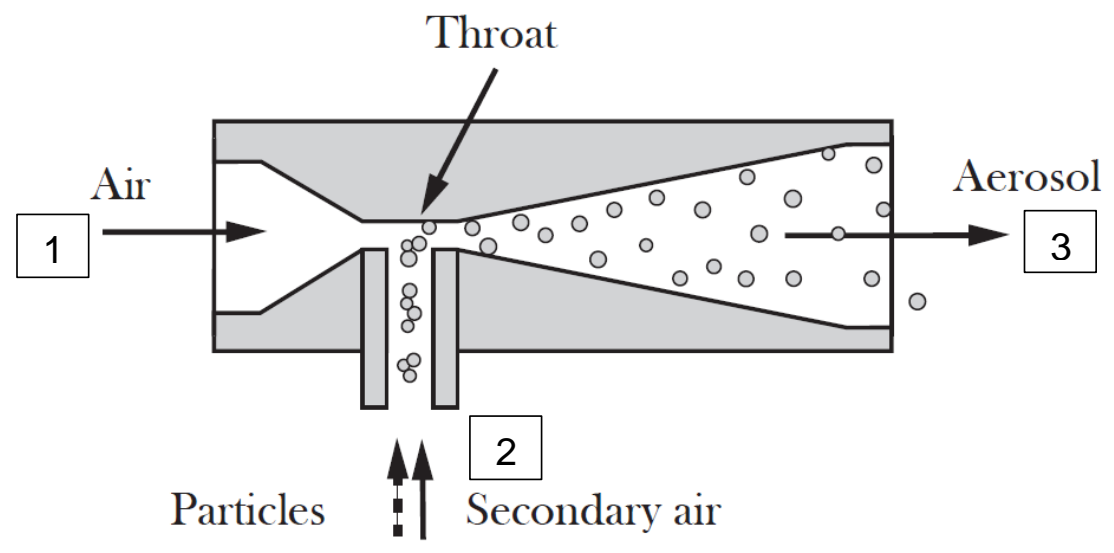

Figure 21 - Venturi [21]

As a fundamental step, for example, the parameters at each area of interest can be found using the Bernoulli equations. The points of interest within the venturi are described as numbered datum points in Figure 21. The flowrate of the venturi is a function of the inlet pressure and is provided by the venturi manufacturer for the particular venturi as:

$$
Q\left(\frac{L}{\min }\right)=0.28[(P)(p s i g)]
$$

Where $Q$ is the volumetric flowrate and $P$ is the inlet pressure.

Using an inlet pressure of $55 \mathrm{psig}$, for example, the flowrate is found to be 15 LPM for the inlet 1. Given the venturi specifications by the manufacturer as a geometry ratio of $A_{1} / A_{2}=4$ for the inlet area and 
secondary inlet area respectfully, the velocity or $\mathrm{v}_{1}$ can be found. Assuming incompressible flow and using the Bernoulli's equation

$$
P_{1}+\frac{1}{2} \rho v_{1}^{2}+\gamma z_{1}=P_{2}+\frac{1}{2} \rho v_{2}^{2}+\gamma z_{2}
$$

where the Bernoulli equation can be simplified to

$$
P_{1}+\frac{1}{2} \rho v_{1}^{2}=P_{2}+\frac{1}{2} \rho v_{2}^{2}
$$

For this example, $\mathrm{P}_{2}$ will be assumed to be at ambient conditions, $\mathrm{P}_{2}=0$ psig. This leaves two unknowns, $v_{1}$ and $v_{2}$. Since

$$
\rho_{1} A_{1} v_{1}=\rho_{2} A_{2} v_{2}
$$

or for incompressible flow

$$
A_{1} v_{1}=A_{2} v_{2}
$$

it can be simplified using the geometry ratio to

$$
4 v_{1}=v_{2}
$$

Therefore,

$$
55+\frac{1}{2} \rho v_{1}^{2}=0+\frac{1}{2} \rho\left(4 v_{1}\right)^{2}
$$

Solving for $\mathrm{v}_{1}$,

$$
v_{1}=\sqrt{\frac{110}{15 \rho}}
$$

Plugging into the flowrate equation

$$
Q_{1}=A_{1} v_{1}
$$

giving a flowrate value of 15 LPM which is confirmed with data provide by the venturi manufacturer.

$v_{2}$ can be found by using the same procedure with the flowrate equation

$$
Q_{2}=A_{2} v_{2}
$$

giving a flowrate value of 12.8 LPM which is again confirmed with data provided by the venturi manufacturer. Knowing the velocities at points 1 and 2 the pressure and flowrates for the exit can be found.

$$
P_{1}-P_{3}=\frac{\rho}{2}\left(v_{3}^{2}-v_{1}^{2}\right)
$$

The exit pressure is atmospheric or $\mathrm{P}_{3}=0$ psig, therefore

$$
P_{1}=\frac{\rho}{2}\left(v_{3}^{2}-v_{1}^{2}\right)
$$


or

$$
v_{3}=\sqrt{\frac{2 P_{1}}{\rho}}+v_{1}
$$

And therefore,

$$
Q_{3}=A_{3} v_{3}
$$

\subsubsection{Particle Chamber}

The particle chamber, as seen in Figure 22, can be analyzed with a control volume analysis with 2 inlets and 1 exit. Using the continuity equation

$$
\sum \rho_{\text {out }} A_{\text {out }} v_{\text {out }}-\sum \rho_{\text {in }} A_{\text {in }} v_{\text {in }}=0
$$

Therefore,

$$
\rho_{2} A_{2} v_{2}=\rho_{4} A_{4} v_{4}+\rho_{5} A_{5} v_{5}
$$

Assuming incompressible flow,

$$
A_{2} v_{2}=A_{4} v_{4}+A_{5} v_{5}
$$

Using the information gathered from the venturi analysis, the inlet flow rates and chamber pressure can determined. For example, the venturi secondary inlet flow was calculated to be 12.8 LPM. Since the flowrate of 2 is known 4 or 5 can be written in terms of one another as

$$
Q_{5}=Q_{2}-Q_{4}
$$

or

$$
Q_{4}=Q_{2}-Q_{5}
$$




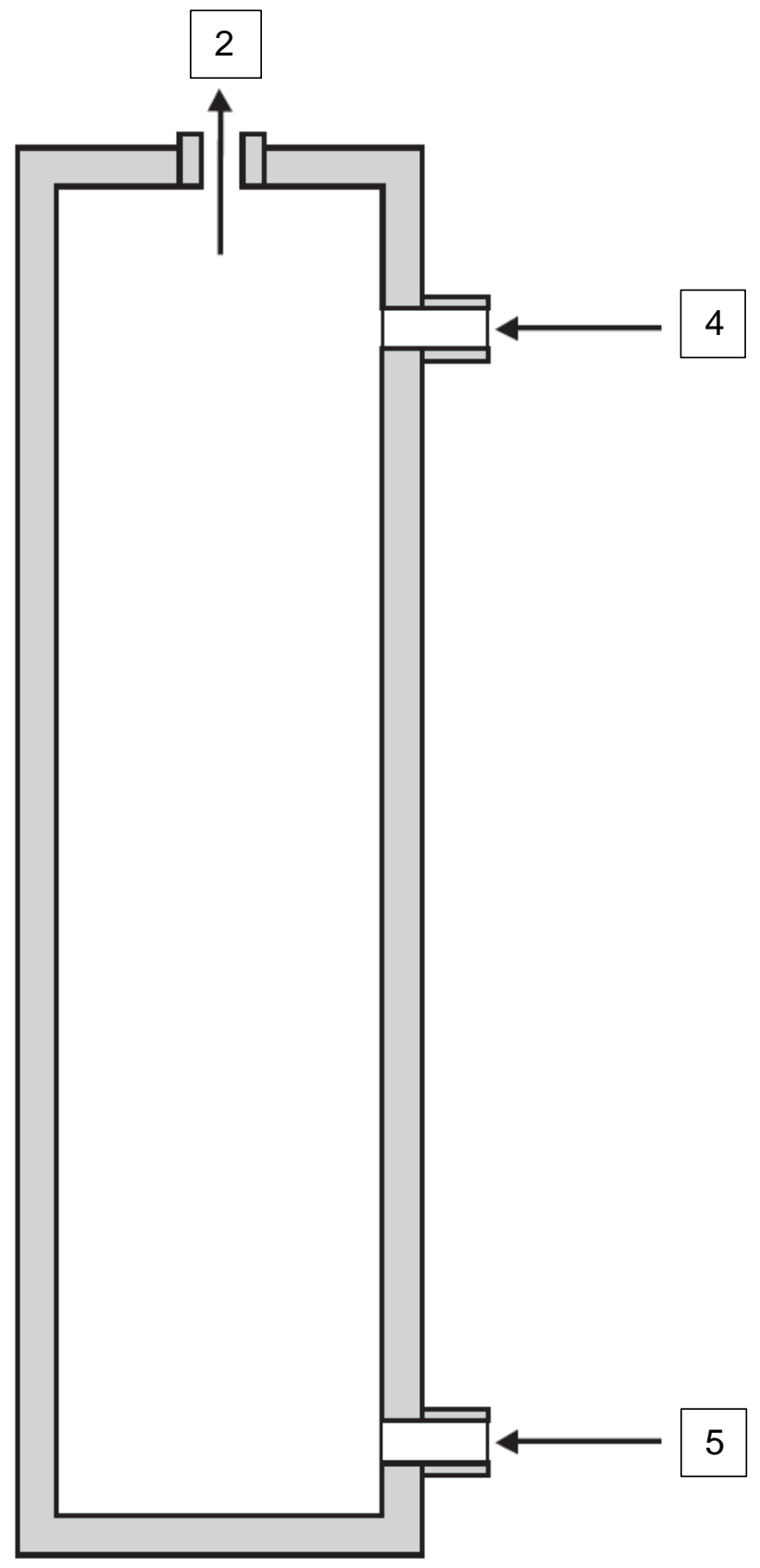

Figure 22 - Particle Chamber

The particle chamber has the following physical dimensions:

- Diameter - 2.3 in

- Length - 11.0 in

- Volume - $45.7 \mathrm{in}^{3}$

- Inlet/exit port size - $0.093 \mathrm{in}^{2}$ 


\subsubsection{Fluidized bed}

The fluidized bed, which can be seen in Figure 23, is created by having dry air pass through a dry powder sample at a flowrate that separates the particles and creates a fluid-like state. As the air flows through the powder layer there will be a pressure drop $\Delta \mathrm{P}$. As the air velocity increases the pressure drop gradually increases and will reach a maximum before fluidizing. Once the bed fluidizes the pressure drop will fall slightly due to the bed of particles expanding and then will become constant. This then remains constant independent of the air flow velocity through the bed. During fluidization the apparent particle weight is equal to the pressure drop as expressed by

$$
\Delta P=L(1-\epsilon)\left(\rho_{p}-\rho_{f}\right) g
$$

Where $L$ is the bed height, $\epsilon$ is the void fraction, and $\rho_{p}$ and $\rho_{f}$ are the densities of the particle and gas (air) respectfully. This allows the estimation of the pressure drop across the bed to be $\sim 6$ mbar to be used in further calculations and later found to have little effect (insignificant) on the venturi inlet flow. Fine particles are entrained into the gas flow and carried as an aerosol while coarser particles fall back to the bed. To help improve the fine particle fraction in the fluidized bed, a vibrator and screen are used. 


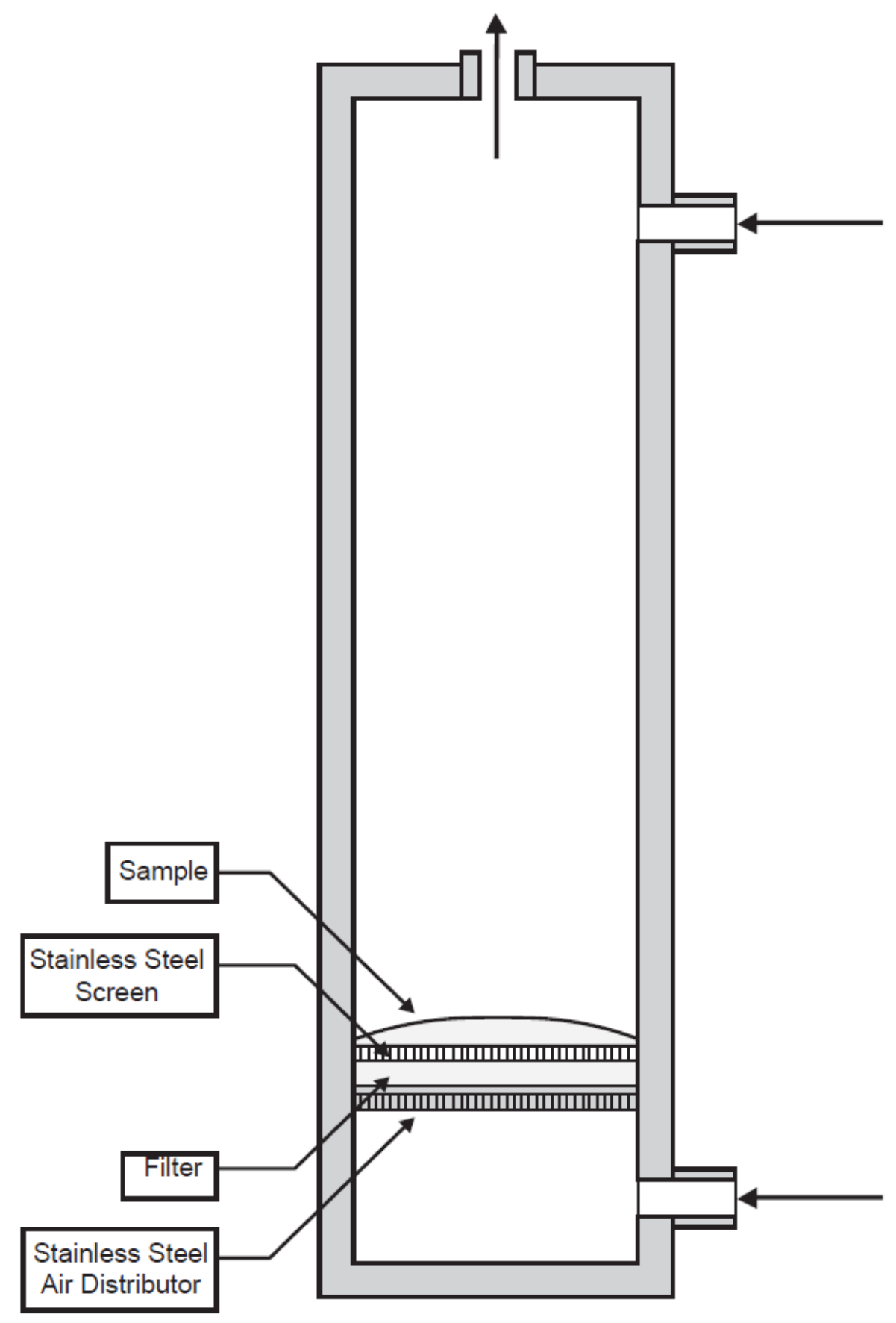

Figure 23 - Fluidized Bed

The Fluidized bed has the following characteristics:

- Diameter - 2.30 in

- Bed height - Varies based on amount of sample compound used

- Initial Flow Rate $\left(Q_{F B}\right):$ 1-2 LPM

- Vibrating Screen specs: Dia. - 2.06 in; Pore diameter - 0.125 in

- Filter specs - 0.183 in (thickness) Felt Material 


\subsubsection{Baffle}

The baffle, as seen in Figure 24, is placed inside of the particle chamber and is used to selectively draw particles from the chamber. The size of the tube, hole location and hole size influence this function. The baffle acts as a particle impactor to separate out larger particles. This application of baffles is well known for particle separation as it is the operating principle in a cascade impactor. As the aerosol makes its way through the opening of the baffle the larger particles will impact the wall of the 90 degree turn and the smaller lighter particle will remain entrained in the flow and pass through. As mechanical vibrations are applied and the air is drawn through the opening, resonance may be induced in the baffle and particle chamber.

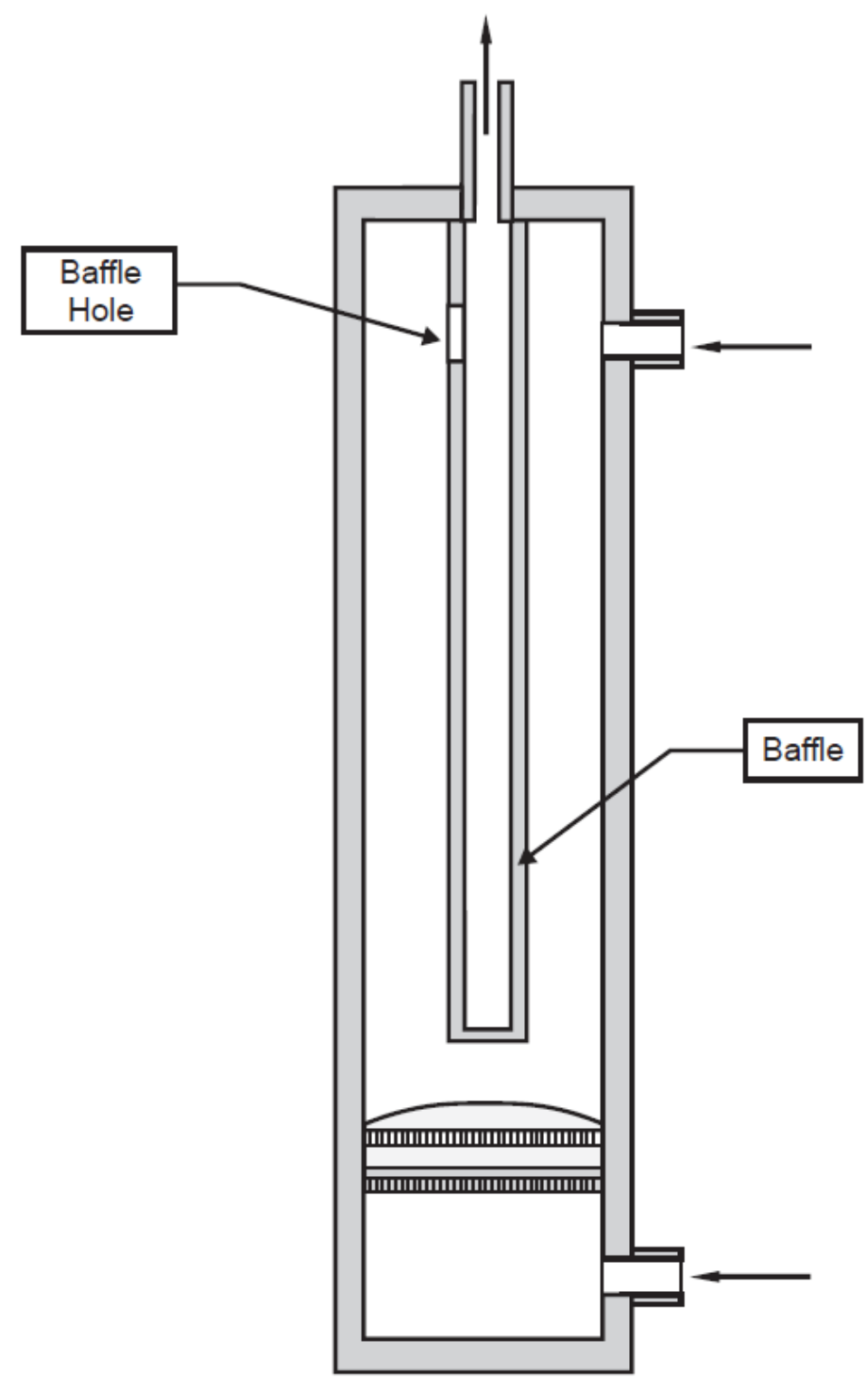

Figure 24 - Baffle 


\subsubsection{Vibrator}

A vibrator is attached to the device and used to create the mechanical vibrations. Mechanical vibration for the treatment of powders in industry is commonly used for a number of reasons especially to assist with fine powder fluidization as seen in Ch.2. In this case mechanical vibrations are used to influence shearing of the screen in the fluidized bed, form fluctuation eddies in the flow and enhance the transport of particles and reduce agglomeration.

A pneumatic vibrator is used which has a piston that acts in the direction $A B$ with an angle $\beta$ from the horizontal axis $\mathrm{X}$, an amplitude (Force, $\vec{F}_{0}$ ) and a frequency $\omega$ as shown in Figure 25 below.

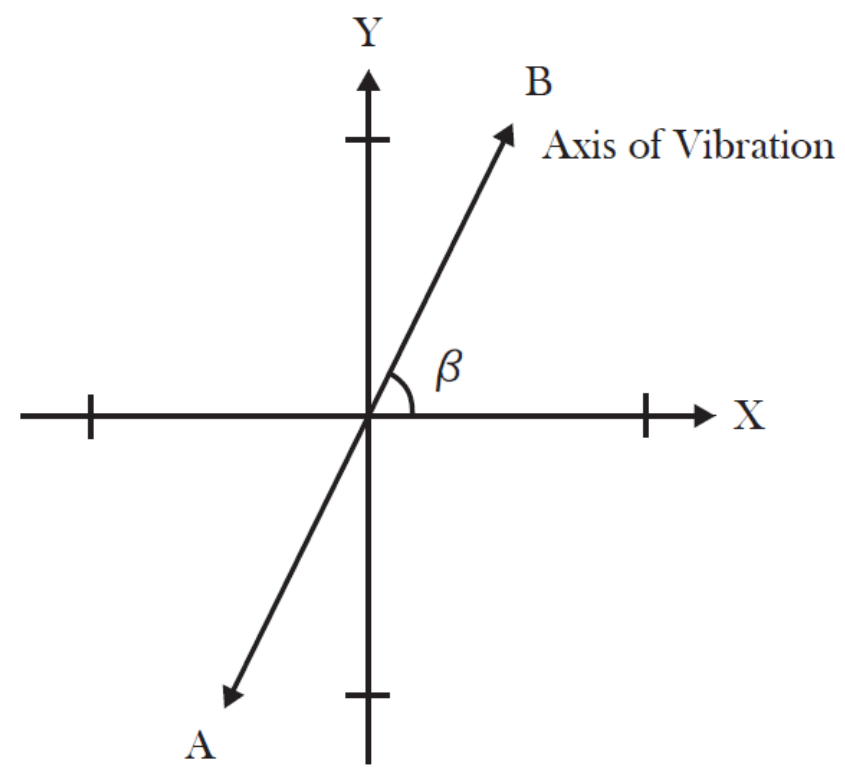

Figure 25 - Axis of Vibration

The vibrational force with respect to time can be represented as

$$
\vec{F}(t)=\vec{F}_{0} \sin \omega t
$$

Where $F_{0}$ is the force (amplitude) and $\omega$ is the vibration frequency.

The axis of vibration, as it relates to the nano particle aerosol generator, can be seen in Figure 26 where the vibrator mounts to the particle chamber providing the ability to change angle of vibration for various settings. 

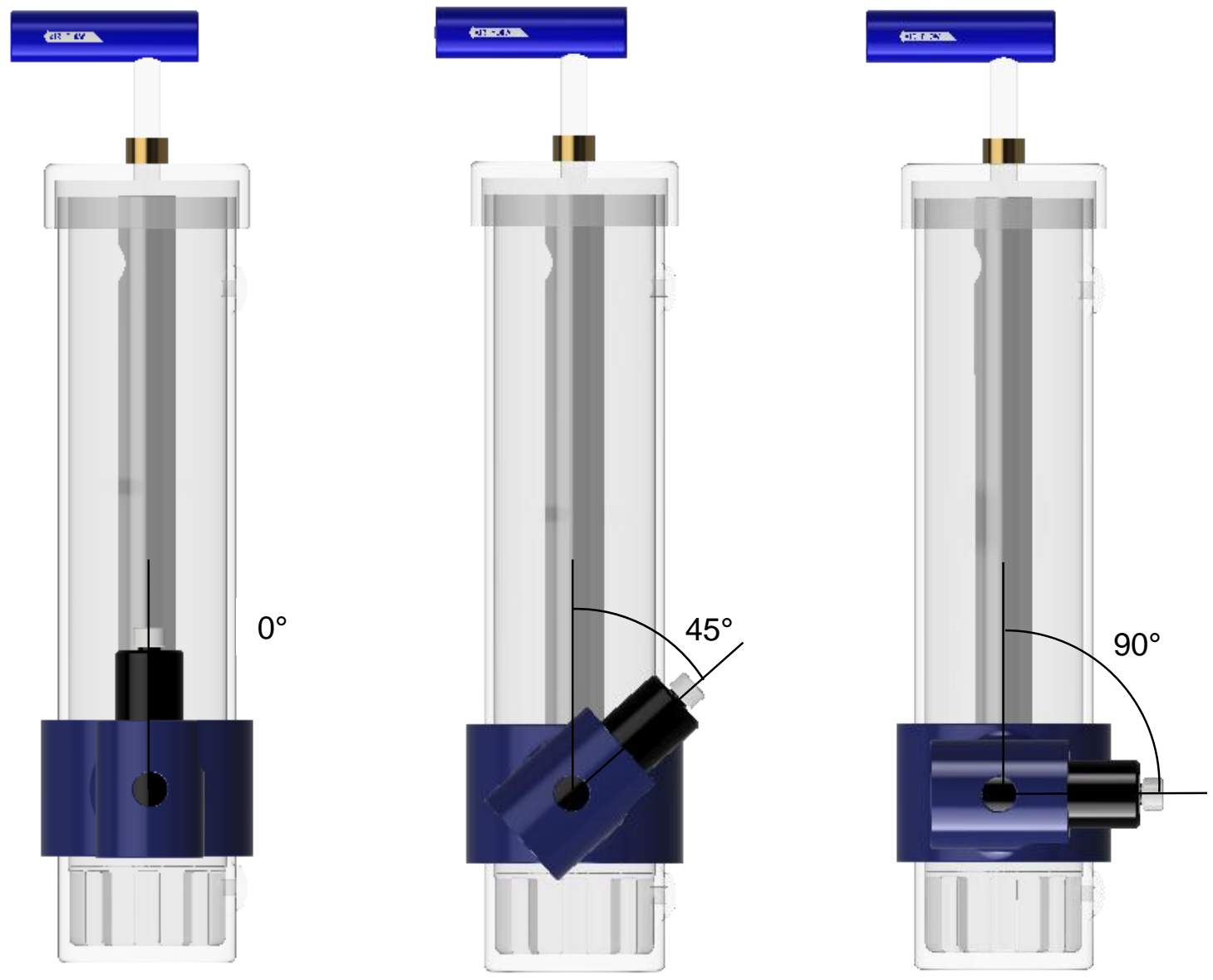

Figure 26 - Axis of Vibration

The frequency and amplitude values are known via the flowrate and pressure of the pneumatic vibrator respectfully. Vibration energy is assumbed to be transferred through the device and absorbed by the dampening device mount. 


\subsection{Combined Component Flow Analysis}

When combining these relationships initial assumptions were made to describe the function of the generator. These assumptions include, steady state and incompressible flow along a streamline, which are necessary for use of the Bernoulli and continuity equations. Therefore, the overall system can be analyzed with a control volume analysis using the continuity equations. Using the datum points as shown in Figure 27 below the continuity equation

$$
\sum \rho_{\text {out }} A_{\text {out }} v_{\text {out }}-\sum \rho_{\text {in }} A_{\text {in }} v_{\text {in }}=0
$$

becomes,

$$
\rho_{3} A_{3} v_{3}=\rho_{1} A_{1} v_{1}+\rho_{4} A_{4} v_{4}+\rho_{5} A_{5} v_{5}
$$

Since it is assumed to be incompressible

$$
Q_{3}=Q_{1}+Q_{4}+Q_{5}
$$

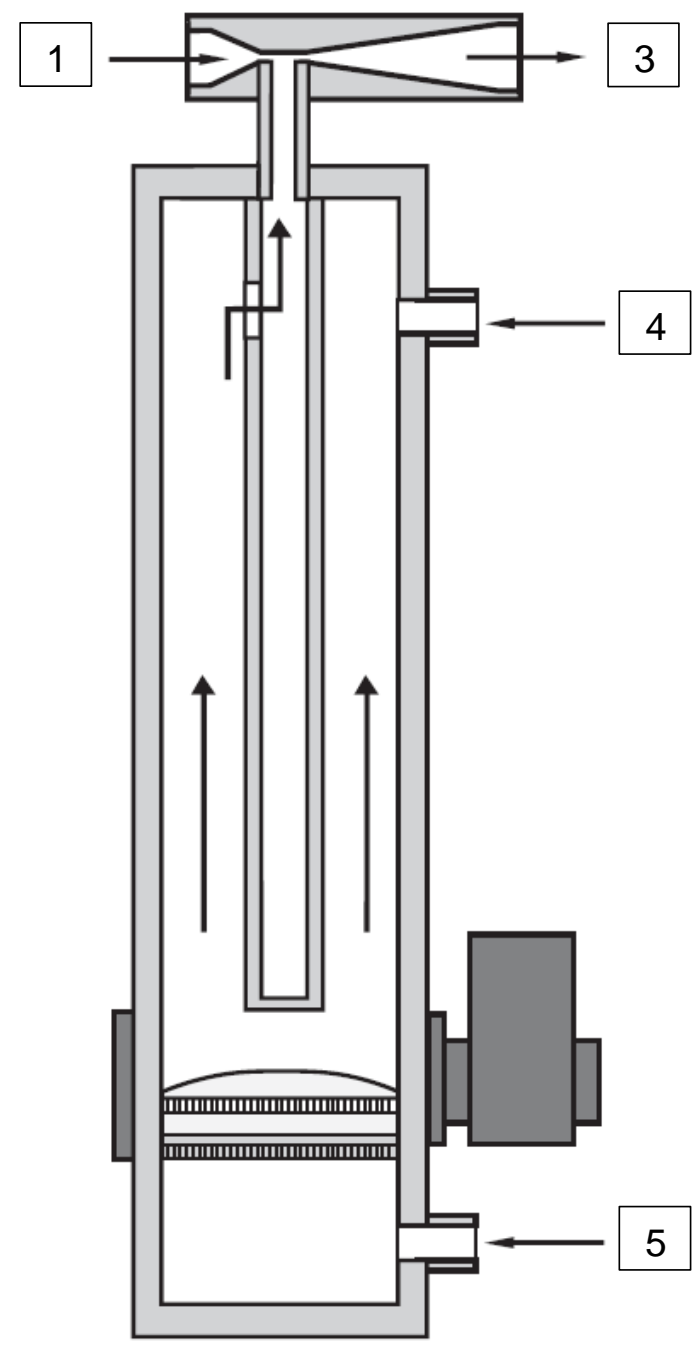

Figure 27 - Nanoparticle Aerosol Generator 


\subsection{Preliminary Device Testing}

Early testing of the device for toxicology inhalation exposure experiments have been established. This device has been used to conduct numerous inhalation studies with several published works out of the Nurkiewicz Toxicology Lab at West Virginia University. This has helped provide a baseline from which to build upon.

Nano- $\mathrm{TiO}_{2}$ aerosols have been generated directly from nano- $\mathrm{TiO}_{2}$ bulk dry powder (Aeroxide $\mathrm{TiO}_{2} \mathrm{P} 25$, Evonik, Germany) with a primary diameter of $21 \mathrm{~nm}$ and density of $3.7 \mathrm{~g} / \mathrm{cm}^{3}$ to demonstrate the nanoparticle aerosol generator. A $4 \mathrm{~g}$ sample was loaded into the nanoparticle aerosol generator. The aerosol was diluted with a 50:1 clean air to aerosol ratio and delivered continuously to a $0.5 \mathrm{~m}^{3}$ inhalation exposure chamber at a flow rate of 90 LPM which was the origin of sampling. Using the Electric Low Pressure Impactor (ELPI, Dekati, Tampere, Finland) which has a measurement range of $24 \mathrm{~nm}$ to 9.5 $\mu \mathrm{m}$, the real-time particle size distribution and concentration profiles were measured. These preliminary measurements using the ELPI are used to demonstrate the single peak distribution over a large scanning range.

Figure 28 and Figure 29 show the particle size distribution and concentration profile measured with the ELPI when the air flow through the $\mathrm{TiO}_{2}$ dry powder is at 1.6 1.8 LPM and the pressure of the vibrator at 60 psig. The aerosols have the following characteristics: 1) single peak distribution 2) median aerodynamic diameter of $164 \mathrm{~nm}$ 3) stable particle concentration, mean gravimetric mass concentration $=\sim 6 \mathrm{mg} / \mathrm{m}^{3}$ during a 3-hour-study.

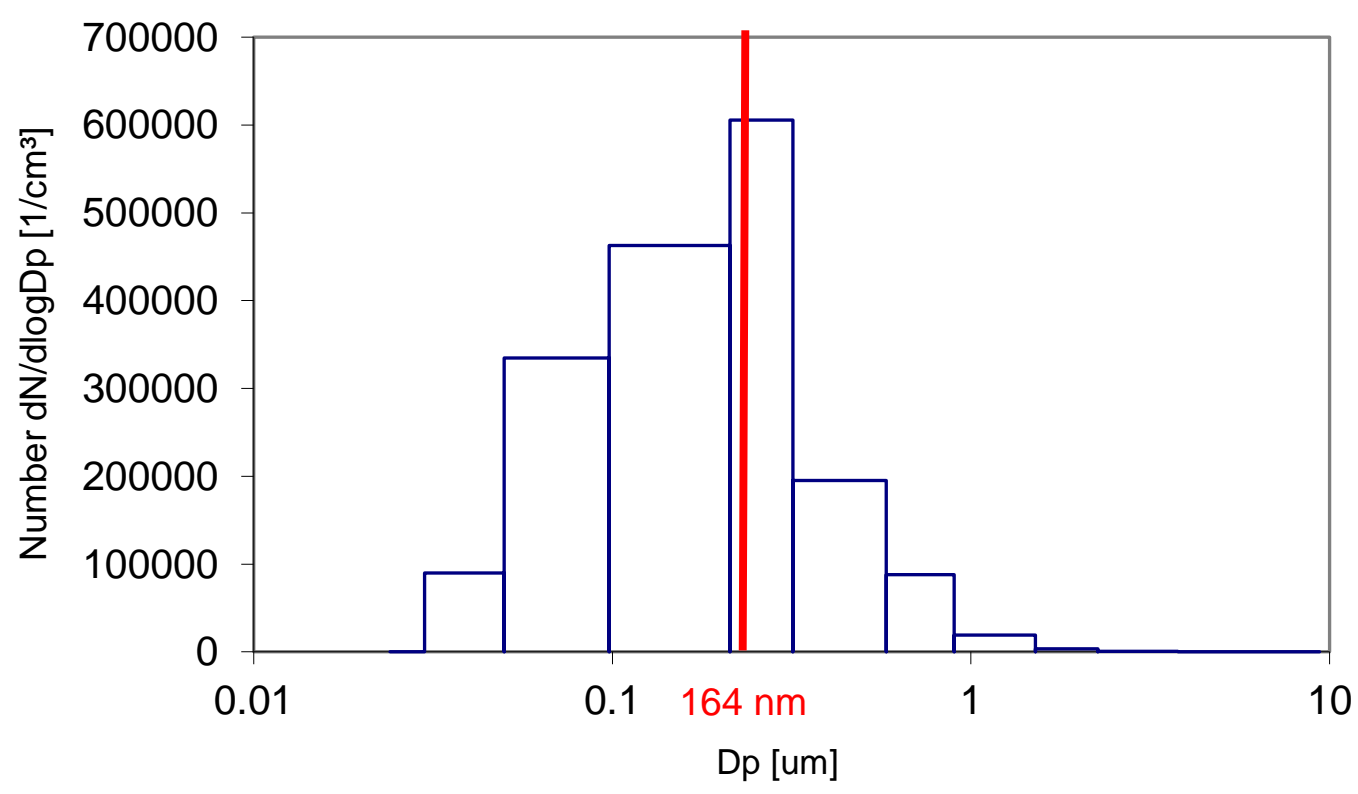

Figure 28 - ELPI Particle Size Distribution 


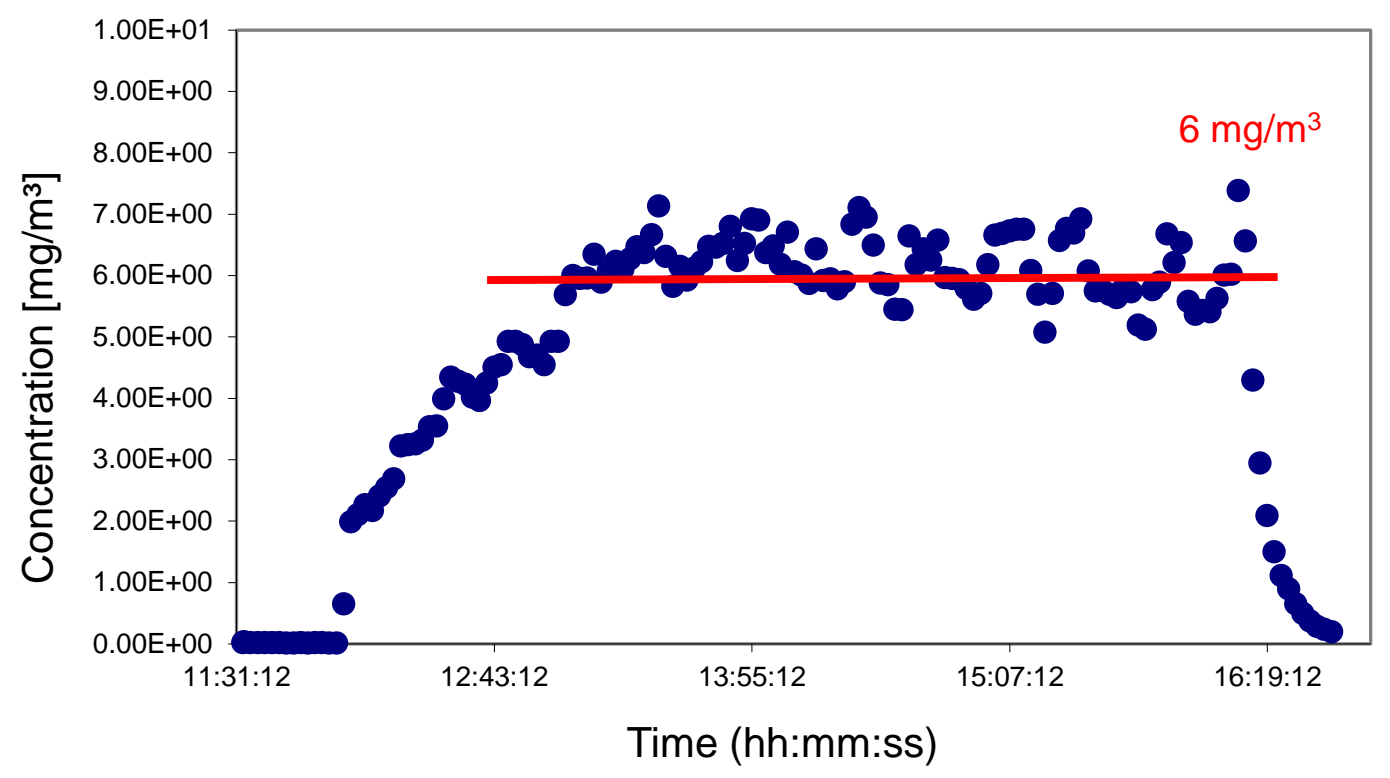

Figure 29 - ELPI Concentration Profile

During the measurement, the air flow rate through the dry powder layer was adjusted slightly to control the particle concentration. The vibration frequency and amplitude of the vibrator were maintained constant. Note: This represents the testing of one generator. Multiple generators can be combined for higher concentrations and longer durations.

It has been demonstrated with early use of the device that the particle size and mass concentration produced by the nanoparticle aerosol generator can be changed by adjusting the air flow rate through the dry powder layer, and adjusting vibration frequency and amplitude [7]. Although, this was not fully understood or quantified and will be explored in detail during the experimental testing. 


\section{CH. 4 DEVELOPMENT OF THE CONTROLLABLE SYSTEM}

A controllable system must be designed and built to satisfy the requirements needed for conducting the modeling experiments. Additionally, this controllable system will be used to support future inhalation experiments. The system must provide the ability to control and vary each controllable input parameter in order to regulate the output for the test compound of interest. The developed system will be used to run the experiments needed to develop the mathematical model as well as provide a platform to be used to test various compounds and expand the abilities of the inhalation facility. Lastly, this will provide a system that can be used by other researchers for diverse applications.

\subsection{Design requirements}

Before designing the controllable system the requirements for the design must be defined. These requirements include:

1. Parameter Control - The system must allow full control of each controllable input parameter which include: vibration frequency, amplitude and orientation; venturi pressure and flowrate; fluidized bed flowrate and differential pressure; and dilution port flowrate.

2. Full Enclosure - The system must be fully enclosure including all of the necessary components needed to generate particles in one unit. The enclosure must retain a slightly negative pressure to contain any fugitive particles and dampen noise and mechanical vibrations.

3. Multiple Generator Capability - The system must allow for multiple generators to produce higher concentrations and longer experiment durations. (Manifold of generators, phasing of generators or using an automatic material feed to the fluidized bed)

To meet these requirements a system schematic was generated for the design. The system schematic, as seen in Figure 30, represents the enclosure with the necessary components for the complete system. 


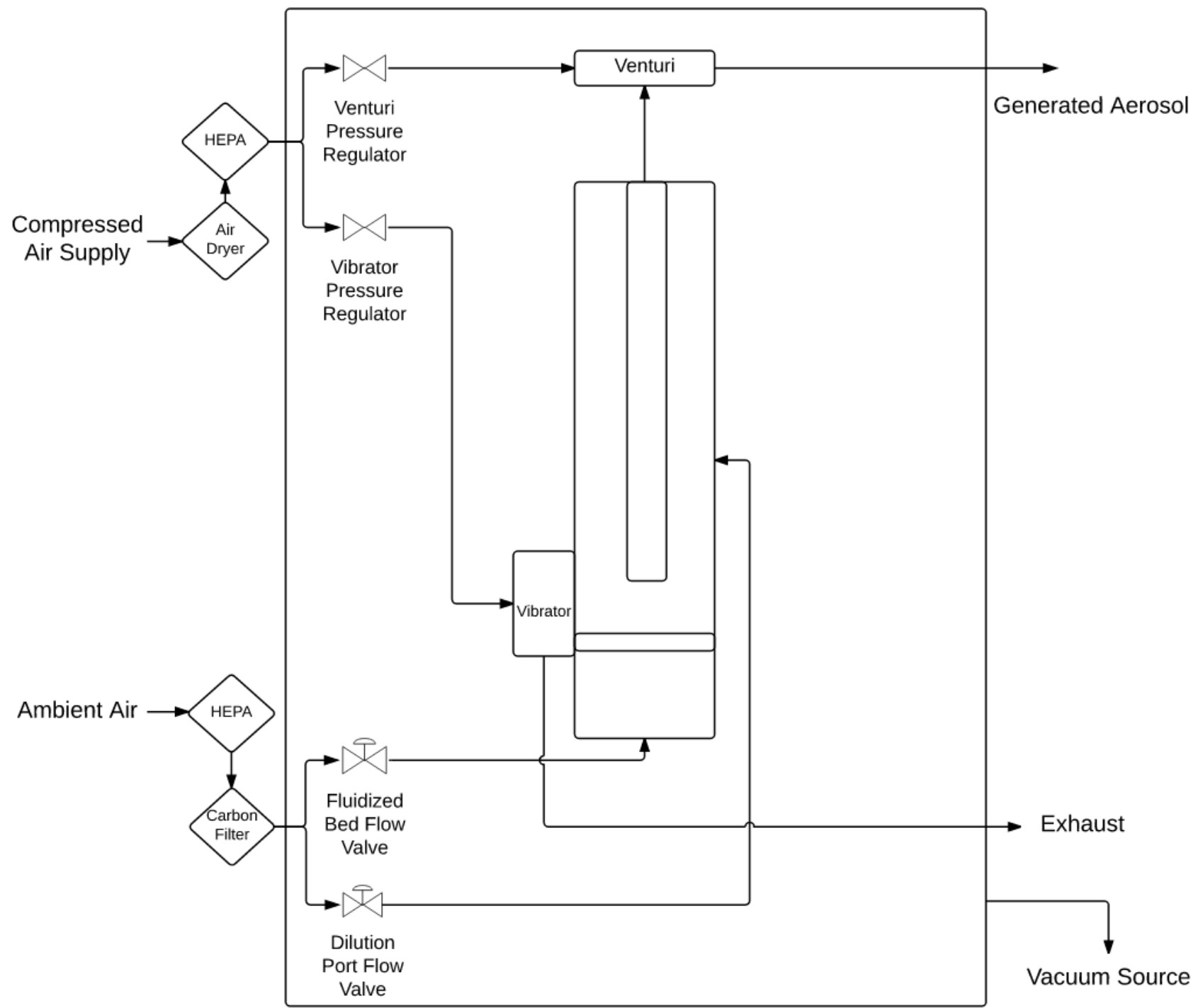

Figure 30 - Nanoparticle Aerosol Generator System Schematic

Using the fundamental analysis given in Ch.3, the specifications for the components of the unit were determined. CAD modeling was used to generate three dimensional models based on the design of the system schematic and chosen component specifications. The three dimensional models were used to assist in the design of specialty components and the overall system. Once the CAD models were complete the components were sourced, fabricated and 3D printed. The system was built and tested for functionality before lab use. The developed system is shown below in Figure 31 and Figure 32 . 


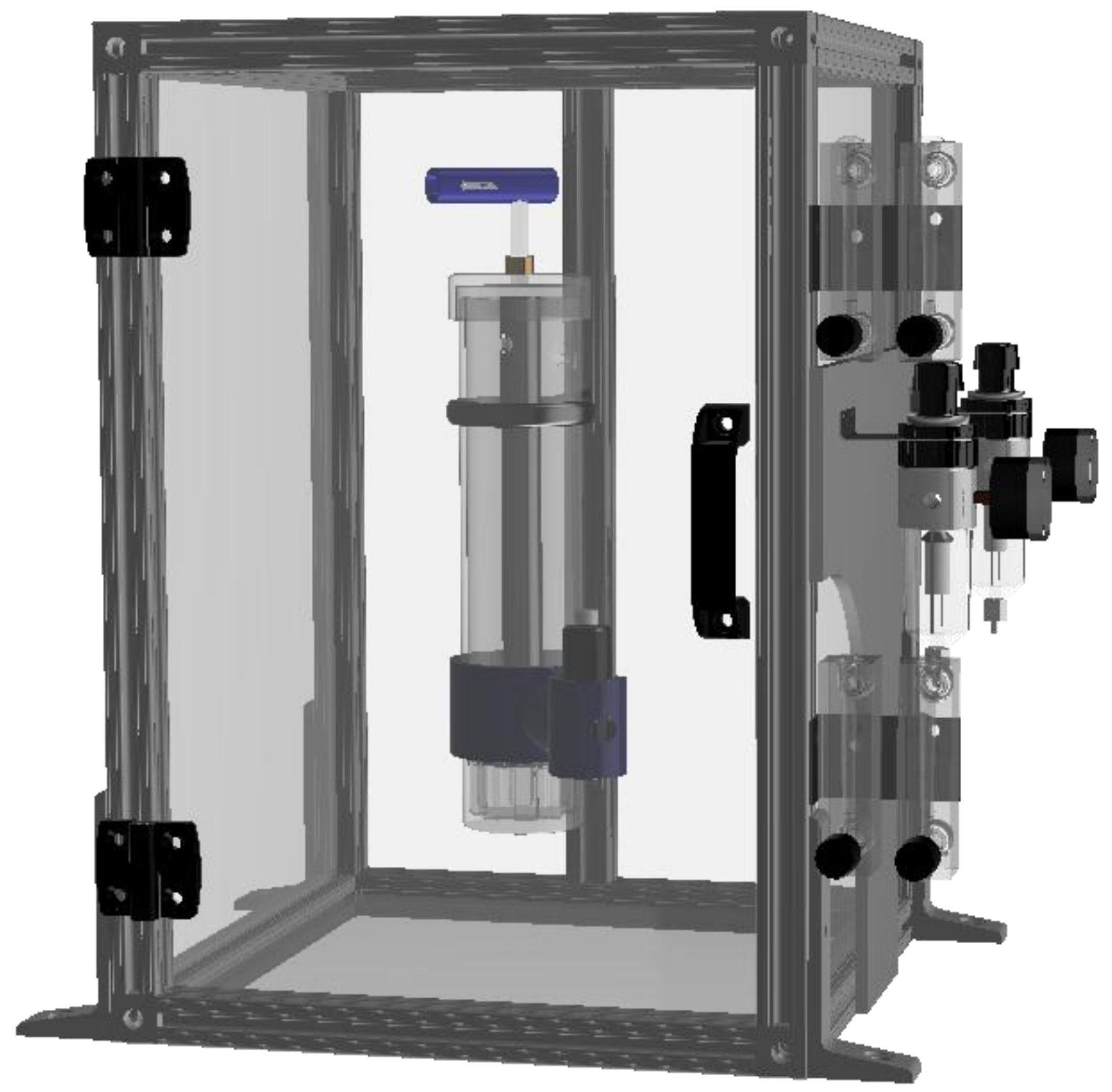

Figure 31 - Nanoparticle Aerosol Generator System Rendering 


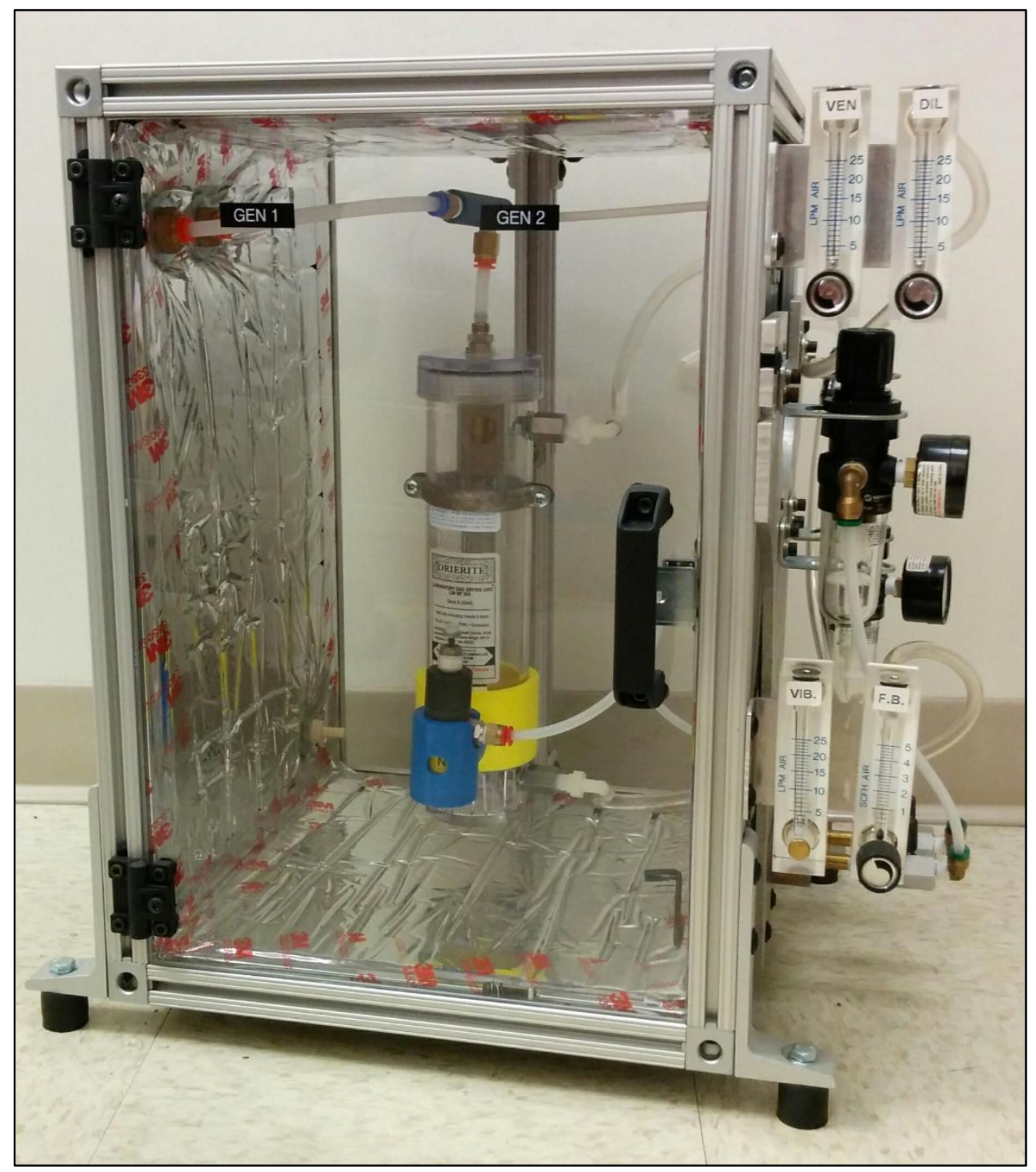

Figure 32 - Nanoparticle Aerosol Generator System Prototype

The nanoparticle aerosol generation system includes all necessary hardware to generate aerosols given a test sample, vacuum and compressed air supply. 


\section{CH. 5 MODELING THE NANO-PARTICLE AEROSOL GENERATION SYSTEM}

For this experimental modeling approach it is hypothesized that the developed system can be characterized to allow the particle size, size distribution and concentration (output) to be varied and set to a desired outcome by precise manipulation of the input parameters based on a predictive mathematical model constructed experimentally. Given that there is limited theoretical information that can be used to model this type of system, experimental approaches must be used. In order to address this hypothesis a design of experiments (DOE) approach is employed to demonstrate the range of the system and provide the necessary information needed to develop a predictive tool by way of an experimental test matrix. Having identified the parameters of interest, the controllable parameters are defined and reduced for the final model and test matrix. The levels of each parameter are determined based on the initial settings and hardware specifications. The experiments will be conducted to provide the necessary data for analysis which is described later in this chapter. The success of this approach will be measured and quantified by comparing the developed predictive model with validation experiments as seen in Section 5.6 .

\subsection{Experimental Design}

A designed experiment will be used to investigate the effects of various manipulations of the input factors. A designed experiment is an appropriate approach to discern and quantify the effect of the input factors. A designed experiment will provide the following insights:

I. Main effects of each input factor

II. Understanding of factor relationships

III. Optimal input settings for a desired output

An input/output model is defined with the various input parameters along with the output parameters of interest. The controllable input parameters include: vibration frequency, amplitude and orientation; venturi pressure and flowrate; fluidized bed flowrate and differential pressure; and dilution port flowrate. The uncontrollable parameters include: venturi size/specification, vibrator size/specification, baffle size/specification, particle chamber size/specification and fluidized bed size/specification. The controllable input parameters provide 8 parameters that can be varied during experimentation. The output parameters of interest are mean particle size, size distribution and concentration. These parameters are represented in Figure 33 below. 
\begin{tabular}{|ll}
\hline Input & Output \\
\hline
\end{tabular}

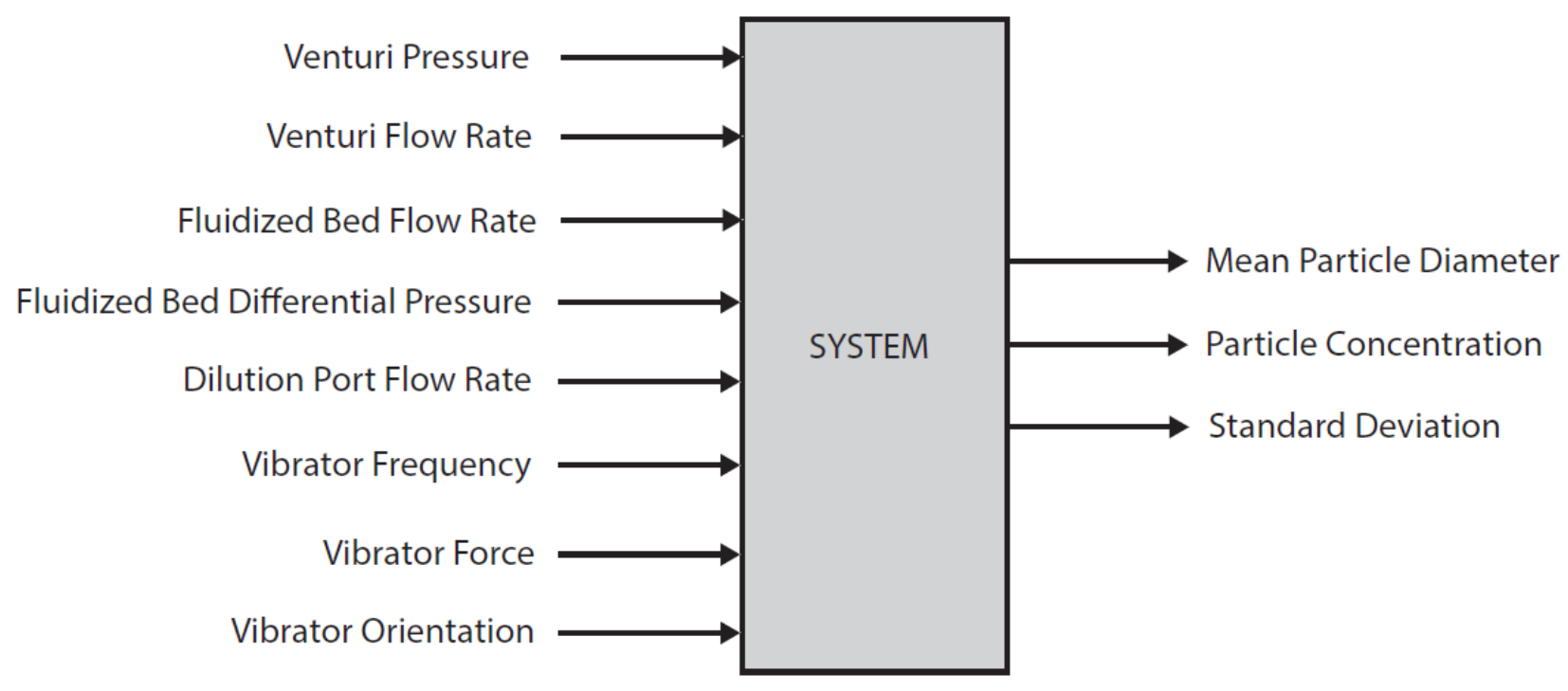

Figure 33 - Input/output Model

The previous input/output model with eight inputs and three outputs, which would be tested at three levels, is large for a design of experiments approach; therefore, it was necessary to simplify the model by reducing the input and output parameters mathematically. To simplify the input/output model the input parameters can be reduced based on fundamental principles presented in Ch. 3. Using this approach it is possible to reduce the number of input parameters which makes the model more appropriate for a designed experiment. This is achieved as follows:

The venturi flowrate is a function of the pressure and venturi dimensions. Since the size of the venturi is fixed, the controllable input parameter can be reduced to "venturi pressure" with the flowrate being a function of that pressure based on the venturi specifications. The fluidized bed flowrate and dilution port flowrate can be expressed as one input term using conservation of mass. Since the flowrate of the secondary inlet of the venturi can be calculated as shown in Section 3.2, using conservation of mass, the flowrate of the dilution port can be defined in terms of the fluidized bed and venturi flowrates. This leads to the need for the fluidized bed flowrate only. Since the fluidized bed and dilution port flowrates are a function of the secondary inlet flowrate of the venturi it is more appropriate to represent them as a flowrate ratio dependent on the venturi secondary inlet flow. This is also demonstrated in Section 3.2. 
The vibrator frequency and amplitude is a function of the pressure used for the vibrator. Therefore, these two inputs can be reduced to one input, "vibrator pressure". The output of the system can be reduced to one parameter of interest, particle size distribution. The particle size distribution curve, as seen in Figure 34 for example, will provide all the necessary data to deduce mean particle size, size distribution and particle concentration [50].

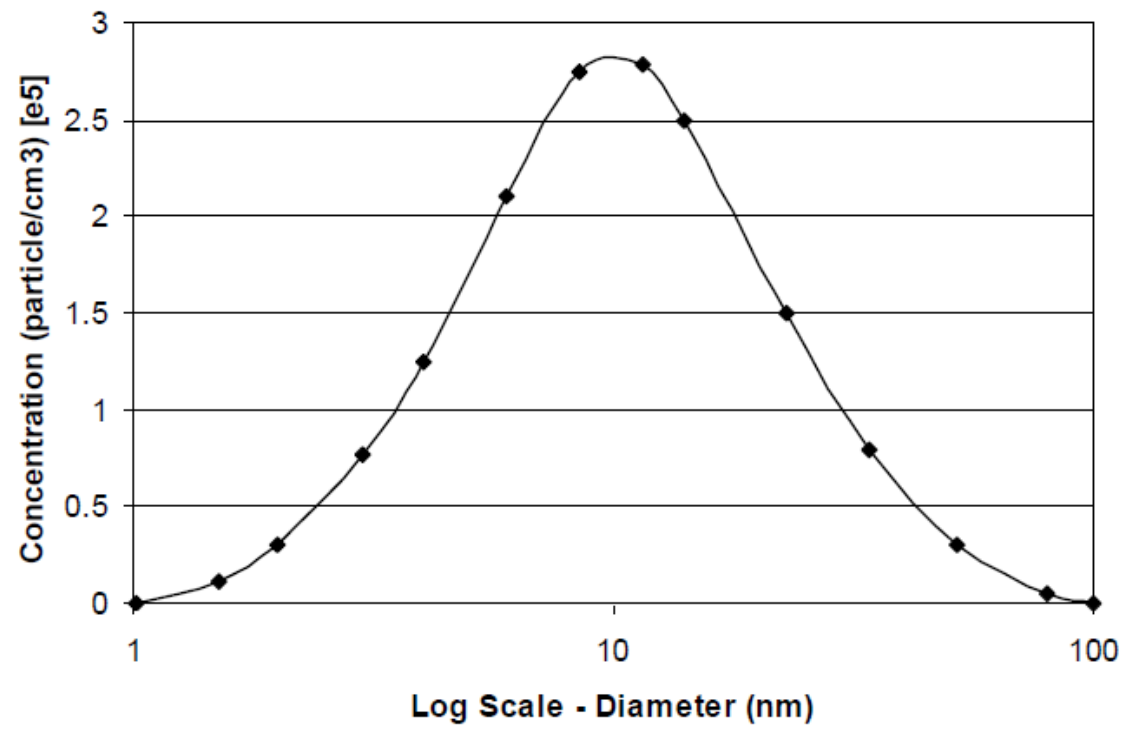

Figure 34 - Lognormal Aerosol Size Distribution Example [50]

Using these fundamental relationships described in Ch. 3, the input/output model can be simplified to four input parameters and one output parameter of interest as shown in Figure 35.

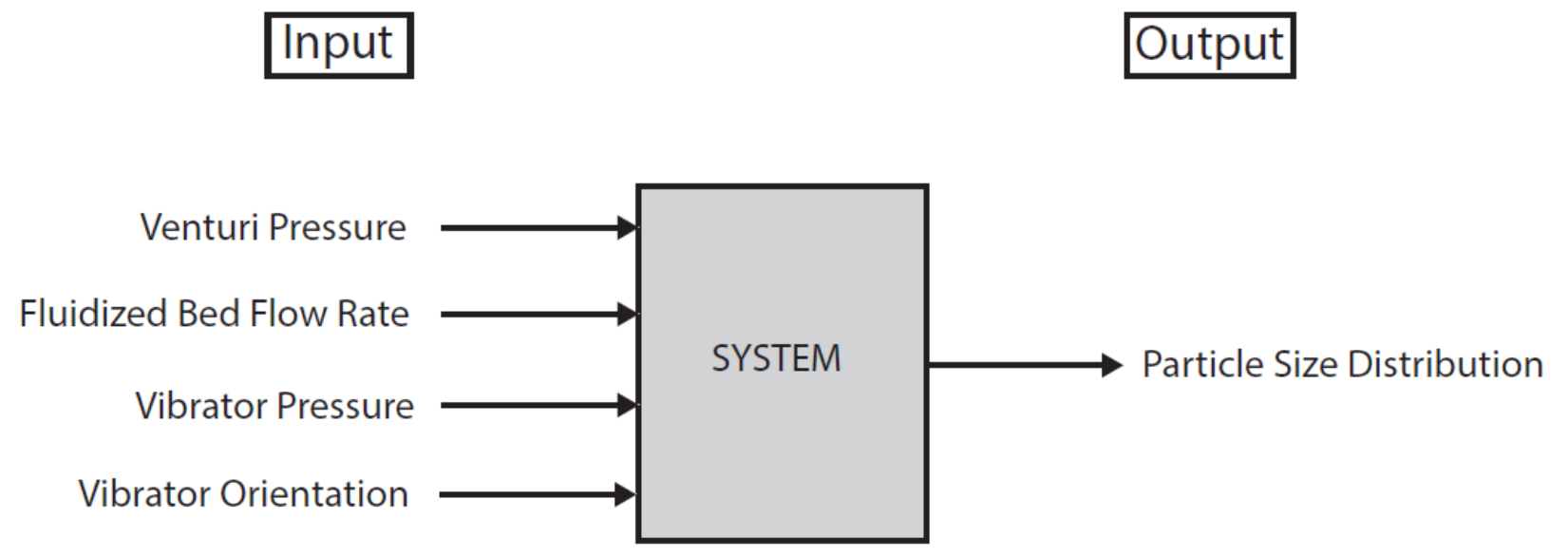

Figure 35 - Simplified Input/Output Model 
Considering the simplified input/output model presented above it is now of interest to determine the effect of four input parameters: Venturi Pressure (A), Fluidized Bed Flowrate (B), Vibrator Pressure (C) and Vibrator Orientation (D) on the output particle size distribution. To define the experimental region of interest for this study three levels are chosen for each input parameter which will provide adequate data needed for the analysis. The starting levels for the four input factors represent midrange operating settings and are represented in Table 3 as Level 2. Level 2 includes: Pveno (psig) Pressure, Qfвo (LPM) Fluidized Bed Flowrate, $P_{\text {Vibo }}$ (psig) Vibrator Pressure and $\theta_{0}$ (Degrees) Vibrator Orientation. The alternate levels of the input factors, for example Venturi Pressure, are based on hardware specifications and are represented as $\mathrm{P}_{\mathrm{ven} 0}-20$ and $\mathrm{P}_{\mathrm{ven} 0}+20$ (psig). The goal for this experiment is to determine the effects of each input parameter compared to the output parameter of interest.

Table 3 - Experimental Test Region

\begin{tabular}{|c|c|c|c|}
\hline \multirow{2}{*}{ Input Factors } & \multicolumn{3}{|c|}{ Levels } \\
\cline { 2 - 4 } & 1 & 2 & 3 \\
\hline A. Venturi Pressure (psig) & $P_{\text {Ven } 0}-20$ & $P_{\text {Ven } 0}$ & $P_{\text {Ven } 0}+20$ \\
\hline B. Fluidized Bed Flowrate (LPM) & $Q_{F B 0}-.5$ & $Q_{F B 0}$ & $Q_{F B 0}+.5$ \\
\hline C. Vibrator Pressure (psig) & $P_{\text {Vib } 0}-20$ & $P_{\text {Vib } 0}$ & $P_{\text {Vib } 0}+20$ \\
\hline D. Vibrator Orientation (degrees) & $\theta_{0}$ & $\theta_{0}+45^{\circ}$ & $\theta_{0}+90^{\circ}$ \\
\hline
\end{tabular}

As a preliminary experimental study, one parameter will be varied while the remaining parameters are set at the mid-level to analyze the fundamental effect that each parameter has on the output response. This method is often referred to as "one-variable-at-a-time" (OVAT) or monothetic analysis and will provide a basic understand of the factor effects and help to refine and tailor the final test matrix. This approach, however, will not give any indication of interactions among factors. This preliminary test matrix will be used to confirm that each parameter definitively has an effect on the output before running the experimental test matrix and later for verification experiments with the predictive model. The preliminary test matrix is demonstrated in Table 4. 
Table 4 - Preliminary Test Matrix

\begin{tabular}{|c|c|c|c|c|}
\hline \multirow{2}{*}{ Expt. No. } & \multicolumn{5}{|c|}{ Input Factors } \\
\cline { 2 - 5 } & $\begin{array}{c}\text { A. Venturi Pressure } \\
(\mathrm{psig})\end{array}$ & $\begin{array}{c}\text { B. Fluidized Bed Flow } \\
\text { Rate (LPM) }\end{array}$ & $\begin{array}{c}\text { C. Vibrator Pressure } \\
(\mathrm{psig})\end{array}$ & $\begin{array}{c}\text { D. Vibrator Orientation } \\
\text { (degrees) }\end{array}$ \\
\hline $\mathbf{1}$ & 2 & 2 & 2 & 1 \\
\hline $\mathbf{2}$ & 2 & 2 & 2 & 3 \\
\hline $\mathbf{3}$ & 2 & 2 & 2 & 1 \\
\hline $\mathbf{4}$ & 2 & 2 & 1 & 1 \\
\hline $\mathbf{5}$ & 2 & 2 & 3 & 1 \\
\hline $\mathbf{6}$ & 2 & 2 & 2 & 1 \\
\hline $\mathbf{7}$ & 2 & 1 & 2 & 1 \\
\hline $\mathbf{8}$ & 2 & 2 & 2 & 1 \\
\hline $\mathbf{9}$ & 2 & 3 & 2 & 1 \\
\hline $\mathbf{1 0}$ & 1 & 2 & 2 & 1 \\
\hline $\mathbf{1 1}$ & 2 & 2 & 2 & 2 \\
\hline $\mathbf{1 2}$ & 3 & 2 & & 2 \\
\hline
\end{tabular}

In order to test each combination of input factors to reveal deeper insights such as factor interaction, optimal conditions, etc. on output response requires using a full factorial design to capture each combination of settings. A full factorial design for this experiment would require $3^{4}$ or 81 experimental runs which is far too many for efficient experimental testing. A matrix experiment using orthogonal arrays is an alternative approach to efficiently conduct the experiments. This matrix experiment (test matrix) consists of a set of experiments where the settings of the various input parameters are changed from one experiment to another. Conducting matrix experiments using special matrices, called orthogonal arrays, allows the effects of several parameters to be determined efficiently and is an important technique in experiment design. This will provide the data needed for the development of the predictive tool later in this chapter. 
Using insights gathered from the preliminary experiments, the test matrix designed for the orthogonal arrays experiment is shown below in Table 5. It consists of nine individual experiments corresponding to the nine rows. The four columns of the matrix represent the four input factors as indicated in Table 3. The entries in the matrix represent the level of each input factor. For example, experiment 1 will consist of $\left(P_{\text {Veno-20), }}\left(Q_{\mathrm{FBO}}-.5\right)\right.$, $\left(\mathrm{P}_{\mathrm{Vib0}}-20\right)$ with the original vibrator orientation of $\theta_{0}$. Experiment 4 will consist of ( $\left.P_{\text {Veno }}\right),\left(Q_{F B 0^{-}} .5\right),\left(P_{\text {Vibo }}\right)$ and 90 degrees of orientation which can also be represented as $A_{2}, B_{1}, C_{2}, D_{3}$.

Table 5 - Experimental Test Matrix

\begin{tabular}{|c|c|c|c|c|}
\hline \multirow{2}{*}{ Expt. No. } & \multicolumn{5}{|c|}{ Input Factors } \\
\cline { 2 - 5 } & $\begin{array}{c}\text { A. Venturi Pressure } \\
(\mathrm{psig})\end{array}$ & $\begin{array}{c}\text { B. Fluidized Bed Flow } \\
\text { Rate (LPM) }\end{array}$ & $\begin{array}{c}\text { C. Vibrator Pressure } \\
(\mathrm{psig})\end{array}$ & $\begin{array}{c}\text { D. Vibrator Orientation } \\
\text { (degrees) }\end{array}$ \\
\hline $\mathbf{1}$ & 1 & 1 & 1 & 1 \\
\hline $\mathbf{2}$ & 1 & 2 & 2 & 3 \\
\hline $\mathbf{3}$ & 1 & 3 & 2 & 3 \\
\hline $\mathbf{4}$ & 2 & 1 & 3 & 2 \\
\hline $\mathbf{5}$ & 2 & 2 & 1 & 2 \\
\hline $\mathbf{6}$ & 2 & 3 & 3 & 3 \\
\hline $\mathbf{7}$ & 3 & 1 & 1 & 1 \\
\hline $\mathbf{8}$ & 3 & 2 & 2 & 2 \\
\hline $\mathbf{9}$ & 3 & 3 & & 3 \\
\hline
\end{tabular}

The matrix experiment as shown in Table 5 is a standard orthogonal array $L_{9}$ as described in Quality Engineering Using Robust Design [51]. The columns in this matrix are mutually orthogonal meaning for any pair of two columns, all combinations of factors occur and they occur an equal number of times, also referred to as the balancing property [51]. This experimental design provides the information needed to conduct the experiments and record the data. The following procedure will be used to conduct the experiments and collect the data for analysis. 


\subsection{Experimental Set-up}

The experimental set-up to complete the outlined test matrices consists of the nanoparticle aerosol generation system outlined in Ch. 4 connected to a particle sampling chamber as seen in Figure 36.

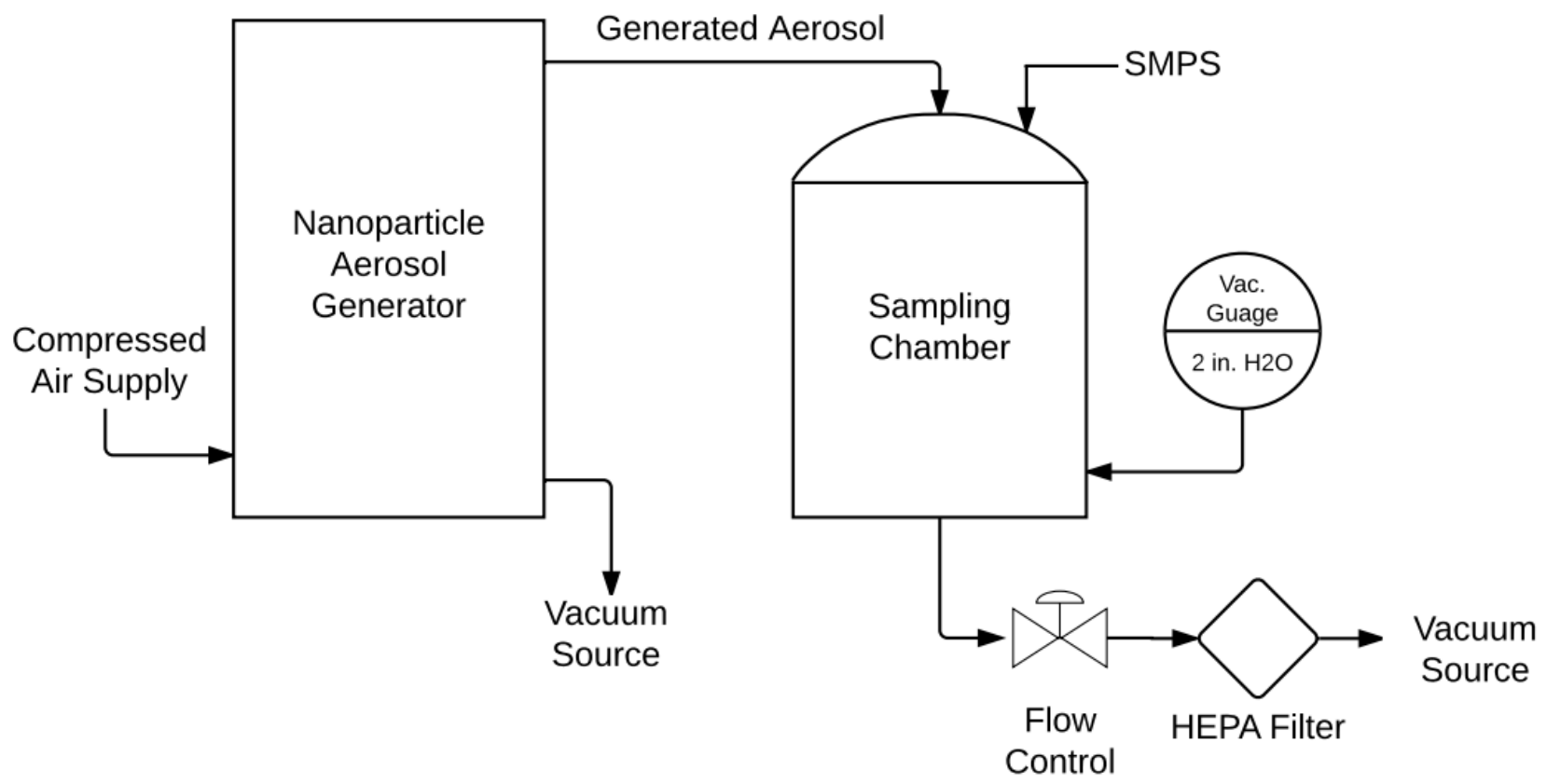

Figure 36 - Sampling Chamber Set-up

The particle sampling chamber developed for this testing, as seen in Figure 36 above, has the following specifications:

- Sealed 30 liter aluminum chamber

- Generated aerosol inlet port

- SMPS sampling port

- 3 flowrate controlled vacuum ports with a multistage HEPA filter

- Vacuum gauge

- Vacuum regulation device set at 2 in. of water 
The experimental set-up as outlined above is shown in Figure 37 below.

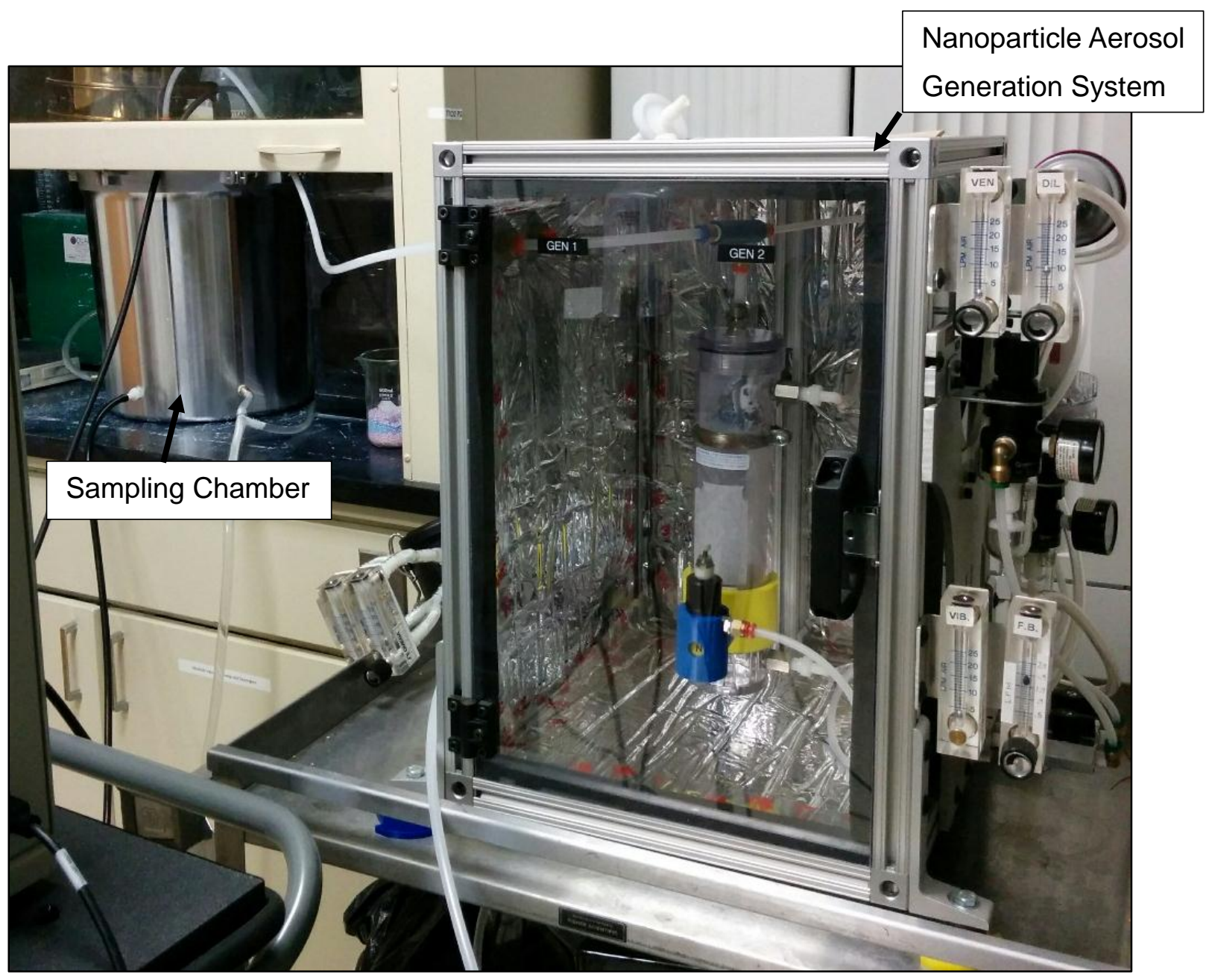

Figure 37 - Nanoparticle Aerosol Generation System Test Set-up

The nanoparticle aerosol generation system seen above is supplied with house air and a vacuum source. The generation system is then connected to the sampling chamber located within the fume hood. The sampling chamber, as seen in Figure 38, consists of a $30 \mathrm{~L}$ aluminum chamber with an aerosol inlet port, SMPS sampling port, pressure relief valve, vacuum gauge and vacuum flow ports. 


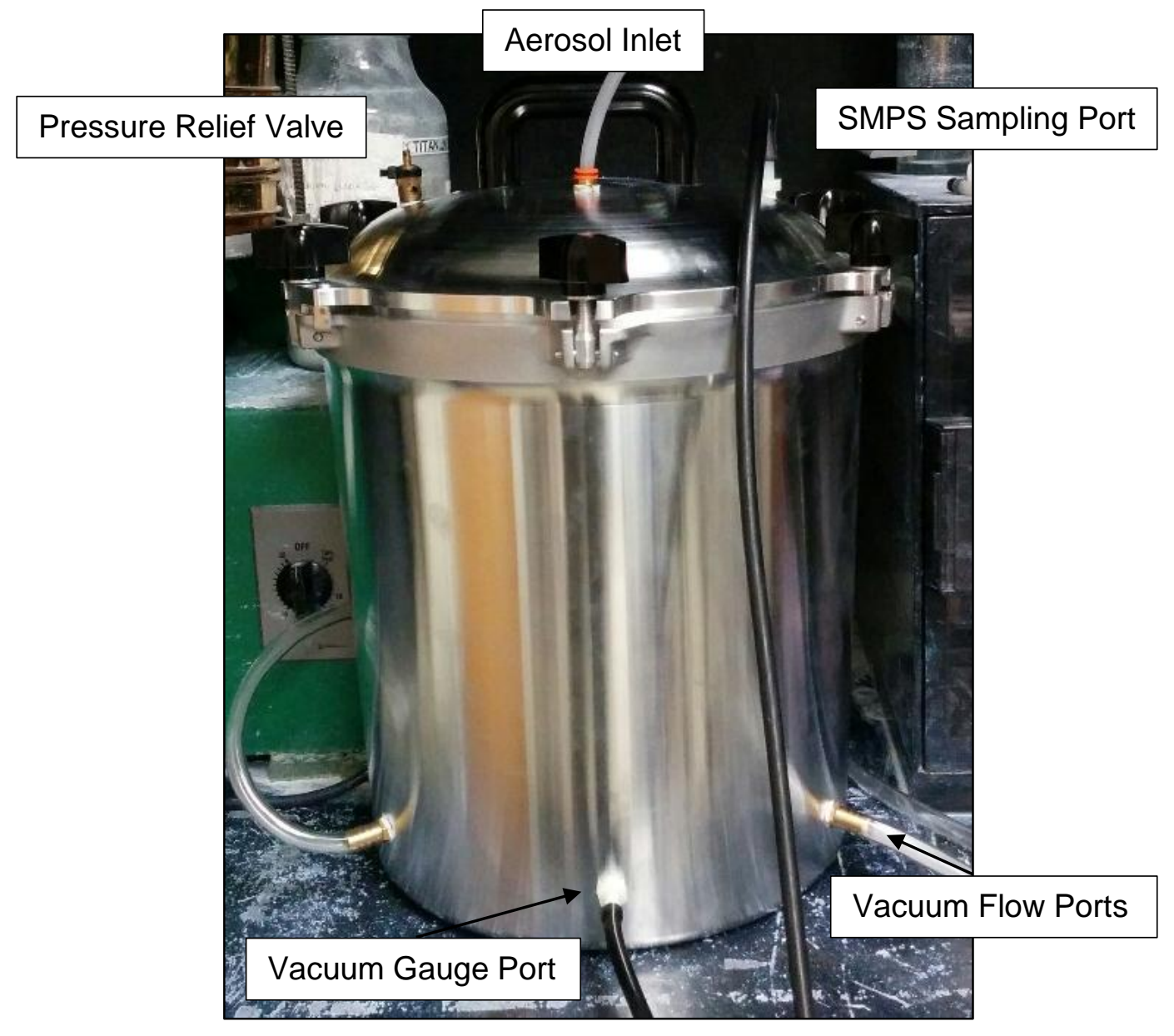

Figure 38 - Sampling Chamber

The Scanning Mobility Particle Sizer (SMPS) used to sample the aerosol along with the vacuum gauge used for the sampling chamber is shown in Figure 39 below. 


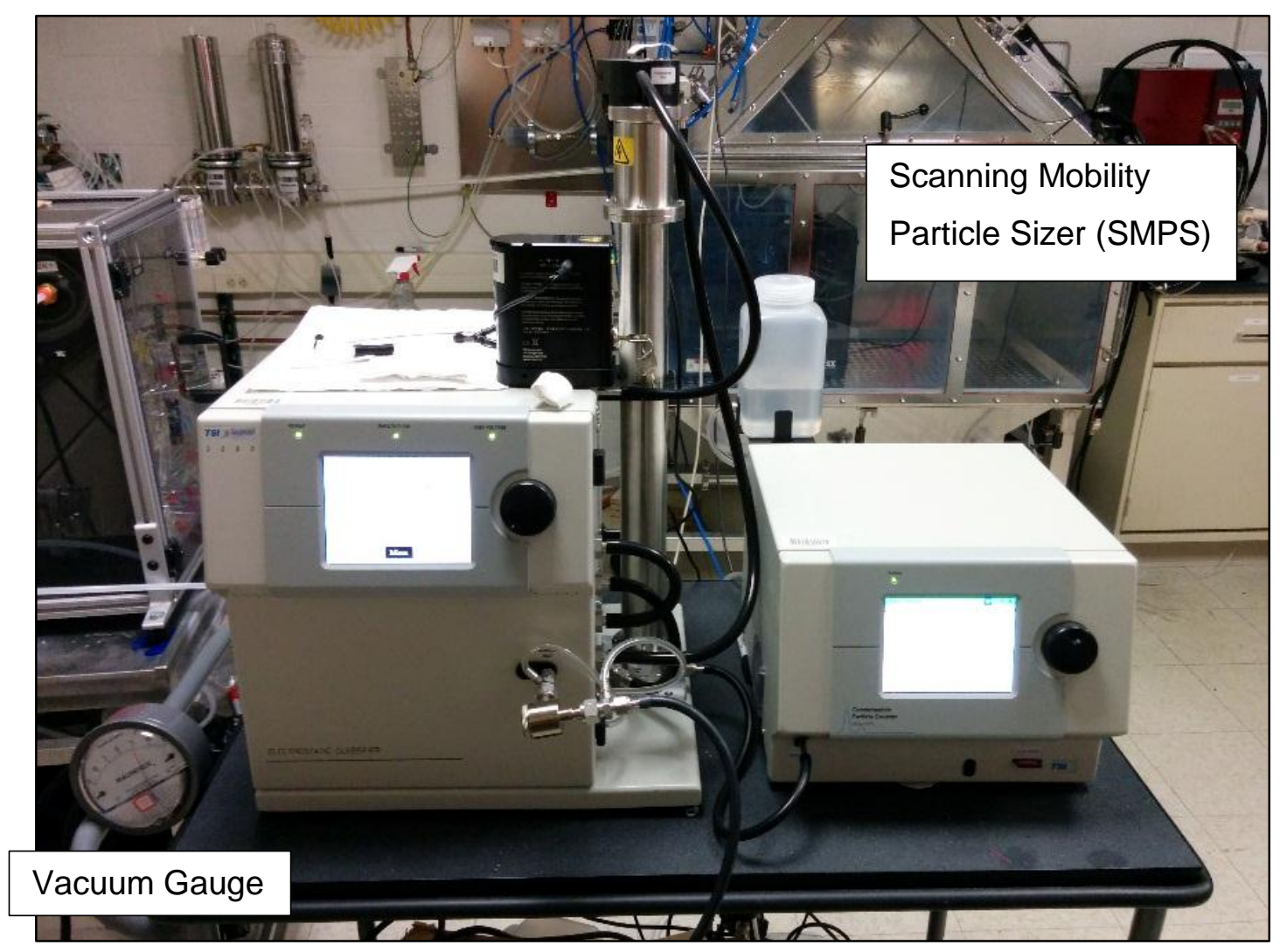

Figure 39 - Scanning Mobility Particle Sizer (SMPS)

Once assembled the entire experimental set-up was vacuum checked for leaks. This was completed by holding the entire system at $15 \mathrm{in}$. of Mercury for $>30 \mathrm{~min}$. The system was then ran dry (without sample compound) for 8 hours to confirm system durability for the intended experiments. 


\subsection{Experimental Procedure}

Before conducting the proposed experiments the operating conditions for the nanoparticle aerosol generation system must be defined. The inhalation facility, where the testing will occur, will have controlled humidity and temperature at $<10 \%$ and $\sim 23$ degrees $C$ respectfully. It has been shown that the higher humidity levels lead to particles that are more likely to agglomerate [42] therefore, the air supply entering the generator is targeted at $<10 \%$ humidity and 23 degrees Celsius. This is achieved by using in-line air dryers. While variation in temperature levels may have an effect on aerosol conditions such as Brownian motion, temperature change is restricted by the needs for animal housing therefore not conducive to much variation for the proposed use of the technology.

The sample being used to conduct these experiments is a Silica Oxide $\left(\mathrm{SiO}_{2}\right)$ nanopowder with spherical particles and a 10-20 nm primary particle diameter, a density of $2.7 \mathrm{~g} / \mathrm{cm}^{3}$ and trace metals basis of 99.5\% supplied by Sigma-Aldrich (See Appendix A for data sheet). This compound was chosen as the test sample due to its stable and well characterized formula. Before aerosolizing, the sample is stored in a desiccator to reduce any moisture content. 3.5 grams of $\mathrm{SiO}_{2}$ was then loaded into the generator for the test experiments.

Based on the experimental design, Table 6 below represents the low (1), mid (2) and high (3) level of each factor that will be tested in the test matrix experiments. These factors being: A. Venturi Pressure, B. Fluidized Bed Flowrate, C. Vibrator Pressure and D. Vibrator Orientation.

Table 6 - Experimental Test Region

\begin{tabular}{|c|c|c|c|}
\hline \multirow{2}{*}{ Input Factors } & \multicolumn{3}{|c|}{ Levels } \\
\cline { 2 - 4 } & 1 (Low) & 2 (Mid) & 3 (High) \\
\hline A. Venturi Pressure (psig) & 35 PSI & 55 PSI & 75 PSI \\
\hline B. Fluidized Bed Flowrate (LPM) & 1 LPM & 1.5 LPM & 2 LPM \\
\hline C. Vibrator Pressure (psig) & 35 PSI & 60 PSI & 75 PSI \\
\hline D. Vibrator Orientation (degrees) & $0^{\circ}$ & $45^{\circ}$ & $90^{\circ}$ \\
\hline
\end{tabular}

The data provided in Table 6 is then used to populate Table 7 and Table 8 below. These defined values provide the input settings needed for each experimental run for both the preliminary and experimental testing of the device. The preliminary testing matrix is shown in Table 7 below. 
Table 7 - Preliminary Test Matrix

\begin{tabular}{|c|c|c|c|c|}
\hline \multirow[b]{2}{*}{ Expt. No. } & \multicolumn{4}{|c|}{ Input Factors } \\
\hline & $\begin{array}{c}\text { A. Venturi Pressure } \\
(p s i g)\end{array}$ & $\begin{array}{l}\text { B. Fluidized Bed Flow } \\
\text { Rate (LPM) }\end{array}$ & $\begin{array}{l}\text { C. Vibrator Pressure } \\
\text { (psig) }\end{array}$ & $\begin{array}{l}\text { D. Vibrator Orientation } \\
\text { (degrees) }\end{array}$ \\
\hline 1 & 55 PSI & $1.5 \mathrm{LPM}$ & 55 PSI & $0^{\circ}$ \\
\hline 2 & $55 P S I$ & $1.5 \mathrm{LPM}$ & $55 P S I$ & $45^{\circ}$ \\
\hline 3 & $55 P S I$ & $1.5 \mathrm{LPM}$ & $55 P S I$ & $90^{\circ}$ \\
\hline 4 & $55 P S I$ & $1.5 \mathrm{LPM}$ & $35 P S I$ & $0^{\circ}$ \\
\hline 5 & 55 PSI & $1.5 \mathrm{LPM}$ & 55 PSI & $0^{\circ}$ \\
\hline 6 & $55 P S I$ & $1.5 \mathrm{LPM}$ & $75 P S I$ & $0^{\circ}$ \\
\hline 7 & $55 P S I$ & $1 L P M$ & $55 P S I$ & $0^{\circ}$ \\
\hline 8 & $55 P S I$ & $1.5 L P M$ & $55 P S I$ & $0^{\circ}$ \\
\hline 9 & $55 P S I$ & $2 L P M$ & $55 P S I$ & $0^{\circ}$ \\
\hline 10 & $35 P S I$ & $1.5 \mathrm{LPM}$ & $55 P S I$ & $0^{\circ}$ \\
\hline 11 & $55 P S I$ & $1.5 \mathrm{LPM}$ & $55 P S I$ & $0^{\circ}$ \\
\hline 12 & 75 PSI & $1.5 \mathrm{LPM}$ & $55 P S I$ & $0^{\circ}$ \\
\hline
\end{tabular}

The preliminary test data defined above provides the input settings needed to run each preliminary experiment which will be recorded for verification later in the analysis. For example, Experiment No. 1 will consist of Venturi Pressure (A) at 55 psig, Fluidized Bed Flowrate (B) at 1.5 LPM, Vibrator Pressure (C) at $55 \mathrm{psig}$ and Vibrator Orientation (D) at 0 degrees. Following this preliminary testing, Table 8 below represents the settings needed for each experimental run to complete the design of experiments test protocol. 
Table 8 - Experimental Test Matrix

\begin{tabular}{|c|c|c|c|c|}
\hline \multirow[b]{2}{*}{$\begin{array}{l}\text { Expt. } \\
\text { No. }\end{array}$} & \multicolumn{4}{|c|}{ Input Factors } \\
\hline & $\begin{array}{l}\text { A. Venturi Pressure } \\
\text { (psig) }\end{array}$ & $\begin{array}{l}\text { B. Fluidized Bed Flow } \\
\text { Rate (LPM) }\end{array}$ & $\begin{array}{l}\text { C. Vibrator Pressure } \\
\text { (psig) }\end{array}$ & $\begin{array}{l}\text { D. Vibrator Orientation } \\
\text { (degrees) }\end{array}$ \\
\hline 1 & $35 P S I$ & $1 L P M$ & 35 PSI & $0^{\circ}$ \\
\hline 2 & $35 P S I$ & $1.5 L P M$ & 55 PSI & $45^{\circ}$ \\
\hline 3 & $35 P S I$ & $2 L P M$ & 75 PSI & $90^{\circ}$ \\
\hline 4 & $55 P S I$ & $1 L P M$ & 55 PSI & $90^{\circ}$ \\
\hline 5 & $55 P S I$ & $1.5 L P M$ & 75 PSI & $0^{\circ}$ \\
\hline 6 & 55 PSI & $2 L P M$ & 35 PSI & $45^{\circ}$ \\
\hline 7 & 75 PSI & $1 L P M$ & 75 PSI & $45^{\circ}$ \\
\hline 8 & 75 PSI & $1.5 L P M$ & $35 P S I$ & $90^{\circ}$ \\
\hline 9 & 75 PSI & $2 L P M$ & 55 PSI & $0^{\circ}$ \\
\hline
\end{tabular}

As seen in Table 8 above each experimental run has defined settings based on the experimental design. This experimental test matrix will be used to conduct the designed experiments and provide the necessary data for the modeling analysis. 


\subsubsection{Sampling Procedure}

The output of the nanoparticle aerosol generation system is measured by sampling the particles within the sample chamber for each experimental run outlined in the test matrix. The output of the system includes the geometric mean particle size, particle concentration and standard deviation. This output, the real-time particle size distribution, will be measured and monitored with a Scanning Mobility Particle Sizer (SMPS, TSI Incorporated, Shoreview MN) for each experimental run in the test matrix [52]. The Scanning Mobility Particle Sizer (SMPS) has a scanning range from $10 \mathrm{~nm}$ to $700 \mathrm{~nm}$ across 64 channels. The data computed and reported by the SMPS will be used to complete the following tables.

Table 9 - Preliminary Test Matrix with Output Particle Characteristics

\begin{tabular}{|c|c|c|c|c|c|c|c|}
\hline \multirow[b]{2}{*}{ Expt. No. } & \multicolumn{4}{|c|}{ Input Factors } & \multicolumn{3}{|c|}{ Output Particle Characteristics } \\
\hline & $\begin{array}{l}\text { A. Venturi } \\
\text { Pressure } \\
\text { (psig) }\end{array}$ & $\begin{array}{l}\text { B. Fluidized } \\
\text { Bed Flow } \\
\text { Rate (LPM) }\end{array}$ & $\begin{array}{l}\text { C. Vibrator } \\
\text { Pressure } \\
\text { (psig) }\end{array}$ & $\begin{array}{l}\text { D. Vibrator } \\
\text { Orientation } \\
\text { (degrees) }\end{array}$ & $\begin{array}{c}\text { Particle } \\
\text { Concentration } \\
\left(1 \times 10^{3}\right)\left(\# / \mathrm{cm}^{3}\right)\end{array}$ & $\begin{array}{c}\text { Mean } \\
\text { Particle Size } \\
(\mathrm{nm})\end{array}$ & $\begin{array}{l}\text { Standard } \\
\text { Deviation }\end{array}$ \\
\hline 1 & $55 P S I$ & $1.5 \mathrm{LPM}$ & $55 P S I$ & $0^{\circ}$ & & & \\
\hline 2 & $55 P S I$ & $1.5 \mathrm{LPM}$ & $55 P S I$ & $45^{\circ}$ & & & \\
\hline 3 & $55 P S I$ & $1.5 \mathrm{LPM}$ & $55 P S I$ & $90^{\circ}$ & & & \\
\hline 4 & 55 PSI & $1.5 \mathrm{LPM}$ & 35 PSI & $0^{\circ}$ & & & \\
\hline 5 & $55 P S I$ & $1.5 \mathrm{LPM}$ & $55 P S I$ & $0^{\circ}$ & & & \\
\hline 6 & $55 P S I$ & $1.5 \mathrm{LPM}$ & $72 P S I$ & $0^{\circ}$ & & & \\
\hline 7 & $55 P S I$ & $1 L P M$ & $55 P S I$ & $0^{\circ}$ & & & \\
\hline 8 & $55 P S I$ & $1.5 \mathrm{LPM}$ & $55 P S I$ & $0^{\circ}$ & & & \\
\hline 9 & 55 PSI & $2 L P M$ & 55 PSI & $0^{\circ}$ & & & \\
\hline 10 & 35 PSI & $1.5 \mathrm{LPM}$ & 55 PSI & $0^{\circ}$ & & & \\
\hline 11 & $55 P S I$ & $1.5 \mathrm{LPM}$ & $55 P S I$ & $0^{\circ}$ & & & \\
\hline 12 & 75 PSI & $1.5 \mathrm{LPM}$ & 55 PSI & $0^{\circ}$ & & & \\
\hline
\end{tabular}

Table 9 above will later be used to represent the recorded measurements of the preliminary test matrix made by the SMPS for particle characteristics; concentration, geometric mean particle size and standard deviation. Table 10 below will present that same recorded data for the experimental test matrix. 
Table 10 - Experimental Test Matrix with Output Particle Characteristics

\begin{tabular}{|c|c|c|c|c|c|c|c|}
\hline \multirow[b]{2}{*}{$\begin{array}{c}\text { Expt. } \\
\text { No. }\end{array}$} & \multicolumn{4}{|c|}{ Input Factors } & \multicolumn{3}{|c|}{ Output Particle Characteristics } \\
\hline & $\begin{array}{l}\text { A. Venturi } \\
\text { Pressure } \\
\text { (psig) }\end{array}$ & $\begin{array}{l}\text { B. Fluidized } \\
\text { Bed Flow } \\
\text { Rate (LPM) }\end{array}$ & $\begin{array}{l}\text { C. Vibrator } \\
\text { Pressure } \\
\text { (psig) }\end{array}$ & $\begin{array}{l}\text { D. Vibrator } \\
\text { Orientation } \\
\text { (degrees) }\end{array}$ & $\begin{array}{c}\text { Particle } \\
\text { Concentration } \\
\left(1 \times 10^{3}\right)\left(\# / \mathrm{cm}^{3}\right)\end{array}$ & $\begin{array}{c}\text { Mean } \\
\text { Particle Size } \\
(\mathrm{nm})\end{array}$ & $\begin{array}{l}\text { Standard } \\
\text { Deviation }\end{array}$ \\
\hline 1 & 35 PSI & $1 L P M$ & 35 PSI & $0^{\circ}$ & & & \\
\hline 2 & $35 P S I$ & $1.5 L P M$ & $55 P S I$ & $45^{\circ}$ & & & \\
\hline 3 & 35 PSI & $2 L P M$ & 75 PSI & $90^{\circ}$ & & & \\
\hline 4 & 55 PSI & $1 L P M$ & 55 PSI & $90^{\circ}$ & & & \\
\hline 5 & 55 PSI & $1.5 L P M$ & 75 PSI & $0^{\circ}$ & & & \\
\hline 6 & 55 PSI & $2 L P M$ & 35 PSI & $45^{\circ}$ & & & \\
\hline 7 & 75 PSI & $1 L P M$ & 75 PSI & $45^{\circ}$ & & & \\
\hline 8 & 75 PSI & $1.5 L P M$ & 35 PSI & $90^{\circ}$ & & & \\
\hline 9 & 75 PSI & $2 L P M$ & $55 P S I$ & $0^{\circ}$ & & & \\
\hline
\end{tabular}

The experiments to be run for the experimental test matrix, as outlined in Table 10, must be conducted in a randomized order. This helps to eliminate influence or residual from one experiment to another. For this reason the experiments were conducted in the following order: 1,9,5,2,4,8,3,7,6. The data collected during the experimental testing and sampling procedures will be stored using an Excel file. This will allow efficient transfer of data to a programming language such as Matlab to develop the predictive model. To provide an adequate amount of data, each run was sampled 8-10 times to confirm that the aerosol reaches stability between input manipulations. It was calculated using the flowrate of the vacuum and sampling chamber volume that the chamber should have full air exchange and reach stability between experimental runs within a few minutes. 


\subsubsection{Data Reduction}

For each run the "raw data" was collected and compiled. The recordings or observations of each run are then used to calculate the summary statistic, $\eta_{i}$, for each output of interest for each experimental run $i$. The summary statistic is defined as

$$
\eta_{i}=\frac{1}{n} \sum_{i=1}^{n} y_{i}
$$

where $y$ is each individual recorded observation and $n$ is the number of observatations for each run. Therefore, $\eta_{i}$ represents the average of the 8-10 recorded observations in experiment $i$. The oberservations $\eta_{i}$ are used to populate the tables above. This data will be refered to as the "reduced data" and will be used for further data analysis.

\subsubsection{Third Party Data}

Third party data will be used to compare and analyze collected data as well as to support the development of the predictive model. Well-established third party data will help to reduce redundant experiments for well characterized applications and confirm accuracy of observations made. This data may be found via patent publications, published work in these areas and work with devices of similar nature.

\subsubsection{Data Storage}

The raw data is stored within the project database established for this project. This database is housed on an internal server within the research facility. This database will provide for easy access for data retrieval and analysis. The database consists of a backup system to regularly backup this information on a protected network. 


\subsection{Data Analysis}

After conducting the matrix experiments, the reduced data was analyzed to determine the effects of the various parameters. Interpretation of the experimental data using graphical analysis and multiple regression analysis was performed.

\subsubsection{Estimation of Factor Effects}

An important first step to analyzing the reduced data is to perform an estimation of the factor effects. This will be used to show the main effects of the input parameters on the concentration, mean particle size and size distribution. This further provides valuable insights to the dominant factors and amount of influence each input factor has on the output which will be quantified later in this chapter with an analysis of variance (ANOVA).

First, the overall mean value of the concentration, geometric mean particle size and standard deviation for the experimental region defined by the input levels and represented in the reduced data is given by

$$
\mu=\frac{1}{9} \sum_{i=1}^{9} \eta_{i}
$$

By examining columns 1, 2, 3 and 4 of the orthogonal array in Table 8 it can be seen that all three levels of every factor are equally represented in the nine experimental runs ( $L_{9}$ orthogonal array). Therefore, $\mu$ is a balanced overall mean over the entire experimental region.

The factor effects at each level can be estimated by averaging the three values that are represented by the settings of $a_{1}$. Therefore,

$$
\mu_{a 1}=\frac{1}{3}\left(\eta_{1}+\eta_{2}+\eta_{3}\right)
$$

Since $a_{1}$ is represented in experiments 1,2 and $3 ; \mu_{a 1}$ is the average of these three terms. This computes the effect of the factor level which is defined as the deviation it causes from the overall mean previously calculated. For example, using this same method the following would be used to calculate $\mu_{c 3}$. It can be seen that $c_{3}$ was used in runs 3,5 , and 7 therefore the equation becomes;

$$
\mu_{c 3}=\frac{1}{3}\left(\eta_{3}+\eta_{5}+\eta_{7}\right)
$$

Since $\mu_{c 3}$ is represented in runs 3,5 and 7 . Using this approach the factor effects for each factor and level can be found to generate the factor effect plots, which is also supported by the balancing property. This method of estimating the factor effects is sometimes referred to as analysis of means (ANOM).

To make this approach of computing the factor effects more appropriate for a programming language such as Matlab, the data and factor effects can be represented in matrix form as seen below. 


$$
\begin{aligned}
& {\left[\begin{array}{l}
\eta_{1} \\
\eta_{2} \\
\eta_{3} \\
\eta_{4} \\
\eta_{5} \\
\eta_{6} \\
\eta_{7} \\
\eta_{8} \\
\eta_{9}
\end{array}\right]=\hat{\mu}\left[\begin{array}{l}
1 \\
1 \\
1 \\
1 \\
1 \\
1 \\
1 \\
1 \\
1
\end{array}\right]+\hat{a}_{1}\left[\begin{array}{l}
1 \\
1 \\
1 \\
0 \\
0 \\
0 \\
0 \\
0 \\
0
\end{array}\right]+\hat{a}_{2}\left[\begin{array}{l}
0 \\
0 \\
0 \\
1 \\
1 \\
1 \\
0 \\
0 \\
0
\end{array}\right]+\hat{a}_{3}\left[\begin{array}{l}
0 \\
0 \\
0 \\
0 \\
0 \\
0 \\
1 \\
1 \\
1
\end{array}\right]+\hat{b}_{1}\left[\begin{array}{l}
1 \\
0 \\
0 \\
1 \\
0 \\
0 \\
1 \\
0 \\
0
\end{array}\right]+\hat{b}_{2}\left[\begin{array}{l}
0 \\
1 \\
0 \\
0 \\
1 \\
0 \\
0 \\
1 \\
0
\end{array}\right]+\hat{b}_{3}\left[\begin{array}{l}
0 \\
0 \\
1 \\
0 \\
0 \\
1 \\
0 \\
0 \\
1
\end{array}\right]+\hat{c}_{1}\left[\begin{array}{l}
1 \\
0 \\
0 \\
1 \\
0 \\
1 \\
0
\end{array}\right]+\hat{c}_{2}\left[\begin{array}{l}
0 \\
1 \\
0 \\
0 \\
0 \\
0 \\
1
\end{array}\right]+\hat{c}_{3}\left[\begin{array}{l}
0 \\
0 \\
1 \\
0 \\
0 \\
1 \\
0 \\
0
\end{array}\right]} \\
& +\hat{d}_{1}\left[\begin{array}{l}
1 \\
0 \\
0 \\
0 \\
1 \\
0 \\
0 \\
0 \\
1
\end{array}\right]+\hat{d}_{2}\left[\begin{array}{l}
0 \\
1 \\
0 \\
0 \\
0 \\
1 \\
1 \\
0 \\
0
\end{array}\right]+\hat{d}_{3}\left[\begin{array}{l}
0 \\
0 \\
1 \\
1 \\
0 \\
0 \\
0 \\
1 \\
0
\end{array}\right]
\end{aligned}
$$

The matrix above represents the summary statistics, the overall mean and deviation from the mean for each factor and level for each experimental run. In order to allow the inverse to be taken later in the analysis this matrix must be simplified. Since $\hat{a}_{1}, \hat{a}_{2}, \hat{a}_{3}$ columns, for example, contain the "average vector" $\hat{\mu}$ requires

$$
\hat{a}_{1}+\hat{a}_{2}+\hat{a}_{3}=0
$$

Therefore,

$$
\begin{aligned}
& \hat{a}_{2}=-\hat{a}_{1}-\hat{a}_{3} \\
& \hat{b}_{2}=-\hat{b}_{1}-\hat{b}_{3} \\
& \hat{c}_{2}=-\hat{c}_{1}-\hat{c}_{3} \\
& \hat{d}_{2}=-\hat{d}_{1}-\hat{d}_{3}
\end{aligned}
$$

This allows the matrix to be written in a simplified form as shown below. This becomes the main effects model for this system.

$$
\left[\begin{array}{l}
\eta_{1} \\
\eta_{2} \\
\eta_{3} \\
\eta_{4} \\
\eta_{5} \\
\eta_{6} \\
\eta_{7} \\
\eta_{8} \\
\eta_{9}
\end{array}\right]=\hat{\mu}\left[\begin{array}{l}
1 \\
1 \\
1 \\
1 \\
1 \\
1 \\
1 \\
1 \\
1
\end{array}\right]+\hat{a}_{1}\left[\begin{array}{c}
1 \\
1 \\
1 \\
-1 \\
-1 \\
-1 \\
0 \\
0 \\
0
\end{array}\right]+\hat{a}_{3}\left[\begin{array}{c}
0 \\
0 \\
0 \\
-1 \\
-1 \\
-1 \\
1 \\
1 \\
1
\end{array}\right]+\hat{b}_{1}\left[\begin{array}{c}
1 \\
-1 \\
0 \\
1 \\
-1 \\
0 \\
1 \\
-1 \\
0
\end{array}\right]+\hat{b}_{3}\left[\begin{array}{c}
0 \\
-1 \\
1 \\
0 \\
1 \\
0 \\
-1 \\
1
\end{array}\right]+\hat{c}_{1}\left[\begin{array}{c}
1 \\
-1 \\
0 \\
0 \\
1 \\
0 \\
1 \\
-1
\end{array}\right]+\hat{c}_{3}\left[\begin{array}{c}
0 \\
-1 \\
-1 \\
1 \\
0 \\
1 \\
0 \\
-1
\end{array}\right]+\hat{d}_{1}\left[\begin{array}{c}
1 \\
-1 \\
0 \\
0 \\
-1 \\
-1 \\
0 \\
1
\end{array}\right]+\hat{d}_{3}\left[\begin{array}{c}
0 \\
-1 \\
1 \\
1 \\
0 \\
-1 \\
-1 \\
1 \\
0
\end{array}\right]
$$

Where $\hat{\beta}$ is defined as 


$$
\hat{\beta}=\left[\begin{array}{l}
\hat{\mu} \\
\hat{a}_{1} \\
\hat{a}_{3} \\
\hat{b}_{1} \\
\hat{b}_{3} \\
\hat{c}_{1} \\
\hat{c}_{3} \\
\hat{d}_{1} \\
\hat{d}_{3}
\end{array}\right]
$$

The estimated vector $\hat{\beta}$ can be found by

$$
\hat{\beta}=\left(X^{T} X\right)^{-1} X^{T} \eta
$$

Where, the matrix $X$ and vector $\eta$ are:

$$
X=\left[\begin{array}{ccccccccc}
1 & 1 & 0 & 1 & 0 & 1 & 0 & 1 & 0 \\
1 & 1 & 0 & -1 & -1 & -1 & -1 & -1 & -1 \\
1 & 1 & 0 & 0 & 1 & 0 & 1 & 0 & 1 \\
1 & -1 & -1 & 1 & 0 & -1 & -1 & 0 & 1 \\
1 & -1 & -1 & -1 & -1 & 0 & 1 & 1 & 0 \\
1 & -1 & -1 & 0 & 1 & 1 & 0 & -1 & -1 \\
1 & 0 & 1 & 1 & 0 & 0 & 1 & -1 & -1 \\
1 & 0 & 1 & -1 & -1 & 1 & 0 & 0 & 1 \\
1 & 0 & 1 & 0 & 1 & -1 & -1 & 1 & 0
\end{array}\right] \quad \eta=\left[\begin{array}{l}
\eta_{1} \\
\eta_{2} \\
\eta_{3} \\
\eta_{4} \\
\eta_{5} \\
\eta_{6} \\
\eta_{7} \\
\eta_{8} \\
\eta_{9}
\end{array}\right]
$$

A Matlab script (See Appendix B) is used to calculate the $\hat{\beta}$ vector. $\hat{\beta}$ is then used to compute vector $\hat{\gamma}$ which provides the data needed to produce the factor effect plots. $\hat{\gamma}$ is defined as:

$$
\hat{\gamma}=\left[\hat{\mu}+\hat{a}_{1}, \hat{\mu}+\hat{a}_{2}, \hat{\mu}+\hat{a}_{3}, \hat{\mu}+\hat{b}_{1}, \hat{\mu}+\hat{b}_{2}, \hat{\mu}+\hat{b}_{3}, \hat{\mu}+\hat{c}_{1}, \hat{\mu}+\hat{c}_{2}, \hat{\mu}+\hat{c}_{3}, \hat{\mu}+\hat{d}_{1}, \hat{\mu}+\hat{d}_{2}, \hat{\mu}+\hat{d}_{3}\right]
$$

Where $\hat{\gamma}$ is rewritten as:

$$
\begin{gathered}
\hat{\gamma}=\left[\hat{\mu}+\hat{a}_{1}, \hat{\mu}-\hat{a}_{1}-\hat{a}_{3}, \hat{\mu}+\hat{a}_{3}, \hat{\mu}+\hat{b}_{1}, \hat{\mu}-\hat{b}_{1}-\hat{b}_{3}, \hat{\mu}+\hat{b}_{3}, \hat{\mu}+\hat{c}_{1}, \hat{\mu}-\hat{c}_{1}-\hat{c}_{3}, \hat{\mu}+\hat{c}_{3},\right. \\
\left.\hat{\mu}+\hat{d}_{1}, \hat{\mu}-\hat{d}_{1}-\hat{d}_{3}, \hat{\mu}+\hat{d}_{3}\right]
\end{gathered}
$$

And solving as follows,

$$
\hat{\gamma}=\hat{\beta} * Y
$$

Where,

$$
Y=\left[\begin{array}{cccccccccccc}
1 & 1 & 1 & 1 & 1 & 1 & 1 & 1 & 1 & 1 & 1 & 1 \\
1 & -1 & 0 & 0 & 0 & 0 & 0 & 0 & 0 & 0 & 0 & 0 \\
0 & -1 & 1 & 0 & 0 & 0 & 0 & 0 & 0 & 0 & 0 & 0 \\
0 & 0 & 0 & 1 & -1 & 0 & 0 & 0 & 0 & 0 & 0 & 0 \\
0 & 0 & 0 & 0 & -1 & 1 & 0 & 0 & 0 & 0 & 0 & 0 \\
0 & 0 & 0 & 0 & 0 & 0 & 1 & -1 & 0 & 0 & 0 & 0 \\
0 & 0 & 0 & 0 & 0 & 0 & 0 & -1 & 1 & 0 & 0 & 0 \\
0 & 0 & 0 & 0 & 0 & 0 & 0 & 0 & 0 & 1 & -1 & 0 \\
0 & 0 & 0 & 0 & 0 & 0 & 0 & 0 & 0 & 0 & -1 & 1
\end{array}\right]
$$


This generates the $\hat{\gamma}$ vector needed to plot the main effects.

\subsubsection{Optimal Factor Levels}

One of the goals of the design of experiments approach is to define the optimal input parameters to reach a desired output given the experimental boundaries set by the test region. The optimal settings for the experimental test region can be determined by evaluating the main effects plots as seen in Section 6.2.2. This information is important for the development of the predictive model to provide optimal settings needed to generate the desired aerosol characteristics.

\subsubsection{Analysis of Variance}

An Analysis of Variance Table (ANOVA Table) will be used to rank the influence of each input factor analyzed in the main effects model. Different inputs affect the output characteristics to different degrees. The relative magnitude of the factor effects can be interpreted from the main effects plots but a better procedure to quantify the relative effect of the different factors can be obtained by the analysis of variance. This can be seen in the following table.

Table 11 - ANOVA Table

\begin{tabular}{|c|c|c|c|c|}
\hline Factor/Source & $\begin{array}{c}\text { Degrees of } \\
\text { Freedom }\end{array}$ & $\begin{array}{c}\text { Sum of } \\
\text { Squares }\end{array}$ & $\begin{array}{c}\text { Mean } \\
\text { Square }\end{array}$ & Influence \\
\hline A. Venturi Pressure & $\mathrm{P}_{1}$ & $\mathrm{~S}_{\mathrm{A}}$ & $\mathrm{S}_{\mathrm{A}} / \mathrm{P}_{1}$ & $\mathrm{~S}_{\mathrm{A}} / \mathrm{S}_{\text {Total }}$ \\
B. Fluidized Bed Flowrate & $\mathrm{P}_{2}$ & $\mathrm{~S}_{\mathrm{B}}$ & $\mathrm{S}_{\mathrm{B}} / \mathrm{P}_{2}$ & $\mathrm{~S}_{\mathrm{B}} / \mathrm{S}_{\text {Total }}$ \\
C. Vibrator Pressure & $\mathrm{P}_{3}$ & $\mathrm{~S}_{C}$ & $\mathrm{~S}_{\mathrm{C}} / \mathrm{P}_{3}$ & $\mathrm{~S}_{\mathrm{C}} / \mathrm{S}_{\text {Total }}$ \\
D. Vibrator Angle & $\mathrm{P}_{4}$ & $\mathrm{~S}_{\mathrm{D}}$ & $\mathrm{S}_{\mathrm{D}} / \mathrm{P}_{4}$ & $\mathrm{~S}_{\mathrm{D}} / \mathrm{S}_{\text {Total }}$ \\
\hline Totals & $\mathrm{P}_{\text {Total }}$ & $\mathrm{S}_{\text {Total }}$ & $\mathrm{S}_{\mathrm{P}} \mathrm{P}_{\text {Total }}$ & \\
\hline
\end{tabular}

The degrees of freedom are calculated by referring to the previous model set-up. It was shown that

$$
a_{2}=-a_{1}-a_{3}
$$

Therefore, factor $\mathrm{A}$ has two degrees of freedom or $\mathrm{P}_{1}=2$.

The sum of squared values of $\eta$ is called the grand total sum of squares. Using the concentration as an example:

$$
\begin{aligned}
& \text { Grand total sum of squares }=\sum_{i=1}^{9} \eta_{i}^{2} \\
& \begin{array}{c}
=(129)^{2}+(497)^{2}+\cdots+(1450)^{2} \\
=7,429,488.2
\end{array}
\end{aligned}
$$

The grand total sum of squares can be decomposed into two parts - Sum of Squares of the mean and total sum of squares which are defined as follows: 


$$
\begin{aligned}
& \text { Sum of Squares of the Mean }=(\text { number of exp. }) *(\mu)^{2} \\
& \qquad=9(764)^{2} \\
& =5,253,264
\end{aligned}
$$

total sum of squares $=($ grand total sum of squares $)-($ sum of squares due to mean $)$

The sum of squares due to factor $A$ is equal to the total squared deviation from the overall mean for factor A. There are three experiments each at levels $A_{1}, A_{2}$, and $A_{3}$. Consequently, the sum of squares due to factor $A$ is:

$$
\begin{gathered}
=3\left(a_{1}-\mu\right)^{2}+3\left(a_{2}-\mu\right)^{2}+3\left(a_{3}-\mu\right)^{2} \\
=3(129-764)^{2}+3(497-764)^{2}+3(1408-764)^{2} \\
=33,813
\end{gathered}
$$

Following this same procedure the sum of squares due to factors $B, C$, and $D$ can be found. These values are tabulated in the Table 14 in the results.

If an error or variance term is included in the model it can also be calculated. The sum of squares due to error is the sum of the squares of the error terms. Thus,

$$
\text { Sum of squares due to error }=\sum_{i=1}^{9} e_{i}^{2}
$$

In the present case the total number of model parameters $\left(\mu, a_{1}, a_{2} \ldots\right)$ is 13 and the number of constraints is 4. The number of model parameters minus the number of constraints is equal to the number of experiments ran. Therefore, the error term will be zero for each experiment. The sum of squares due to error will also be zero. Note that this was due to the minimal amount of experiments needed to conduct the orthogonal arrays. If time and energy was abundant more experimental runs (i.e. 18 runs) could be used to compute the error or variance terms with the analysis of variance. This would be useful for creating confidence intervals or error bars in the analysis. 


\subsubsection{Interaction Among Input Factors}

Understanding the interactions of the dominant input factors uncovered with the analysis of variance is also an important aspect to this analysis. Analyzing the interactions among the dominant input factors can be used to determine if they have synergistic interactions, antisynergistic interactions or have no interaction on one other. Based on the ANOVA analysis the interactions of interest, using concentration as an example, will be between factors $B$ and $C$ since they have the greatest influence on the output.

The interaction terms are found by creating a matrix that include the dominant factors along with each combination of the interactions from those factors. For example, the interaction model for factors $B$ and $\mathrm{C}$ on concentration are shown below.

$$
\begin{gathered}
{\left[\begin{array}{l}
\eta_{1} \\
\eta_{2} \\
\eta_{3} \\
\eta_{4} \\
\eta_{5} \\
\eta_{6} \\
\eta_{7} \\
\eta_{8} \\
\eta_{9}
\end{array}\right]=\hat{\mu}\left[\begin{array}{l}
1 \\
1 \\
1 \\
1 \\
1 \\
1 \\
1 \\
1 \\
1
\end{array}\right]+\hat{b}_{1}\left[\begin{array}{c}
1 \\
-1 \\
0 \\
1 \\
-1 \\
0 \\
1 \\
-1 \\
0
\end{array}\right]+\hat{b}_{3}\left[\begin{array}{c}
0 \\
-1 \\
1 \\
0 \\
-1 \\
1 \\
0 \\
-1 \\
1
\end{array}\right]+\hat{c}_{1}\left[\begin{array}{c}
1 \\
-1 \\
0 \\
-1 \\
0 \\
1 \\
0 \\
1 \\
-1
\end{array}\right]+\hat{c}_{3}\left[\begin{array}{c}
0 \\
-1 \\
1 \\
-1 \\
1 \\
0 \\
1 \\
0 \\
-1
\end{array}\right]} \\
+\left[\begin{array}{c}
1 \\
1 \\
0 \\
-1 \\
0 \\
0 \\
0 \\
-1 \\
0
\end{array}\right]+\hat{b}_{1} \hat{c}_{3}\left[\begin{array}{c}
0 \\
1 \\
0 \\
-1 \\
-1 \\
0 \\
1 \\
0 \\
0
\end{array}\right]+\hat{b}_{3} \hat{c}_{1}\left[\begin{array}{l}
0 \\
1 \\
0 \\
0 \\
0 \\
1 \\
0 \\
-1 \\
-1
\end{array}\right]+\hat{b}_{3} \hat{c}_{3}\left[\begin{array}{c}
0 \\
1 \\
1 \\
0 \\
-1 \\
0 \\
0 \\
0 \\
-1
\end{array}\right]
\end{gathered}
$$

Where $\hat{\beta}$ is defined as

$$
\hat{\beta}=\left[\begin{array}{c}
\hat{\mu} \\
\hat{b}_{1} \\
\hat{b}_{3} \\
\hat{c}_{1} \\
\hat{c}_{3} \\
\hat{b}_{1} \hat{c}_{1} \\
\hat{b}_{1} \hat{c}_{3} \\
\hat{b}_{3} \hat{c}_{1} \\
\hat{b}_{3} \hat{c}_{3}
\end{array}\right]
$$

The estimated vector $\hat{\beta}$ can be found using the same procedure as the main effects model

$$
\hat{\beta}=\left(X^{T} X\right)^{-1} X^{T} \eta
$$

Where, 


$$
X=\left[\begin{array}{ccccccccc}
1 & 1 & 0 & 1 & 0 & 1 & 0 & 0 & 0 \\
1 & -1 & -1 & -1 & -1 & 1 & 1 & 1 & 1 \\
1 & 0 & 1 & 0 & 1 & 0 & 0 & 0 & 1 \\
1 & 1 & 0 & -1 & -1 & -1 & -1 & 0 & 0 \\
1 & -1 & -1 & 0 & 1 & 0 & -1 & 0 & -1 \\
1 & 0 & 1 & 1 & 0 & 0 & 0 & 1 & 0 \\
1 & 1 & 0 & 0 & 1 & 0 & 1 & 0 & 0 \\
1 & -1 & -1 & 1 & 0 & -1 & 0 & -1 & 0 \\
1 & 0 & 1 & -1 & -1 & 0 & 0 & -1 & -1
\end{array}\right] \quad \eta=\left[\begin{array}{l}
\eta_{1} \\
\eta_{2} \\
\eta_{3} \\
\eta_{4} \\
\eta_{5} \\
\eta_{6} \\
\eta_{7} \\
\eta_{8} \\
\eta_{9}
\end{array}\right]
$$

The $\hat{\beta}$ values are then used to generate the values $B_{1} C_{1}, B_{1} C_{2}, B_{1} C_{3}$, etc. required to plot the interactions. For example, $B_{1} C_{1}, B_{1} C_{2}$ and $B_{2} C_{2}$, which are points on the interactions plot, are computed as follows.

$$
\begin{aligned}
& B_{1} C_{1}=\hat{\mu}+\widehat{b_{1}}+\widehat{c_{1}}+\widehat{b_{1} c_{1}} \\
& B_{1} C_{2}=\hat{\mu}+\widehat{b_{1}}+\widehat{c_{2}}+\widehat{b_{1} c_{2}} \\
& B_{2} C_{2}=\hat{\mu}+\widehat{b_{2}}+\widehat{c_{2}}+\widehat{b_{2} c_{2}}
\end{aligned}
$$

Where the interaction terms $b_{1} c_{2}$ and $b_{2} c_{2}$, for example, can be found by

$$
\begin{gathered}
b_{1} c_{2}=b_{1}\left(-c_{1}-c_{3}\right)=-b_{1} c_{1}-b_{1} c_{3} \\
b_{2} c_{2}=\left(-b_{1}-b_{3}\right)\left(-c_{1}-c_{3}\right)=-b_{1} c_{1}-b_{1} c_{3}
\end{gathered}
$$

Therefore, the above equations can be rewritten as

$$
\begin{gathered}
B_{1} c_{2}=\widehat{\mu}+\widehat{b_{1}}-\widehat{c_{1}}-\widehat{c_{3}}-\widehat{b_{1} c_{1}}-\widehat{b_{1} c_{3}} \\
B_{2} C_{2}=\hat{\mu}-\widehat{b_{1}}-\widehat{b_{3}}-\widehat{c_{1}}-\widehat{c_{3}}+\widehat{b_{1} c_{1}}+\widehat{b_{1} c_{3}}+\widehat{b_{3} c_{1}}+\widehat{b_{3} c_{3}}
\end{gathered}
$$

Using this approach all of the interaction terms needed to generate the interaction plots as seen in Section 6.2.4 can be found. 


\subsection{Predictive Model}

By using the main effects model previously constructed it is possible to predict the output based on selected input settings. To increase prediction accuracy the predictive model only includes the two highest influencers. Note that since the sum of squares of factors $A$ and $D$ are small, using the concentration analysis as an example, they will not be included in predicting the values. These factors can be ignored because if contributions from all factors are included, it will be seen that the predicted improvements of $\hat{\eta}$ exceed the actual realized improvements; that is, the prediction would be biased towards the higher end. By ignoring the contributions from factors with small sum of squares, this bias can be reduced. This is a rule of thumb outlined by Taguchi et al. [53]. The interaction terms from the interaction model previously constructed that have a significant influence can also be included in the predictive model to improve predictions. Although, the predictive model of interest will not include the interaction terms due to the small influence they have on the model. This, along with a variance and error model, can be added to the predictive model if desired with further experimentation and testing to improve prediction accuracy.

\subsubsection{Optimal Setting}

As a starting point for the predictive model it is desired to develop a prediction for the optimal settings. The optimal settings for the highest concentration, for example, have previously been determined based on the main effects plots and ANOVA analysis to be $A_{3}, B_{3}, C_{3}, D_{1}$. To predict an estimate of the concentration value $\hat{\eta}$ at these settings a predictive model was developed based on the main effects model. This value $\hat{\eta}$ at input settings $A_{3}, B_{3}, C_{3}$, $D_{1}$ is represented as $\hat{\eta}_{A_{3} B_{3} C_{3} D_{1}}$ which is composed of the sum of the overall mean $\hat{\mu}$ and the effect of the factor levels at $\hat{a}_{3}, \hat{b}_{3}, \hat{c}_{3}, \hat{d}_{1}$. This is shown in the following equation.

$$
\hat{\eta}_{A_{3} B_{3} C_{3} D_{1}}=\hat{\mu}+\hat{a}_{3}+\hat{b}_{3}+\hat{c}_{3}+\hat{d}_{1}
$$

This can be written in vector form as

$$
\hat{\eta}_{A_{3} B_{3} C_{3} D_{1}}=\left[\begin{array}{lllllllll}
1 & 0 & 1 & 0 & 1 & 0 & 1 & 1 & 0
\end{array}\right]\left[\begin{array}{c}
\mu \\
a_{1} \\
a_{3} \\
b_{1} \\
b_{3} \\
c_{1} \\
c_{3} \\
d_{1} \\
d_{3}
\end{array}\right]
$$

Taking the $\hat{\beta}$ vector computed in the main effects analysis and multiplying it by a vector that represents $A_{3}, B_{3}, C_{3}, D_{1}$ results in a prediction of the concentration at those settings. 
Likewise, the same procedure can be used to estimate the value $\hat{\eta}$ for the mean particle size at the optimal settings $A_{3}, B_{1}, C_{1}, D_{2}$ as follows.

$$
\hat{\eta}_{A_{3} B_{1} C_{1} D_{2}}=\hat{\mu}+\hat{a}_{3}+\hat{b}_{1}+\hat{c}_{1}+\hat{d}_{2}
$$

In vector form,

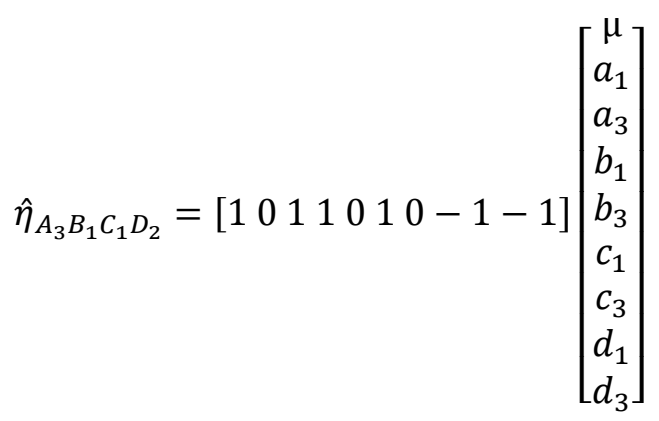

Where $\hat{\eta}_{A_{3} B_{1} C_{1} D_{2}}$ is an estimation of the mean particle size at $A_{3}, B_{1}, C_{1}, D_{2}$.

\subsection{Model Validation}

After developing the predictive model based on the information gathered from the factor effects, optimal settings, degree of input influence and interactions among factors; the model must be tested and validated. This is done by comparing predictions made by the developed model with experiments not conducted in the experimental test matrix from which the model was constructed. The predictions used to validate this model will correspond to runs 2, 6, 7, 9, 10 and 12 conducted in the preliminary testing for comparison. These runs were chosen to compare the predictive model because they represent the high, mid and low settings of each parameter conducted in the preliminary testing matrix. This will be used to validate the prediction model and calculate the error for each prediction.

\subsubsection{Prediction Tests}

The prediction tests are conducted to test the accuracy of the predictive model estimations. These tests include:

\subsubsection{Prediction Test Midpoint (Preliminary Run 2)}

A prediction test at the midpoint settings $A_{2}, B_{2}, C_{2}, D_{2}$ is represented as follows.

$$
\hat{\eta}_{A_{2} B_{2} C_{2} D_{2}}=\hat{\mu}+\hat{a}_{2}+\hat{b}_{2}+\hat{c}_{2}+\hat{d}_{2}
$$




$$
\hat{\eta}_{A_{2} B_{2} C_{2} D_{2}}=[1-1-1-1-1-1-1-1-1]\left[\begin{array}{c}
\mu \\
a_{1} \\
a_{3} \\
b_{1} \\
b_{3} \\
c_{1} \\
c_{3} \\
d_{1} \\
d_{3}
\end{array}\right]
$$

\subsubsection{Prediction Test 1(Preliminary Run 6)}

A prediction test corresponding to preliminary run 6 which represents settings $A_{2}, B_{2}, C_{3}, D_{1}$ is represented as follows.

$$
\begin{aligned}
& \hat{\eta}_{A_{2} B_{2} C_{3} D_{1}}=\hat{\mu}+\hat{a}_{2}+\hat{b}_{2}+\hat{c}_{3}+\hat{d}_{1} \\
& \hat{\eta}_{A_{2} B_{2} C_{3} D_{1}}=\left[\begin{array}{lll}
1-1-1-1-1-1-1 & 1 & 0
\end{array}\right]\left[\begin{array}{c}
\mu \\
a_{1} \\
a_{3} \\
b_{1} \\
b_{3} \\
c_{1} \\
c_{3} \\
d_{1} \\
d_{3}
\end{array}\right]
\end{aligned}
$$

\subsubsection{Prediction Test 2 (Preliminary Run 7)}

A prediction test corresponding to preliminary run 7 which represents settings $A_{2}, B_{1}, C_{2}, D_{1}$ is represented as follows.

$$
\begin{aligned}
& \hat{\eta}_{A_{2} B_{1} C_{2} D_{1}}=\hat{\mu}+\hat{a}_{2}+\hat{b}_{1}+\hat{c}_{2}+\hat{d}_{1} \\
& \hat{\eta}_{A_{2} B_{1} C_{2} D_{1}}=\left[\begin{array}{lllll}
1-1-1 & 1 & 0-1-1 & 1 & 0
\end{array}\right]\left[\begin{array}{l}
\mu \\
a_{1} \\
a_{3} \\
b_{1} \\
b_{3} \\
c_{1} \\
c_{3} \\
d_{1} \\
d_{3}
\end{array}\right]
\end{aligned}
$$

\subsubsection{Prediction Test 3 (Preliminary Run 9)}

A prediction test corresponding to preliminary run 9 which represents settings $A_{2}, B_{3}, C_{2}, D_{1}$ is represented as follows. 


$$
\begin{aligned}
& \hat{\eta}_{A_{2} B_{3} C_{2} D_{1}}=\hat{\mu}+\hat{a}_{2}+\hat{b}_{3}+\hat{c}_{2}+\hat{d}_{1} \\
& \hat{\eta}_{A_{2} B_{3} C_{2} D_{1}}=\left[\begin{array}{lllll}
1-1-1 & 0 & 1-1-1 & 1 & 0
\end{array}\right]\left[\begin{array}{c}
\mu \\
a_{1} \\
a_{3} \\
b_{1} \\
b_{3} \\
c_{1} \\
c_{3} \\
d_{1} \\
d_{3}
\end{array}\right]
\end{aligned}
$$

\subsubsection{Prediction Test 4 (Preliminary Run 10)}

A prediction test corresponding to preliminary run 10 which represents settings $A_{1}, B_{2}, C_{2}, D_{1}$ is represented as follows.

$$
\begin{aligned}
& \hat{\eta}_{A_{1} B_{2} C_{2} D_{1}}=\hat{\mu}+\hat{a}_{1}+\hat{b}_{2}+\hat{c}_{2}+\hat{d}_{1}
\end{aligned}
$$

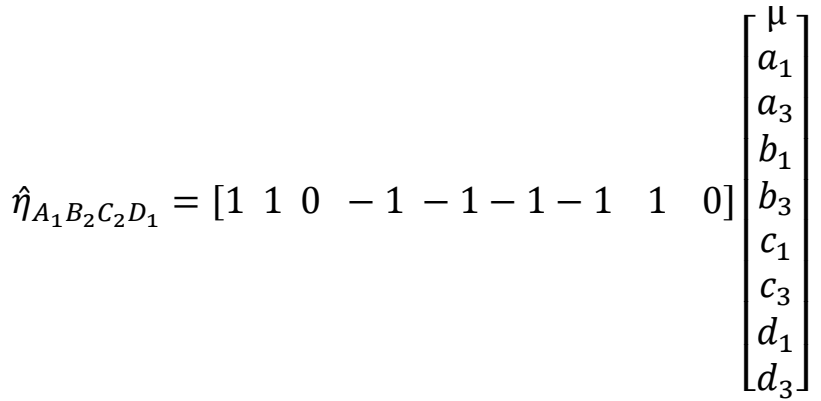

\subsubsection{Prediction Test 5 (Preliminary Run 12)}

Lastly, the prediction test corresponding to preliminary run 12 which represents settings $A_{3}, B_{2}, C_{2}, D_{1}$ is represented as follows.

$$
\begin{aligned}
& \hat{\eta}_{A_{3} B_{2} C_{2} D_{1}}=\hat{\mu}+\hat{a}_{3}+\hat{b}_{2}+\hat{c}_{2}+\hat{d}_{1} \\
& \hat{\eta}_{A_{3} B_{2} C_{2} D_{1}}=\left[\begin{array}{lllll}
1 & 0 & 1-1-1-1-1 & 1 & 0
\end{array}\right]\left[\begin{array}{l}
\mu \\
a_{1} \\
a_{3} \\
b_{1} \\
b_{3} \\
c_{1} \\
c_{3} \\
d_{1} \\
d_{3}
\end{array}\right]
\end{aligned}
$$




\subsubsection{Prediction Error}

Once the predictions are made using the predictive model and prediction tests outlined above it is required to compare the estimations to the experimental results in the preliminary test matrix. There the prediction error of the model can be determined. The prediction error is computed as follows:

$$
\% \text { Error }=\left|\frac{\text { observed-Predicted }}{\text { observed }}\right| *(100)
$$

The prediction errors for each prediction test are tabulated in Section 6.4. 


\section{CH. 6 RESULTS}

\subsection{Experimental Results}

The sampling procedure provides the raw data for the observations of each experimental run conducted as outlined in the experiment procedure. An example of the raw data collected from the SMPS is shown below.

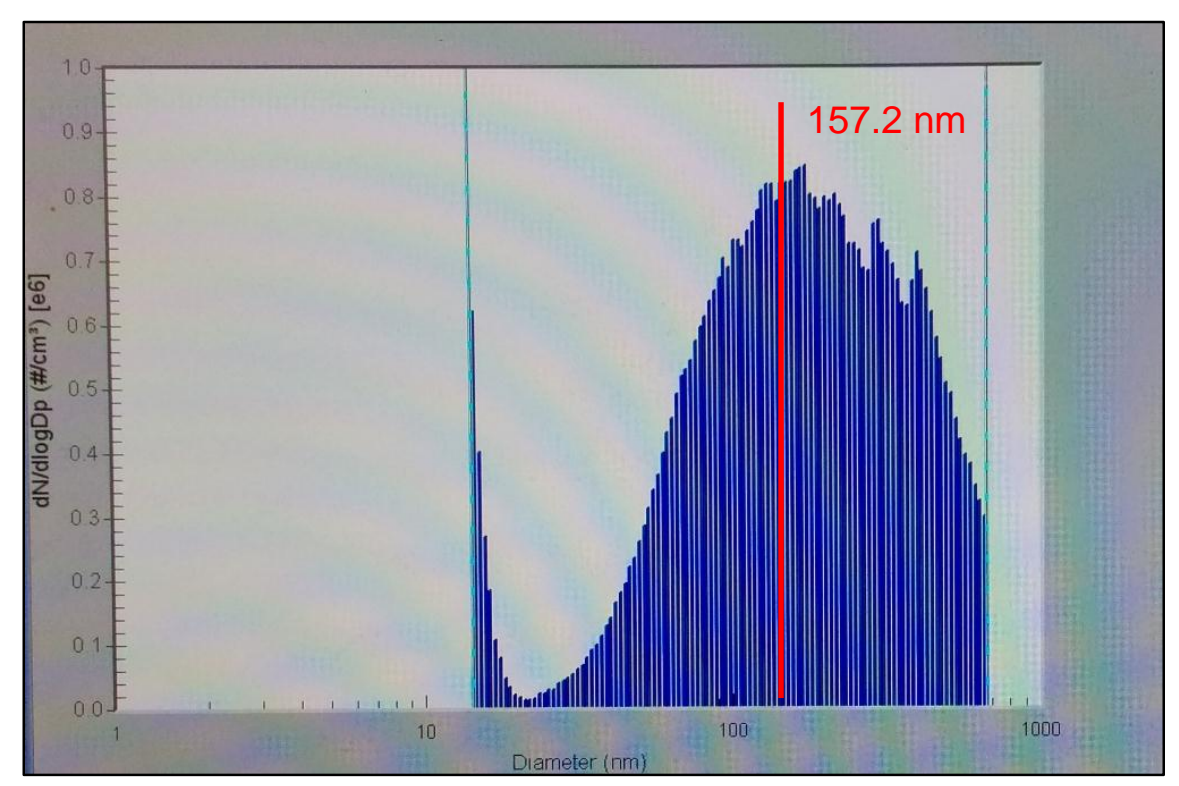

Figure 40 - Size Distribution Example (Run 12 Preliminary Test Matrix)

As seen in Figure 40 the SMPS displays the real time particle size distribution on a log scale. The particle size distribution shows a single peak distribution with a geometric mean particle size at $157.2 \mathrm{~nm}$ for this specific example. The SMPS program generates the values seen in Figure 41 below.

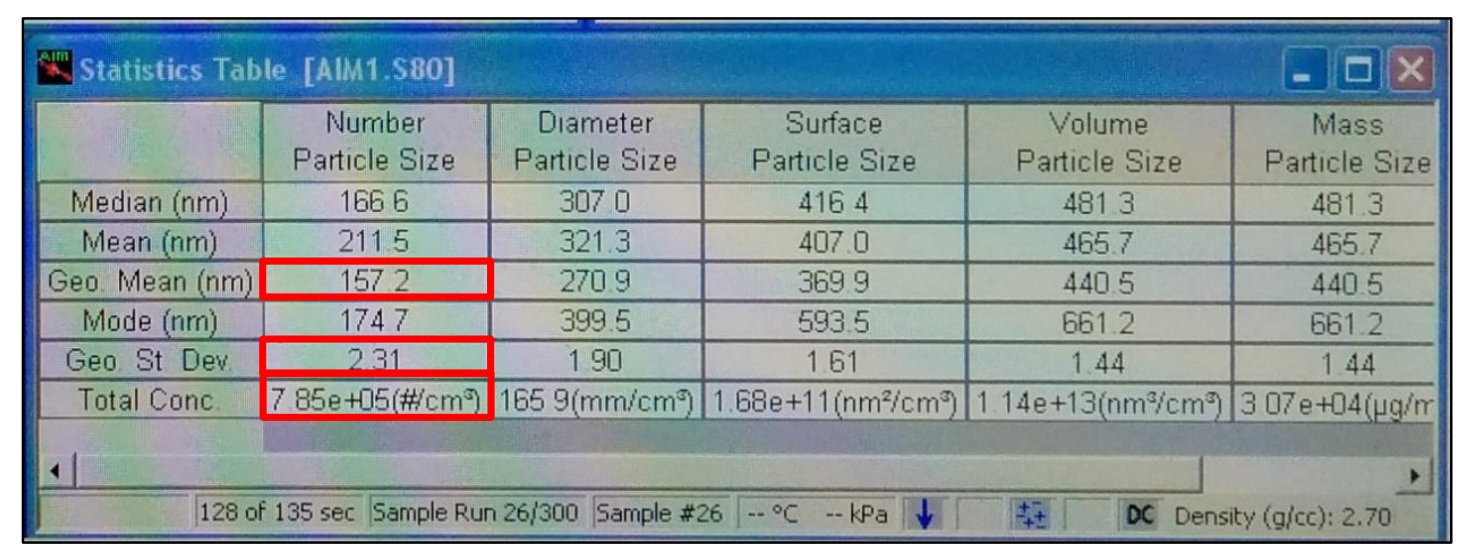

Figure 41 - Statistic Table Example as Displayed by the SMPS (Run 12 Preliminary Test Matrix)

For this raw data collection the geometric mean particle size $(\mathrm{nm})$, geometric standard deviation and total concentration based on the number particle size calculation is of interest as seen highlighted in the figure 
above. This raw data was collected and reduced as outlined in the data reduction section to populate the tables within this chapter.

\subsubsection{Test Compound}

The sample compound used for the experimental testing was independently characterized by the Electron Microscopy Facilities located in the Engineering Sciences Building at West Virginia University. The aerosols were pulled onto filter paper using a vacuum pump in order to conduct Scanning Electron Microscopy (SEM) of the sample. A Hitachi S-4700 Scanning Electron Microscope was used to image the particles which can be seen in Figure 42 below.

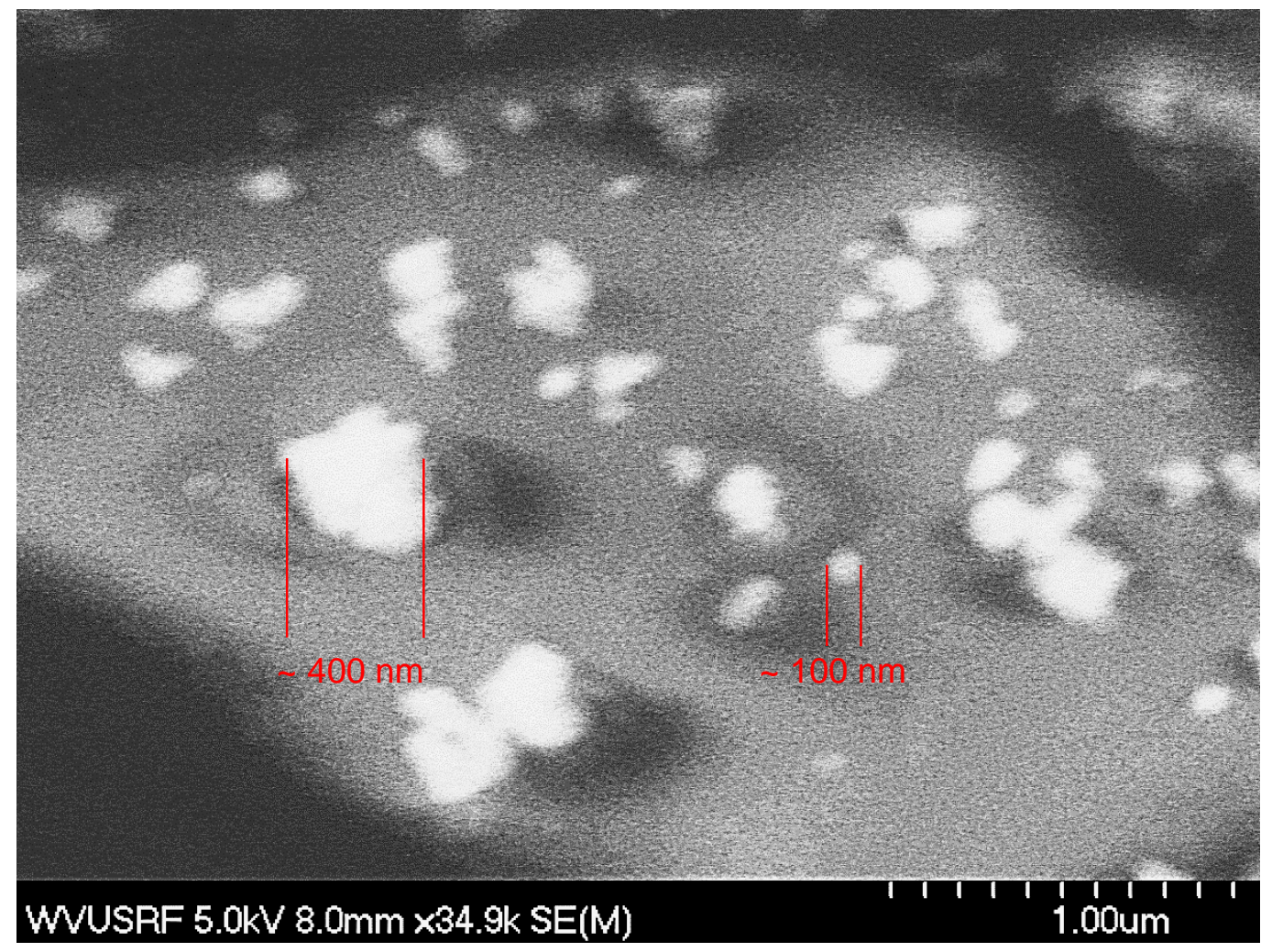

Figure 42 - SEM Image of Aerosol Sample

The SEM image shows agglomerations of $\mathrm{SiO}_{2}$ particles with sizes ranging from 50 - $500 \mathrm{~nm}$ which confirm the aerosols measured by the SMPS. Higher resolution images may be achieved by using other characterization techniques if needed. 


\subsubsection{Preliminary Test Matrix Results}

The experimental procedure for the preliminary test matrix was conducted and recorded. The corresponding reduced data is shown in Table 12 below.

Table 12 - Preliminary Test Matrix Results

\begin{tabular}{|c|c|c|c|c|c|c|c|}
\hline \multirow[b]{2}{*}{ Expt. No. } & \multicolumn{4}{|c|}{ Input Factors } & \multicolumn{3}{|c|}{ Output Particle Characteristics } \\
\hline & $\begin{array}{c}\text { Venturi } \\
\text { Pressure } \\
\text { (psig) }\end{array}$ & $\begin{array}{c}\text { Fluidized } \\
\text { Bed Flow } \\
\text { Rate (LPM) }\end{array}$ & $\begin{array}{c}\text { Vibrator } \\
\text { Pressure } \\
\text { (psig) }\end{array}$ & $\begin{array}{c}\text { Vibrator } \\
\text { Orientation } \\
\text { (degrees) }\end{array}$ & $\begin{array}{c}\text { Particle } \\
\text { Concentration } \\
\left(1 \times 10^{3}\right)\end{array}$ & $\begin{array}{c}\text { Geometric } \\
\text { Mean Particle } \\
\text { Size }(n m)\end{array}$ & $\begin{array}{l}\text { Standard } \\
\text { Deviation }\end{array}$ \\
\hline 1 & $55 P S I$ & $1.5 L P M$ & 55 PSI & $0^{\circ}$ & 764 & 156.6 & 2.33 \\
\hline 2 & 55 PSI & $1.5 L P M$ & 55 PSI & $45^{\circ}$ & 541 & 145.8 & 2.31 \\
\hline 3 & $55 P S I$ & $1.5 L P M$ & 55 PSI & $90^{\circ}$ & 383 & 142.3 & 2.28 \\
\hline 4 & $55 P S I$ & $1.5 L P M$ & 35 PSI & $0^{\circ}$ & 213 & 137.8 & 2.27 \\
\hline 5 & $55 P S I$ & $1.5 L P M$ & 55 PSI & $0^{\circ}$ & 828 & 157.0 & 2.30 \\
\hline 6 & $55 P S I$ & $1.5 L P M$ & 72 PSI & $0^{\circ}$ & 911 & 151.1 & 2.33 \\
\hline 7 & $55 P S I$ & $1 L P M$ & 55 PSI & $0^{\circ}$ & 423 & 142.2 & 2.30 \\
\hline 8 & $55 P S I$ & $1.5 L P M$ & 55 PSI & $0^{\circ}$ & 892 & 157.0 & 2.30 \\
\hline 9 & $55 P S I$ & $2 L P M$ & 55 PSI & $0^{\circ}$ & 1,289 & 157.7 & 2.37 \\
\hline 10 & 35 PSI & $1.5 L P M$ & $55 P S I$ & $0^{\circ}$ & 521 & 164.1 & 2.39 \\
\hline 11 & $55 P S I$ & $1.5 L P M$ & 55 PSI & $0^{\circ}$ & 956 & 157.0 & 2.30 \\
\hline 12 & 75 PSI & $1.5 L P M$ & 55 PSI & $0^{\circ}$ & 729 & 143.1 & 2.32 \\
\hline
\end{tabular}

For each experimental run the reduced data for the output particle characteristic of interest; concentration, geometric mean size and standard deviation was used to populate the above table. This data provides a fundamental understanding with regards to factor effects and will later be used for model validation with the prediction tests. 


\subsubsection{Experimental Test Matrix Results}

Likewise, the experimental test matrix and the corresponding reduced data is shown in Table 13 below.

Table 13 - Experimental Test Matrix Results

\begin{tabular}{|c|c|c|c|c|c|c|c|}
\hline \multirow[b]{2}{*}{$\begin{array}{l}\text { Expt. } \\
\text { No. }\end{array}$} & \multicolumn{4}{|c|}{ Input Factors } & \multicolumn{3}{|c|}{ Output Particle Characteristics } \\
\hline & $\begin{array}{c}\text { Venturi } \\
\text { Pressure } \\
\text { (psig) }\end{array}$ & $\begin{array}{c}\text { Fluidized Bed } \\
\text { Flow Rate } \\
\text { (LPM) }\end{array}$ & $\begin{array}{c}\text { Vibrator } \\
\text { Pressure } \\
\text { (psig) }\end{array}$ & $\begin{array}{c}\text { Vibrator } \\
\text { Orientation } \\
\text { (degrees) }\end{array}$ & $\begin{array}{c}\text { Particle } \\
\text { Concentrati } \\
\text { on }\left(1 \times 10^{3}\right)\end{array}$ & $\begin{array}{c}\text { Mean Particle } \\
\text { Size (nm) }\end{array}$ & $\begin{array}{l}\text { Standard } \\
\text { Deviation }\end{array}$ \\
\hline 1 & 35 PSI & $1 L P M$ & 35 PSI & $0^{\circ}$ & 129 & 161.0 & 2.36 \\
\hline 2 & 35 PSI & $1.5 \mathrm{LPM}$ & 55 PSI & $45^{\circ}$ & 497 & 167.0 & 2.42 \\
\hline 3 & $35 P S I$ & $2 L P M$ & $75 P S I$ & $90^{\circ}$ & 1,408 & 180.4 & 2.43 \\
\hline 4 & 55 PSI & $1 L P M$ & 55 PSI & $90^{\circ}$ & 181 & 147.8 & 2.35 \\
\hline 5 & 55 PSI & $1.5 \mathrm{LPM}$ & 75 PSI & $0^{\circ}$ & 1,282 & 177.3 & 2.42 \\
\hline 6 & 55 PSI & $2 L P M$ & 35 PSI & $45^{\circ}$ & 940 & 154.5 & 2.34 \\
\hline 7 & $75 P S I$ & $1 L P M$ & 75 PSI & $45^{\circ}$ & 619 & 145.3 & 2.27 \\
\hline 8 & $75 P S I$ & $1.5 \mathrm{LPM}$ & $35 P S I$ & $90^{\circ}$ & 373 & 142.5 & 2.29 \\
\hline 9 & 75 PSI & $2 L P M$ & 55 PSI & $0^{\circ}$ & 1,450 & 161.5 & 2.36 \\
\hline
\end{tabular}

For each experimental run the reduced data for the output particle characteristics of interest; concentration, geometric mean size and standard deviation was used to populate the above table. This data provided the necessary information for the modeling analysis. 


\subsection{Data Analysis Results}

After reducing the experimental data and populating the tables above the factor effects plots, optimal settings, ANOVA analysis, factor interactions and predictive models can be generated. These are done for each output parameter of interest separately. The output parameters of interest include: particle concentration, geometric mean particle size and geometric standard deviation.

\subsubsection{Factor Effects}

The factor effects are computed as outlined in Section 5.4. Using Matlab, the factor effects plots for concentration, geometric particle size and standard deviation are generated and shown below.
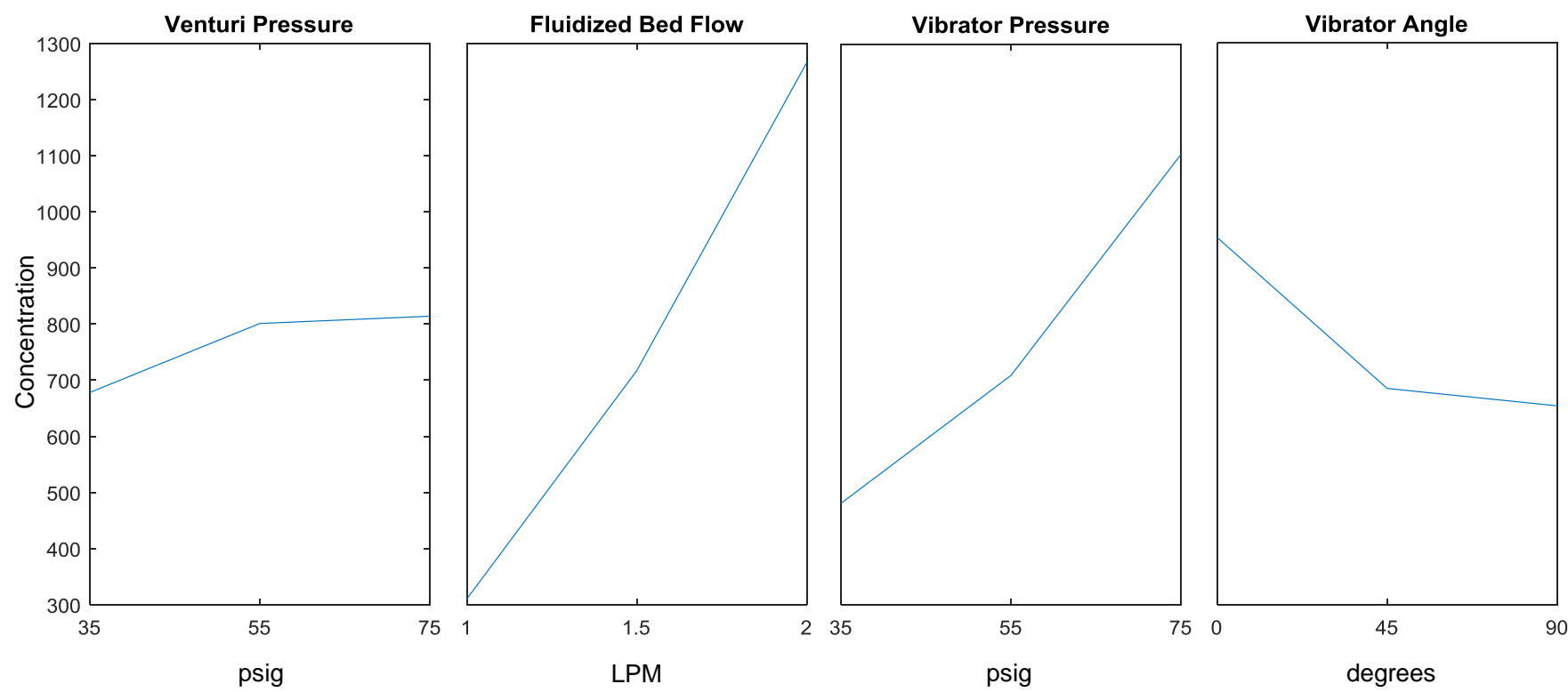

Figure 43 - Factor Effect Plot for Particle Concentration

Figure 43 represents the factor effect plots for the particle concentration at the various input settings. It can be seen from these plots that the fluidized bed flow (Factor B) and vibrator pressure (Factor C) have a significant influence on the concentration output as seen by the slope of the curves. Additionally, the optimal settings can be determined from these plots by analyzing the settings that produce the highest concentrations. 
Figure 44 below represents the factor effect plots for the mean particle size at the various input settings.
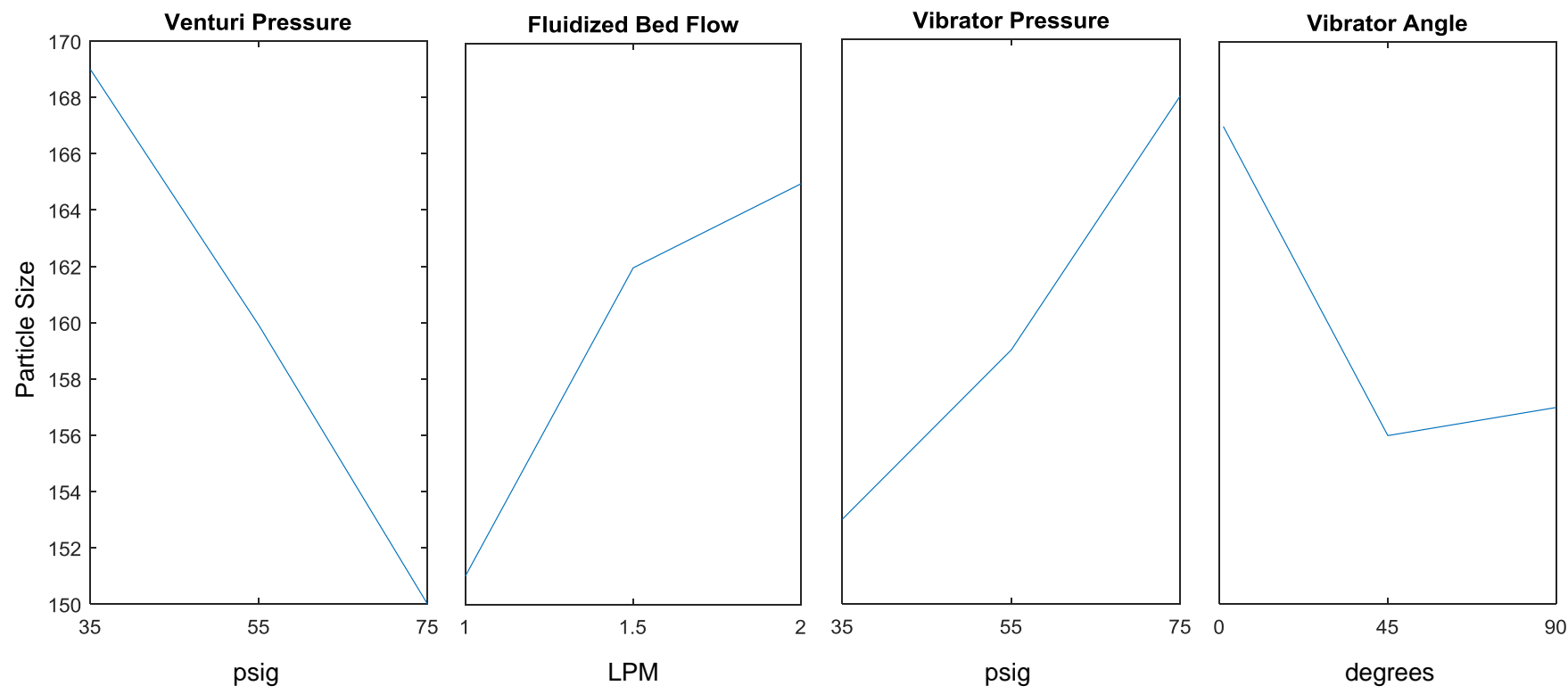

Figure 44 - Factor Effect Plot for Mean Particle Size

It can be seen from the plots above that all four input factors have influence on the mean particle size output. As before, the optimal settings can be determined from these plots by analyzing the settings that produce the smallest mean particle size.

Figure 45 below represents the factor effect plots for the standard deviation of the particle distribution at the various input settings.
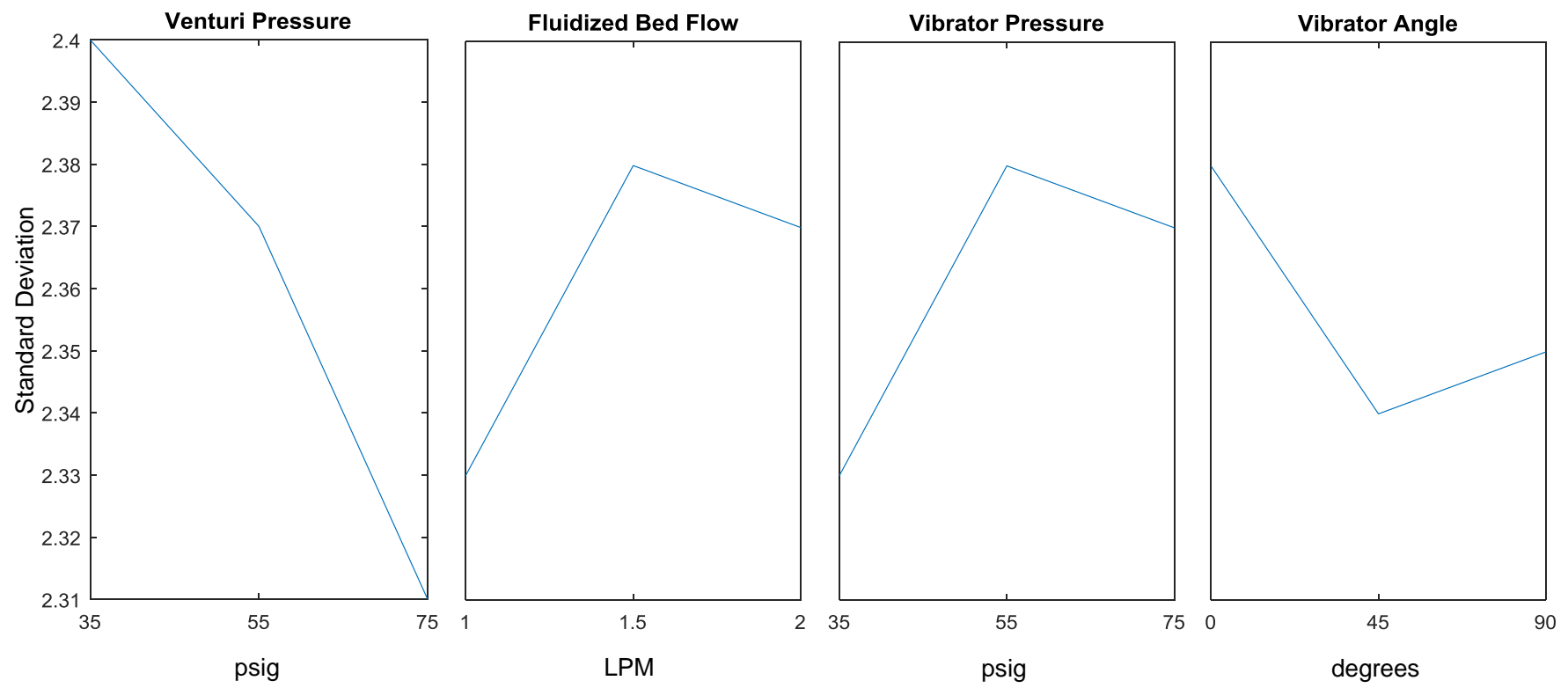

Figure 45 - Factor Effect Plot for Geometric Standard Deviation 
It can be seen from the plots above that all four input factors have influence on the standard deviation although under closer examination little change actually occurs. As before, the optimal settings can be determined from these plots by analyzing the settings that produce the smallest standard deviation with the goal of producing tighter, single peak distributions.

\subsubsection{Optimal Factor Levels}

By evaluating the main effects plots it can be seen that the optimal setting for the highest particle concentration would be $A_{3}, B_{3}, C_{3}$, and $D_{1}$. This is demonstrated in Figure 46 below.
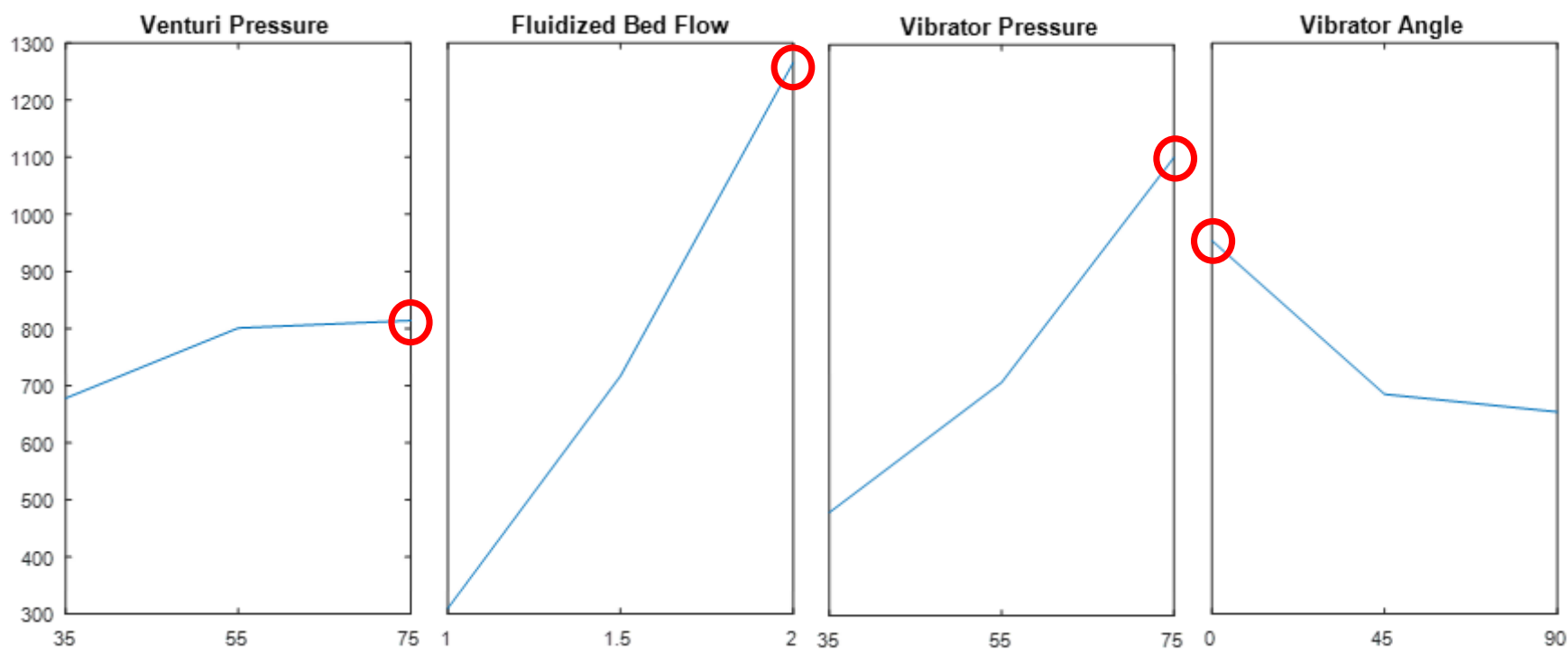

Figure 46 - Optimal Settings (Concentration)

Likewise, the optimal settings for the smallest geometric mean particle size would be $A_{3}, B_{1}, C_{1}$, and $D_{2}$ as seen in Figure 47. 

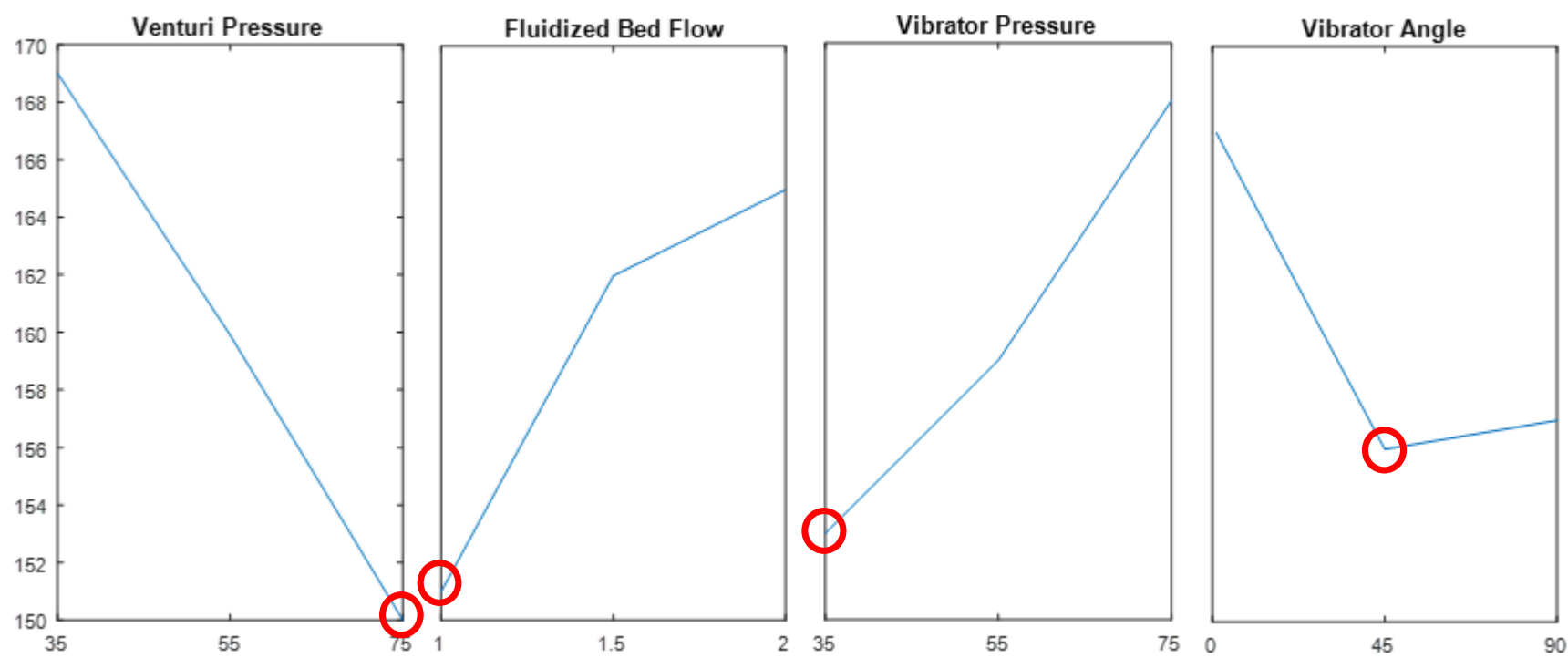

Figure 47 - Optimal Settings (Particle Size)

Lastly, the optimal settings for the smallest geometric standard deviation or tightest single peak distribution would be $A_{3}, B_{1}, C_{1}$, and $D_{2}$ although there is little variation in distribution throughout the entire experimental range.
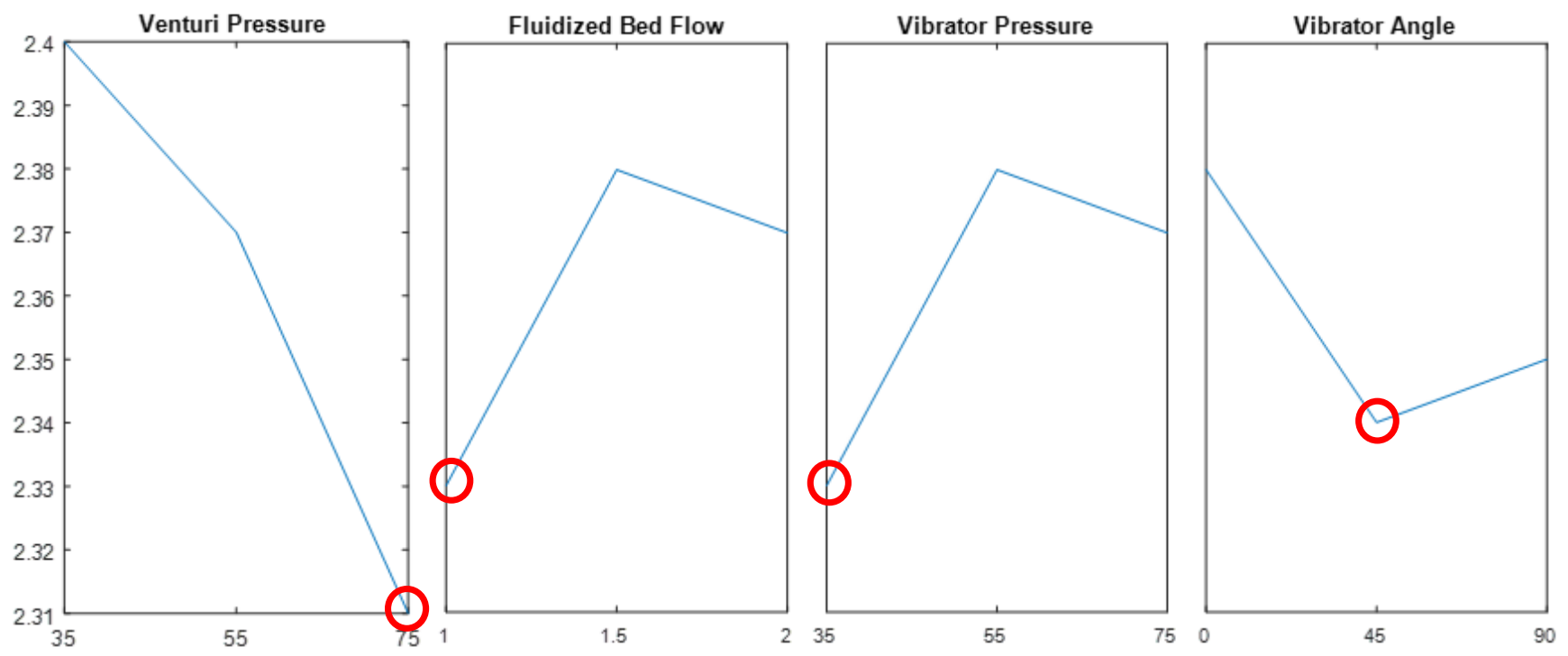

Figure 48 - Optimal Settings (Standard Deviation)

\subsubsection{Analysis of Variance}

As interpreted from the main effects plots each input parameter can be seen to have an effect on the output. This can be better quantified by conducting an analysis of variance. The ANOVA table is used to quantify and rank the influence of each factor on the output. The results of the ANOVA analysis are tabulated below. 
Table 14 - ANOVA Table for Concentration

\begin{tabular}{|l|c|c|c|c|}
\hline $\begin{array}{c}\text { Factor/Source } \\
\text { (Concentration) }\end{array}$ & $\begin{array}{c}\text { Degrees of } \\
\text { Freedom }\end{array}$ & $\begin{array}{c}\text { Sum of } \\
\text { Squares }\end{array}$ & $\begin{array}{c}\text { Mean } \\
\text { Square }\end{array}$ & Influence \\
\hline A. Venturi Pressure & 2 & 33,813 & 16,907 & $1.6 \%$ \\
B. Fluidized Bed Flowrate & 2 & $1,381,336$ & 690,668 & $63.6 \%$ \\
C. Vibrator Pressure & 2 & 593,523 & 296,761 & $27.3 \%$ \\
D. Vibrator Angle & 2 & 162,789 & 81,395 & $7.5 \%$ \\
\hline Total & 8 & $2,171,461$ & $1,085,730$ & $100 \%$ \\
\hline
\end{tabular}

Thus, factor B represents a major portion of the total variation for particle concentration. As seen in the table it is responsible for $(1,381,336 / 2,171,461.5)^{*} 100=63.6 \%$ of the variation to the overall mean. Factor $\mathrm{C}$ is responsible for the second largest at $27.3 \%$.

Table 15 - ANOVA Table for Particle Size

\begin{tabular}{|l|c|c|c|c|}
\hline $\begin{array}{c}\text { Factor/Source } \\
\text { (Mean Particle Size) }\end{array}$ & $\begin{array}{c}\text { Degrees of } \\
\text { Freedom }\end{array}$ & $\begin{array}{c}\text { Sum of } \\
\text { Squares }\end{array}$ & $\begin{array}{c}\text { Mean } \\
\text { Square }\end{array}$ & Influence \\
\hline A. Venturi Pressure & 2 & 583 & 291 & $39.7 \%$ \\
B. Fluidized Bed Flowrate & 2 & 328 & 164 & $22.3 \%$ \\
C. Vibrator Pressure & 2 & 340 & 170 & $23.2 \%$ \\
D. Vibrator Angle & 2 & 217 & 108 & $14.8 \%$ \\
\hline Total & 8 & 1468 & 734 & $100 \%$ \\
\hline
\end{tabular}

As seen in Table 15 above factor A represents a major portion of the total variation in particle size. As seen in the table it is responsible for $(583 / 1468)^{*} 100=39.7 \%$ of the variation to the overall mean. Factors $\mathrm{B}$ and $\mathrm{C}$ are responsible for the next largest variation of $22.3 \%$ and $23.2 \%$ respectfully. 
Table 16 - ANOVA Table for Standard Deviation

\begin{tabular}{|l|c|c|c|c|}
\hline $\begin{array}{c}\text { Factor/Source } \\
\text { (Standard Deviation) }\end{array}$ & $\begin{array}{c}\text { Degrees of } \\
\text { Freedom }\end{array}$ & $\begin{array}{c}\text { Sum of } \\
\text { Squares }\end{array}$ & $\begin{array}{c}\text { Mean } \\
\text { Square }\end{array}$ & Influence \\
\hline A. Venturi Pressure & 2 & .0144 & .0072 & $57.5 \%$ \\
B. Fluidized Bed Flowrate & 2 & .0047 & .0023 & $18.5 \%$ \\
C. Vibrator Pressure & 2 & .0039 & .002 & $15.7 \%$ \\
D. Vibrator Angle & 2 & .0021 & .001 & $8.3 \%$ \\
\hline Total & 8 & .0251 & .0126 & $100 \%$ \\
\hline
\end{tabular}

As seen in Table 16 above factor A represents a major portion of the total variation in the standard deviation. As seen in the table it is responsible for $(.0144 / .0251)^{\star} 100=57.5 \%$ of the variation to the overall mean. Factors $B$ and $C$ are responsible for the next largest variation of $18.5 \%$ and $15.7 \%$ respectfully.

The ANOVA analysis allows each factor to be represented in terms of the influence it has on the output. This can, alternatively, be represented graphically as seen in the figures below.

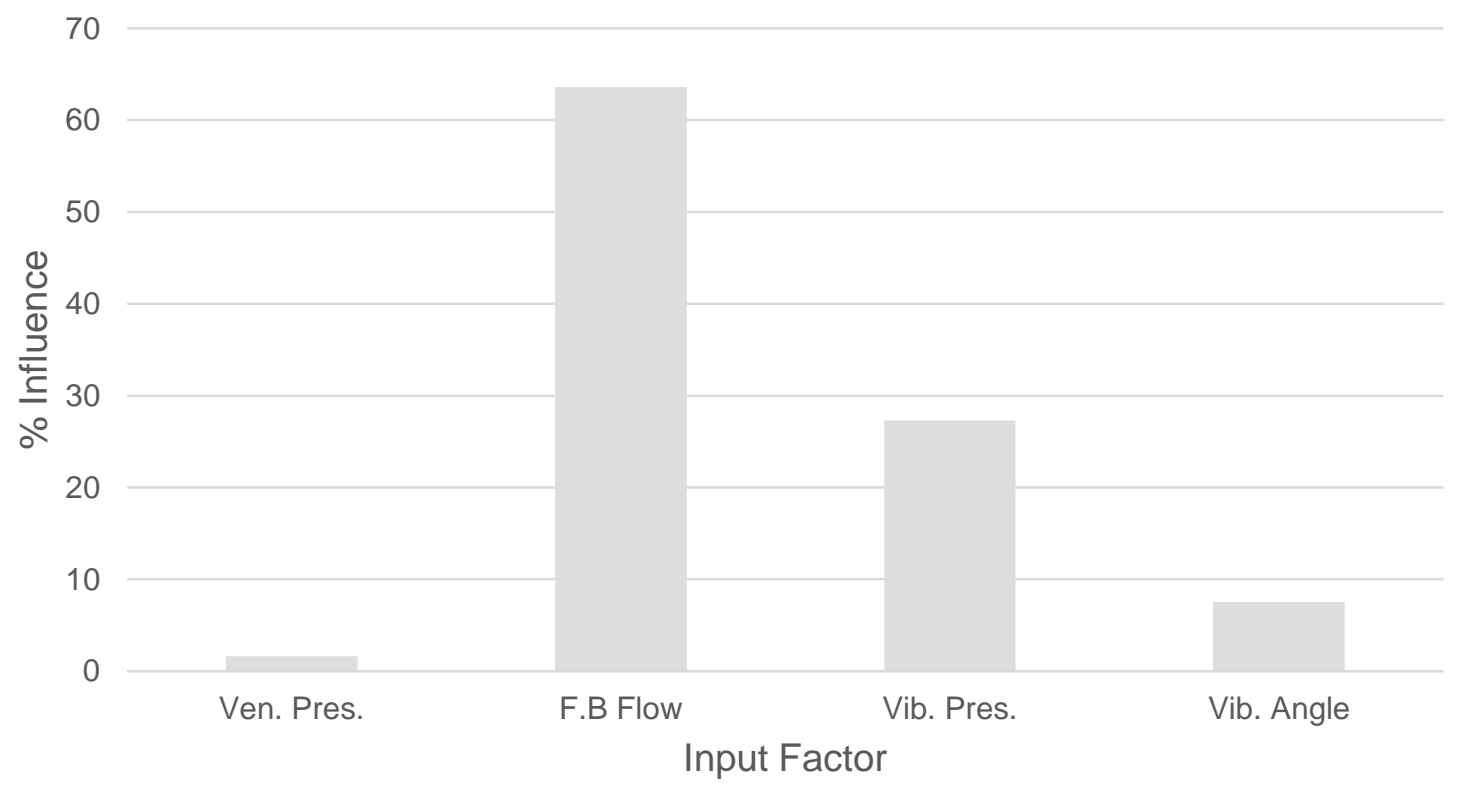

Figure 49 - Influence of each factor on Concentration

Figure 49 represents the influence each factor has on the concentration. As previously determined factors $B$ and $C$ have the dominating influence on the output concentration making up $90 \%$ of the overall influence. 


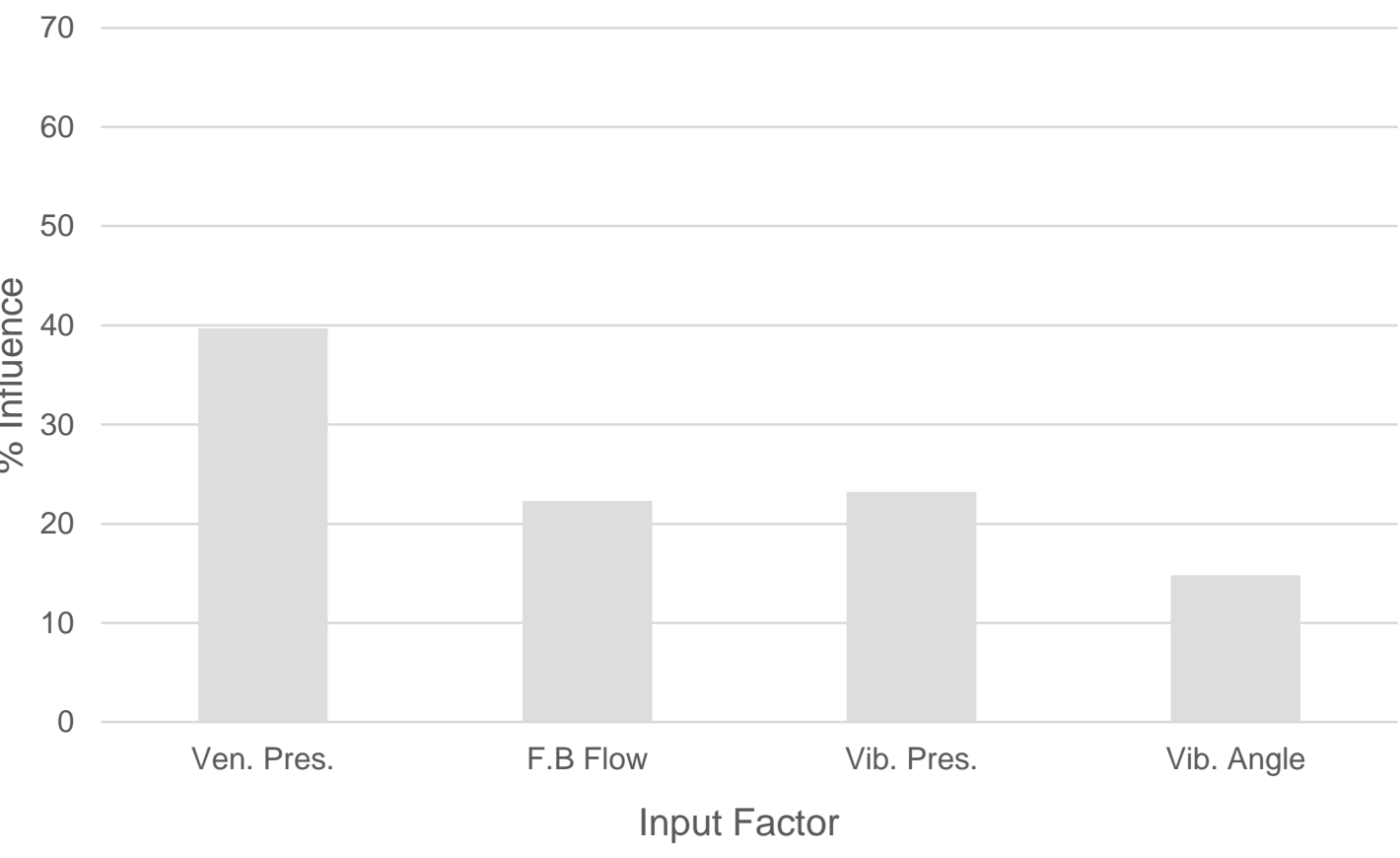

Figure 50 - Influence of each factor on Particle Size

Figure 50 represents the influence each factor has on the mean particle size. As previously determined factor $A$ has the dominating influence with factors $B$ and $C$ following. Factors $A, B$ and $C$ make up $~ 85$ $\%$ of the overall influence on particle size output.

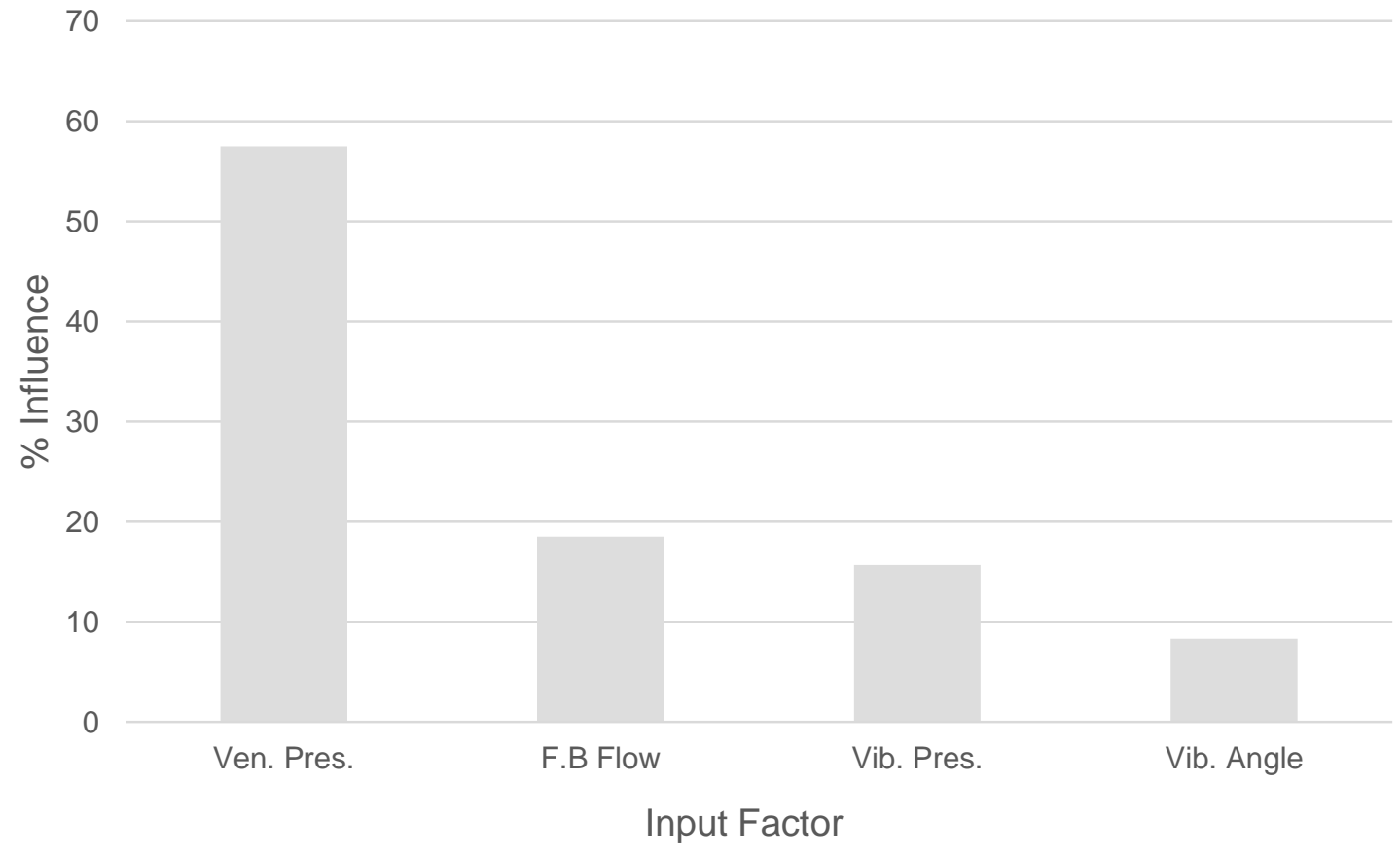

Figure 51 - Influence of each factor on Standard Deviation 
Figure 51 represents the influence each factor has on the standard deviation. As previously determined factor $A$ has the dominating influence with factors $B$ and $C$ following. Factors $A, B$ and $C$ make up $>90 \%$ of the overall influence on standard deviation.

\subsubsection{Interaction Among Input Factors}

The interactions of the two dominant factors for the concentration are shown in Table 17 below.

Table 17 - Interaction Values for Factors B and C on Concentration

\begin{tabular}{|c|c|c|c|c|c|c|c|c|c|}
\hline Interaction & $\widehat{b_{1} c_{1}}$ & $\overline{b_{1} c_{2}}$ & $\overline{b_{1} c_{3}}$ & $\overline{b_{2} c_{1}}$ & $\overline{b_{2} c_{2}}$ & $\overline{b_{2} c_{3}}$ & $\overline{b_{3} c_{1}}$ & $\overline{b_{3} c_{2}}$ & $\overline{b_{3} c_{3}}$ \\
\hline Conc. (1x10 $)\left(\# / \mathbf{c m}^{3}\right)$ & 103 & -73.67 & -29.33 & -60.67 & -165.33 & 226 & -42.33 & 239 & -196.66 \\
\hline
\end{tabular}

It can be noted that only the larger interactions would be of interest in this model. These interactions, $\widehat{b_{2} c_{2}}, \widehat{b_{2} c_{3}}, \widehat{b_{3} c_{2}}$ and $\widehat{b_{3} c_{3}}$, which are bold and highlighted in red in the table above can be seen as significant. This is evident in the interactions plot, as seen in Figure 52 , between $B$ and $C$ below when comparing to the main effects plot, which does not include interactions, in Figure 53.

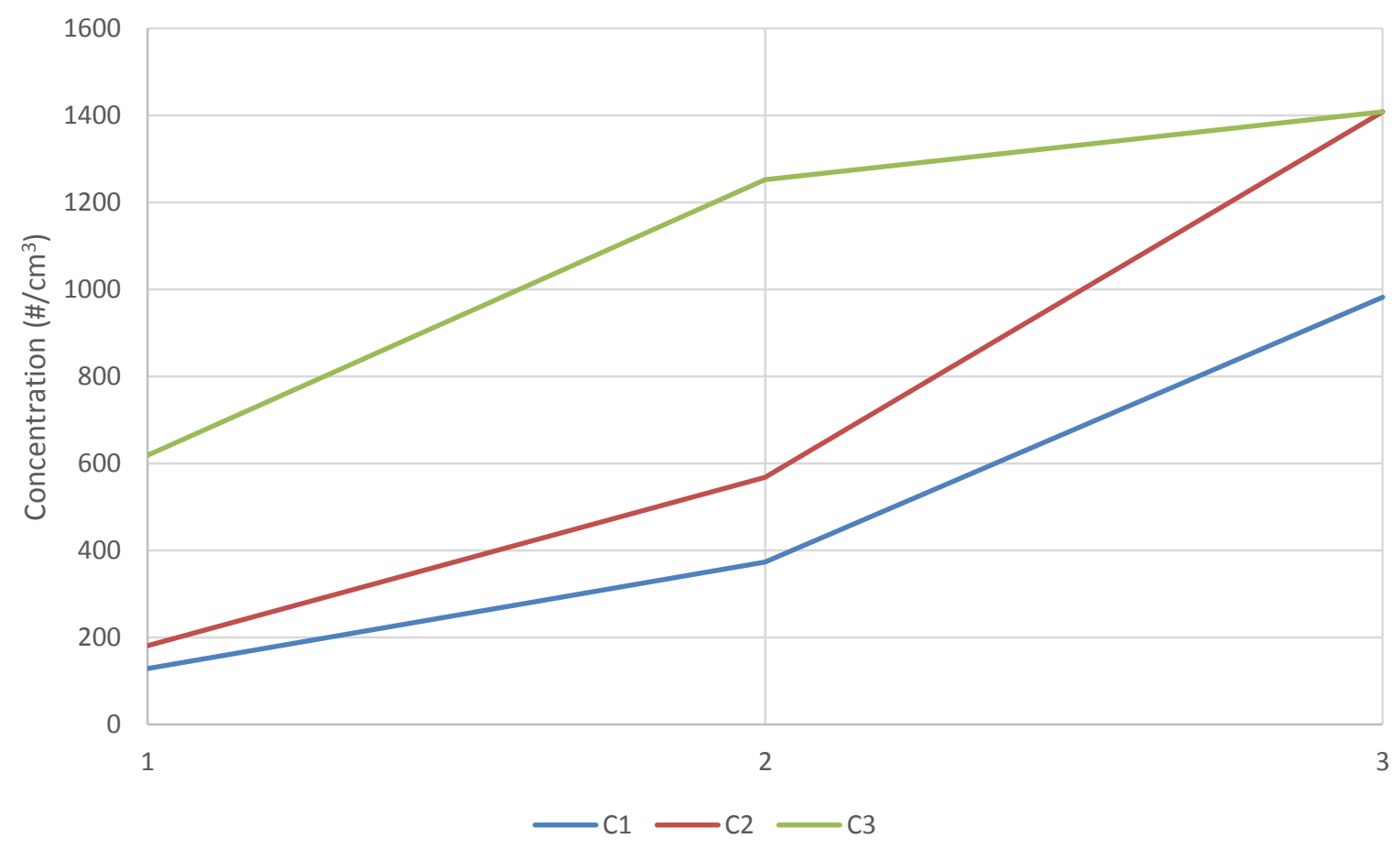

Figure 52 - Interaction Plot for Factors B and C on Concentration 


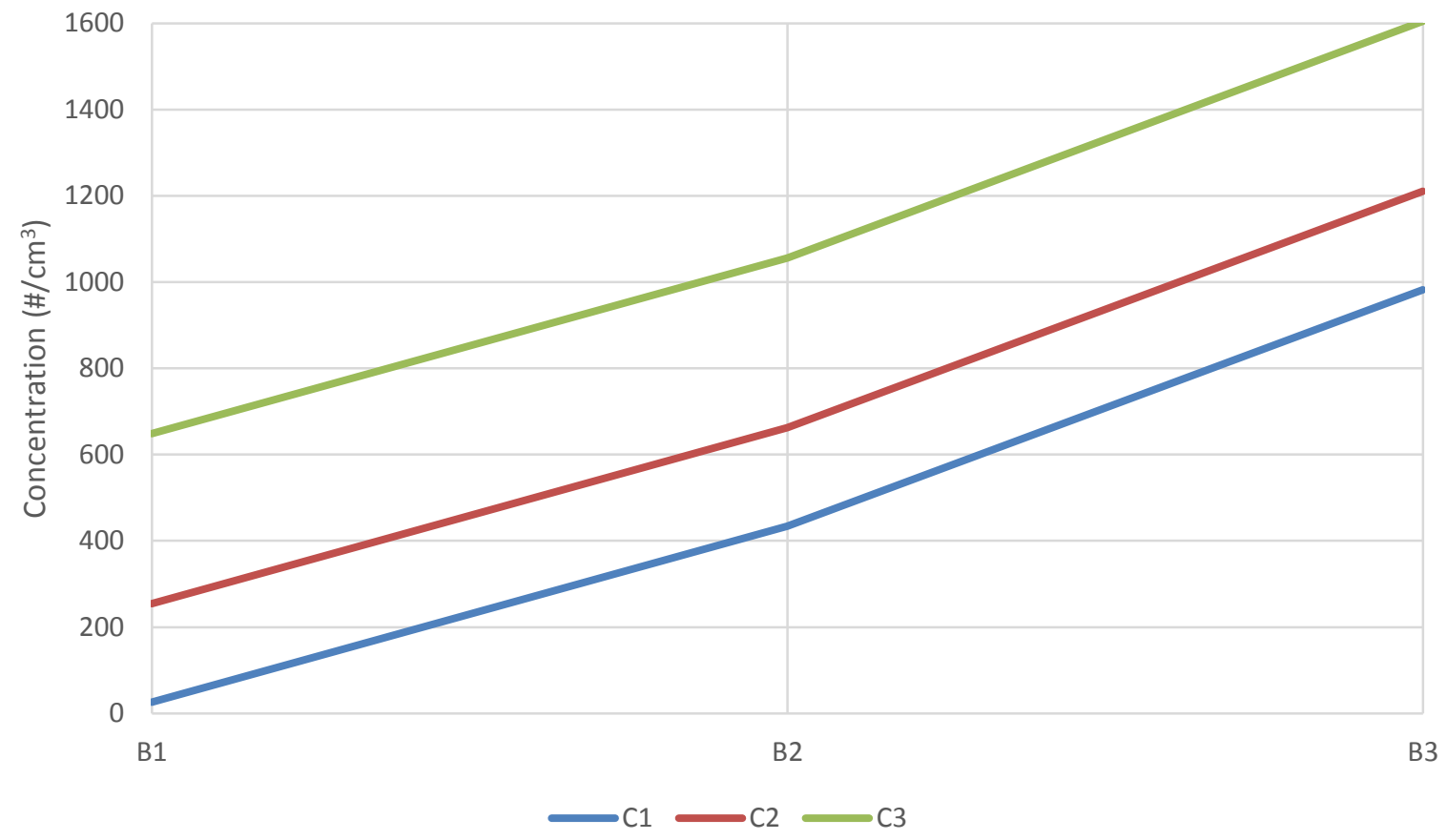

Figure 53 - Main Effects Plot for Factors B and C on Concentration

It can be seen that the larger interactions occur at the points that have been identified as significant. This can be represented as a surface plot to help visualize the output with the chosen input settings.

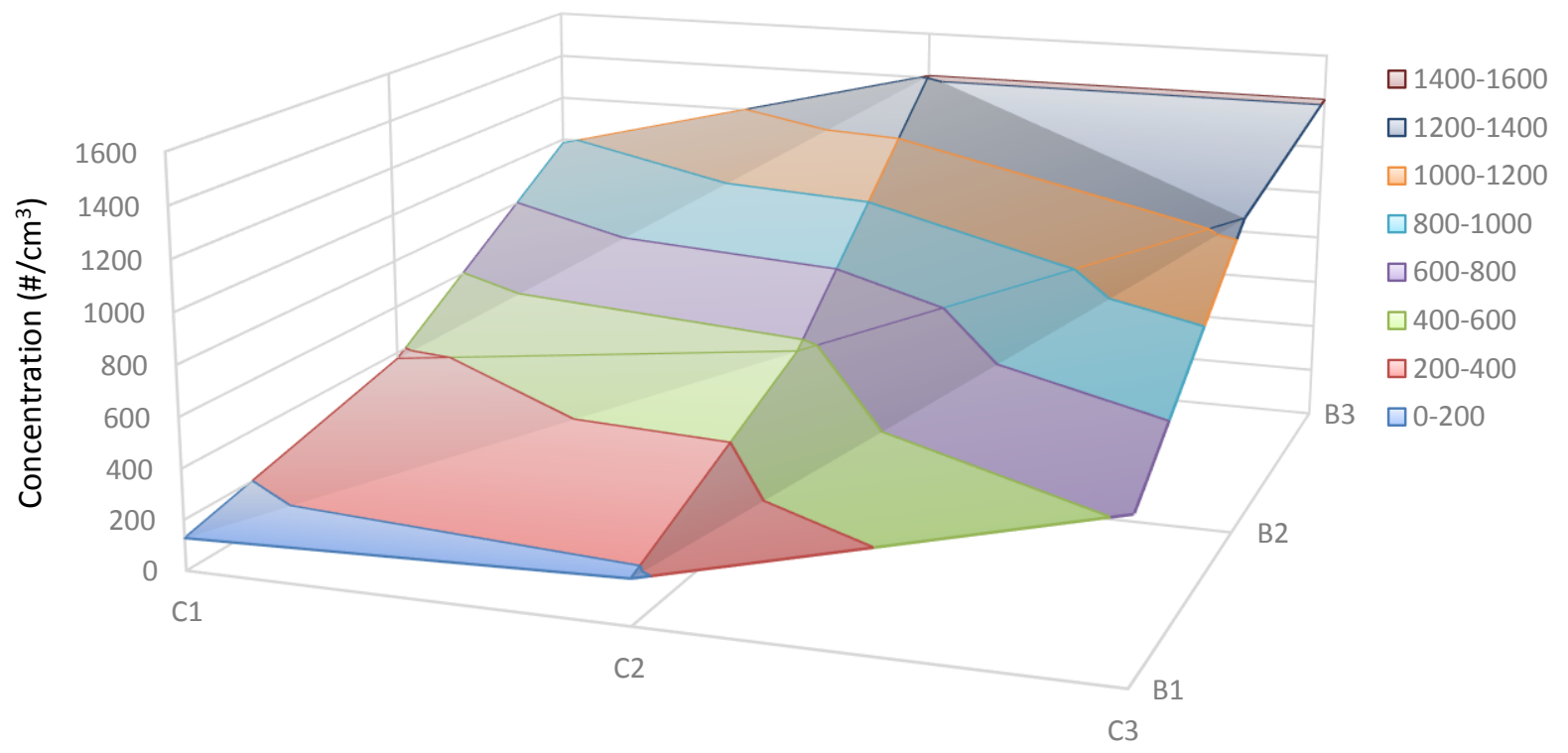

Figure 54 - Interaction Surface Plot for Factors B and C on Concentration 
It can be seen from Figure 54 the concentration that can be achieved with the various combinations of factors $B$ and $C$. Although slight interaction among certain combinations of input factors have been identified, they are not significant enough to include in the model at this time.

\subsection{Predictive Model Results}

A Matlab script for the predictive model was written (See Appendix B) to compute the desired predictions. Based on the optimal settings determined previously in this chapter the predictive model can be used to estimate the concentration and mean particle size at these settings. The optimal settings for the highest concentration are $A_{3}, B_{3}, C_{3}$, and $D_{1}$. The predictive model estimates the concentration of these settings at $1604 \times 10^{3}\left(\# / \mathrm{cm}^{3}\right)$. Likewise, the predictive model estimates the geometric mean particle size at the optimal settings of $A_{3}, B_{1}, C_{1}$, and $D_{2}$ to be $130.3 \mathrm{~nm}$. These results are tabulated in the table below.

Table 18 - Prediction Results for Optimal Settings

\begin{tabular}{|c|c|c|c|c|c|c|}
\hline & \multicolumn{4}{|c|}{ Input Factors } & \multicolumn{2}{c|}{ Output Estimations } \\
\hline Optimal Settings & $\begin{array}{c}\text { A. Venturi } \\
\text { Pressure }\end{array}$ & $\begin{array}{c}\text { B. Fluidized Bed } \\
\text { Flow Rate }\end{array}$ & $\begin{array}{c}\text { C. Vibrator } \\
\text { Pressure }\end{array}$ & $\begin{array}{c}\text { D. Vibrator } \\
\text { Orientation }\end{array}$ & $\begin{array}{c}\text { Concentration } \\
\left(1 \times 10^{3}\right)\end{array}$ & $\begin{array}{c}\text { Mean Particle } \\
\text { Size }(\mathrm{nm})\end{array}$ \\
\hline $\mathrm{A}_{3}, \mathrm{~B}_{3}, \mathrm{C}_{3}, \mathrm{D}_{1}$ & $75 P S I$ & $2 \mathrm{LPM}$ & $75 P S I$ & $0^{\circ}$ & $\underline{1,604}$ & 163.5 \\
\hline $\mathrm{A}_{3}, \mathrm{~B}_{1}, \mathrm{C}_{1}, \mathrm{D}_{2}$ & $75 P S I$ & $1 \mathrm{LPM}$ & $35 P S I$ & $45^{\circ}$ & 76 & $\underline{130.3}$ \\
\hline
\end{tabular}

\subsection{Modeling Validation Results}

To validate the predictive model estimations, the preliminary test matrix results were used for comparison. These values were used because none of the experiments conducted in the preliminary test matrix share the same settings of those in the experimental test matrix. The predictive model was used to estimate the concentration and geometric particle size of runs 2, 6, 7, 9, 10 and 12 from the preliminary test matrix results. The predicted values were compared to the experimental value and used to compute the prediction error of the model.

Table 19 - Prediction Error for Concentration $\left(\# / \mathrm{cm}^{3}\right)$

\begin{tabular}{|c|c|c|c|}
\hline Expt. No. & Experimental & $\frac{\text { Predicted }}{\text { Error }}$ \\
\hline 2 & 541 & 583 & $8 \%$ \\
\hline 6 & 911 & 1056 & $16 \%$ \\
\hline 7 & 423 & 444 & $5 \%$ \\
\hline 9 & 1289 & 1245 & $3 \%$ \\
\hline 10 & 521 & 576 & $11 \%$ \\
\hline 12 & 729 & 712 & $2 \%$ \\
\hline
\end{tabular}


Table 19 above shows the experimental value alongside the predicted value for concentration. This comparison is used to predict the percent error of the prediction. The same comparison is conducted for the mean particle size below in Table 20.

Table 20 - Prediction Error for Geometric Particle Size (nm)

\begin{tabular}{|c|c|c|c|}
\hline Expt. No. & Experimental & Predicted & Error \\
\hline 2 & 145.8 & 157.4 & $8 \%$ \\
\hline 6 & 151.1 & 167.8 & $11 \%$ \\
\hline 7 & 142.2 & 150.6 & $6 \%$ \\
\hline 9 & 157.7 & 164.7 & $4 \%$ \\
\hline 10 & 164.1 & 168.5 & $3 \%$ \\
\hline 12 & 143.1 & 148.8 & $4 \%$ \\
\hline
\end{tabular}

\subsection{Repeatability Study}

A repeatability study was conducted to validate that the developed system is repeatable and consistent over time. The midpoint settings $A_{2}, B_{2}, C_{2}, D_{2}$ were used for this study. The following repeatability observations were recorded.

Table 21 - Repeatability Study

\begin{tabular}{|c|c|c|c|c|}
\hline Date & $\frac{\text { Concentration }}{\left(\# / \mathbf{c m}^{3}\right)}$ & $\frac{\text { Mean Particle Size }}{(\mathbf{n m})}$ & St. Deviation & Time (Hrs.) \\
\hline 17-Oct & 764 & 156.6 & 2.33 & $1: 00$ \\
\hline 17-Oct & 1031 & 156.6 & 2.28 & $6: 00$ \\
\hline & & & & \\
\hline 19-Oct & 892 & 154.5 & 2.38 & $7: 00$ \\
\hline 19-Oct & 1203 & 157.7 & 2.33 & $12: 00$ \\
\hline & & & & \\
\hline 20-Oct & 1026 & 163.0 & 2.21 & $13: 00$ \\
\hline 20-Oct & 1384 & 163.0 & 2.21 & $18: 00$ \\
\hline
\end{tabular}

Based on the repeatability study data presented in Table 21 it was found that the concentration gradually increases over time. This is primarily due to particle accumulation on the inner surface of the system and experimental set-up. Although the concentration gradually increases the mean particle size and standard deviation have little to no variation over time. Figure 55 below is used to illustrate the accumulation of concentration over time. 


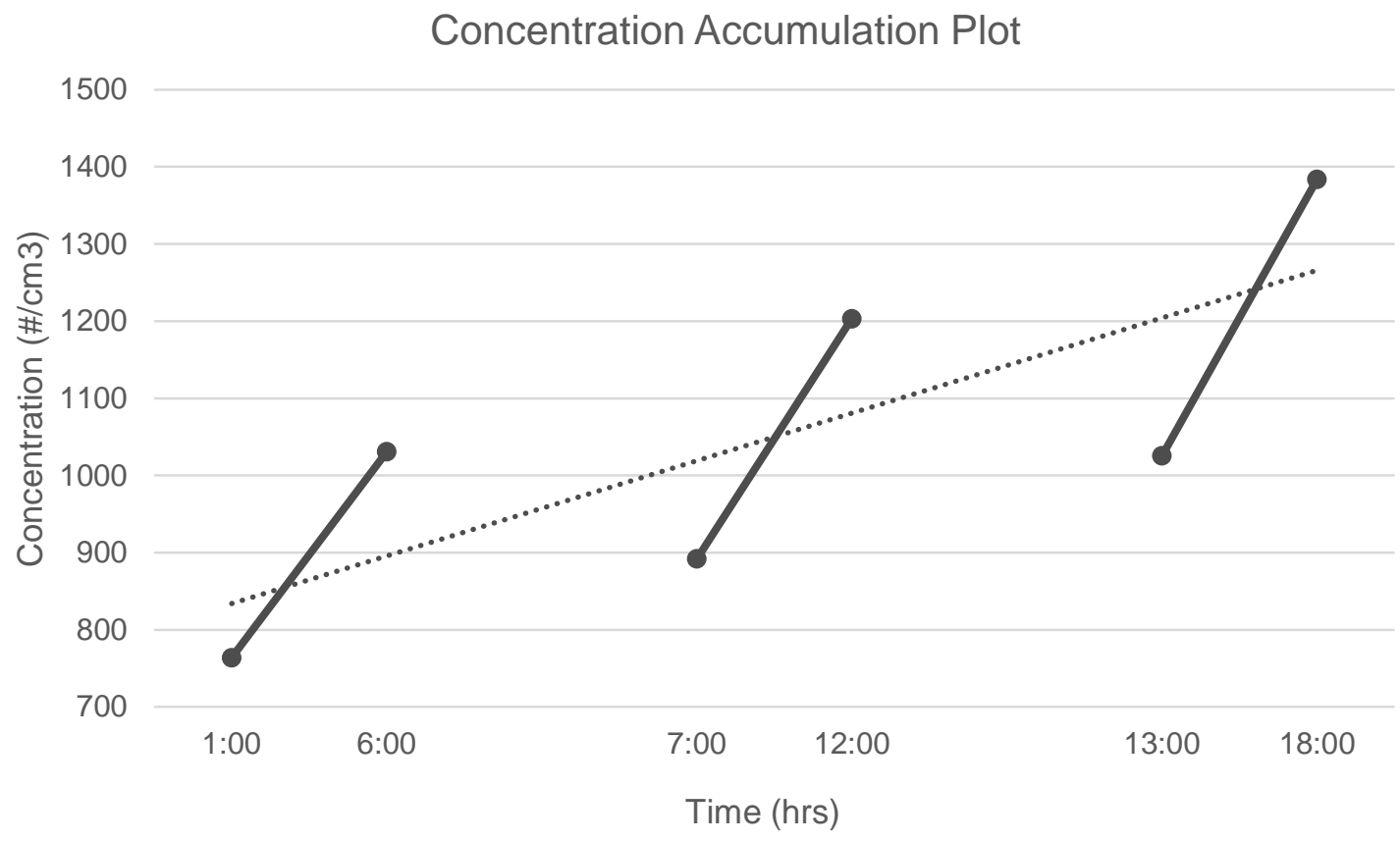

Figure 55 - Concentration Accumulation Factor Plot

It can be seen from Figure 55 that the concentration accumulates as the system runs. This is evident between hours 1:00 - 6:00 with an almost identical trend observed between hours 7:00 - 12:00 and 13:00 - 18:00. This is primarily due to particle build up within the system over time as the system is being operated. To account for this accumulation of particles over time concentration accumulation factors were developed for during a run as well as for following a previous run cycle. During a system run it can be seen that the concentration will increase roughly $300\left(\# / \mathrm{cm}^{3}\right)$ over a 5 hour timeframe. Therefore, using the slope of this line the concentration increase due to time while running can be defined as

$$
\text { Concentration Increase }(\# / \mathrm{cm} 3)=60 * t(\mathrm{hrs})
$$

This accounts for the accumulation in the system as it is running.

To account for the accumulation from a previous run a second equation can be defined. For this case, as the system is shut down, allowed to settle and restarted the following 24 hours it can be seen to retain a residual concentration from the previous run. This accumulation due to the residual is represented by the slope of the trend line in Figure 55. Between system runs the concentration accumulation due to residual can be defined as follows.

$$
\text { New Start }=\text { Previous Start }+\left(\frac{\text { Previous End-Previous Start }}{2}\right)
$$

Where the residual from the previous run can be accounted for in the new run to be started. 


\subsection{Results Discussion}

The experimental results have demonstrated that the nanoparticle aerosol generation system produces a unimodal particle size distribution with a geometric mean particle size below $200 \mathrm{~nm}$, standard deviation under 2.5 and the ability to hold consistent long term concentrations. Off line particle characterization confirmed aerosol measurements made during the test experiments. The factor effects analysis has shown that each input factor chosen for this model has an effect on the output. This highlights an appropriately designed experiment which was outlined in Ch. 5. Although each factor has some degree of influence, it must be noted that each input factor has a different effect and degree of influence on the output characteristics. The developed model for this system was also demonstrated to accurately predict outputs based on input settings with an average prediction accuracy of $92.5 \%$ and $94 \%$ for particle concentration and size respectfully. Optimal settings were determined to be achieved at levels $A_{3}, B_{3}$, $C_{3}, D_{1}$ and $A_{3}, B_{1}, C_{1}, D_{2}$ for particle concentration and size respectfully. Furthermore, the system was demonstrated to be repeatable when applying the concentration accumulation factor.

When reviewing the results of the factor effects for concentration it can be seen that there are two driving input factors that control the output concentration. These factors being the flowrate through the fluidized bed and the vibrator pressure. This confirms fundamental review and previous intuition that flowrate through the fluidized bed is primarily responsible for particle concentration control. It can also be noted that this control is almost linear in regards to input manipulation and output response. It was also found that the vibrator pressure has an almost linear response but with slightly less influence on output. It can also be noted here that there was a slight interaction among factors $B$ and $C$ on concentration. The results from the interactions analysis may suggest the presence of a resonance frequency in the system which may explain these interactions. The orientation of the vibrator has shown to have a slight effect on the output and is recommended to operate in the vertical position unless smaller particles are desired. Lastly, the venturi pressure proved to have little effect on the concentration output when operated in the experimental region as tested in this study.

Based on the factor effects analysis for particle size output it can be seen that the venturi pressure has a dominant influence on the output in a linear fashion. This makes sense providing the nature of the venturi and use of the high shear flow and expansion to deagglomerate particles. Based on these findings the venturi pressure should be run at the highest pressure recommended by the venturi manufacturer. This allows the highest concentration with the lowest mean particle size to be achieved. With regards to the fluidized bed flow and vibrator pressure it can be seen that particle size increases as these factors are increased. It can be noted that while factors $B$ and $C$ are used to increase concentration the mean particle size also increases almost linearly with the concentration. This shows a direct relationship 
between mean particle size and concentration. As the concentration increases (increased area under the particle size distribution curve) the mean particle size will inherently shift. Lastly, although it is recommended to operate the vibrator in the vertical direction the orientation may be adjusted to 45 degrees in order to help reduce overall particle size when desired.

Standard deviation has proven to have little variation among all the experiments with all values typically falling within 2.3 - 2.4. The factor effects analysis can still be used to achieve a lower standard deviation or tighter size distribution if desired. It can be seen that the lowest standard deviation is achieved when the venturi pressure is again at its maximum with similar relationships to the mean particle size with factors $B, C$ and $D$. Furthermore, as the dominant factors used to increase concentration are increased the particle size and size distribution are also increased. 


\section{CH. 7 SUMMARY AND CONCLUSIONS}

The nanoparticle aerosol generation system has potential to be commercialized as a research tool as well as in diverse consumer and commercial applications. Achieving the full potential of this technology depends on research and development on many fronts. As a preluding step to commercialization a series of design and experimental testing based investigations have been presented to characterize and advance the understanding of the technology.

The work presented in this dissertation contributes to advancing the nanoparticle aerosol generation technology in three primary areas which support the central hypothesis. The central hypothesis being that the particle size and concentration (output) can be varied by precise manipulation of the input parameters. Moreover, the output (particle size and concentration) can be set to a desired value based on a predictive mathematical model constructed experimentally. The first contribution is providing a fundamental analysis of the technology in order to size and spec components for the desired system to be developed. To achieve this a fundamental review of the operation is presented along with an analytical analysis of the specific components and overall system. This is followed by the second contribution with the development and demonstration of the controllable system which is later used for experimental testing and modeling analysis. The experimental testing of the controllable system provides valuable information for further development. The third contribution presented in this dissertation is a greater understanding of the nanoparticle aerosol generation system through experimental modeling. An experimental model was used to develop a predictive tool to optimize the settings over the set experimental range which were defined by the initial hardware specifications. The experimental mathematical model was then tested with respect to the experimental testing results. This allowed for the accuracy of the model to be quantified. The modeling results demonstrate that the system is capable of varying both concentration and particle size by precise manipulation of the input parameters. Moreover, these values can be predicted based on the mathematical model constructed experimentally. The model proved to be effective with an average prediction accuracy of $92.5 \%$ and $94 \%$ for particle concentration and size respectfully. 


\section{CH. 8 RECOMMENDATIONS AND CONTINUED WORK}

The nanoparticle aerosol generator has already had a significant impact on the identification of toxic level of nanomaterial for inhalation exposures. Furthermore, in addition to its inhalation toxicology and research applications, development of this technology will be continued for new applications such as: 1) clinical applications - pulmonary aerosol drug delivery devices; and 2) industrial applications nanomaterial surface coating applications, nano-composite generation techniques and nanoscale chemical processes. It is believed that this technology will be used to support future developments in the nanotechnology space and help bring to market more efficient drug delivery systems, new optical coatings and new materials with unique physical/electrical properties.

Continuous development of the nanoparticle aerosol generator will proceed in order to make the generator more efficient and capable of aerosolizing new nanomaterials of interest to researchers and the commercial markets. The developed system and mathematical model are able to be modified or adjusted to accommodate many future research goals. This provides a foundation for future endeavors that may involve further research, development or commercialization of the technology.

The questions and assumption throughout this work may be further explored with the knowledge gained as a result of this dissertation. With this gained knowledge it is recommended to explore the minimum and maximums of the system outputs and where the system converges or diverges. For example, this was seen in the venturi pressure on the concentration. The venturi started to reach its peak influence on concentration between levels 2 and 3 suggesting that it converges at level 3 . This analysis should be further explored for the remaining factors on each output characteristic. Additionally, a fundamental energy analysis of the system should be explored. Energy is required to break up and aerosolize the particles. As the desired particle sizes become smaller more energy is needed. It would be helpful to analyze this on a pure energy basis to compare the energy required to deagglomerate particles at the desired size vs. the energy being introduced to the system.

It is recommended to explore charge and magnetism models for both the device and the aerosolized particles. This has been initiated with the development of a stainless steel prototype as seen in Figure 56 below in an effort to better understand the effect of system charge, charge of particles and the related aerosol response. 


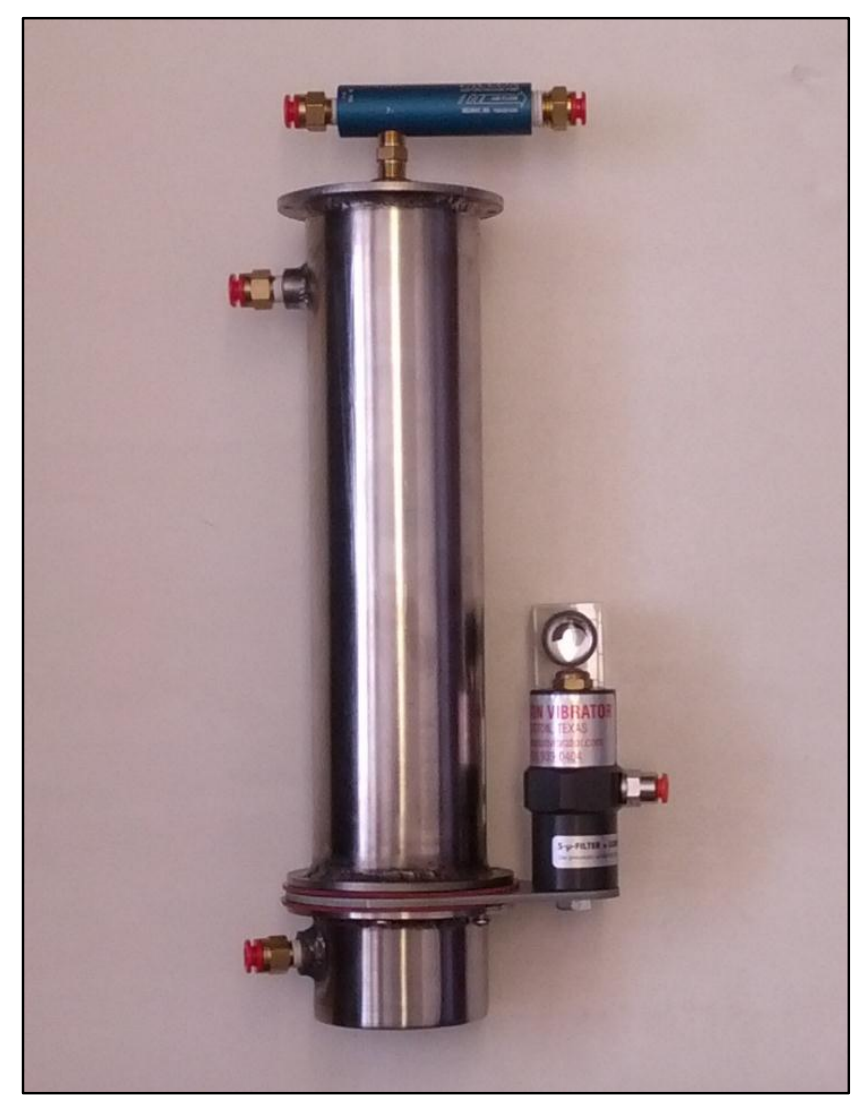

Figure 56 - Stainless Steel Prototype

The stainless steel unit above will allow the device to be grounded and retain a negative charge to eliminate the question of static charge buildup within the particle chamber. To extend this measure Teflon tubing is used for the transportation of the aerosol to the test chamber. While this effort allows grounding of the hardware components additional techniques may be used to control or influence the charge of the aerosolized particles. These methods, as previously described in section 1.4.1, include:

I. Field charging by passing the particles through an electrical field

II. Diffusion charging which is due to thermal collisions between particles and ions

III. Photoelectron charging in which electrons are emitted from particles by UV irradiation

A vibrations study is recommended to explore the response of variation in vibrational energy on the system. It has been shown that vibrational energy plays a significant role in the system and should be further explored to quantify parameters such as resonance, frequency and force regions. A method to adjust vibrational frequency and force independently is recommended to study these effects.

A study with variation in the uncontrollable parameters described in the initial system modeling is recommended. For example, the venturi, vibrator and baffle sizing should be explored. The baffle design should be analyzed in an effort to characterize the effects of the hole location, tube length, tube diameter, etc. Additionally, various fluidized bed techniques can be explored. These recommended investigations 
will provide valuable information for scalability and similitude studies. Dimensionless modeling, using the Buckingham $\mathrm{Pi}$ Theorem, is recommended to achieve this scalability and to uncover important relationships such as the influence of the generator size and dimensions on the output characteristics. Lastly, based on the repeatability study and the accumulation observations that were made in regards to the concentration it is recommended to clean the system regularly. The accumulation factor can be used to help predict input settings between runs and cleanings. With the results of the study it is recommended to clean roughly every $8-16$ hours of run time to reduce the influence of accumulation on the operation. 


\section{REFERENCES}

[1] T. Knuckles, J. Yi, D. Frazer, H. Leonard, B. Chen, V. Castranova and T. Nurkiewicz, "Nanoparticle Inhalation Alters Arteriolar Vasoreactivity through Sympathetic and Cyclooxygenase-Mediated Pathways," Nanotoxicology, vol. 6, no. 7, pp. 724-735, 2012.

[2] J. Yi, B. Chen, D. Schwegler-Berry, D. Frazer, V. Castranova, C. McBride, T. Knuckles, P. Stapelton, V. Minarchick and T. Nurkiewicz, "Whole-Body Nanoparticle Aerosol Inhalation Exposures," Journal of Visualized Experiments, no. 75, 2013.

[3] A. Tiwari, C. Fields and L. Marr, "A Cost-Effective Method of Aerosolizing Dry Powdered Nanoparticles," Aerosol Science and Technology, vol. 47, pp. 1267-1275, 2013.

[4] D. To, X. Yin, S. Sundaresan and R. Dave, "Deagglomeration of nano-particle aggregates via rapid expansion of high suspensions," AlChE Journal, vol. 55, no. 11, pp. 2756-3032, 2009.

[5] L. Schmoll, S. Elzey, V. Grassian and P. O’Shaughnessy, "Nanoparticle aerosol generation methods from bulk powders for inhalation exposure studies," Nanotoxicology, vol. 3, pp. 365-275, 2009.

[6] T. Nurkiewicz, D. Porter, A. Hubbs, J. Cumpston, B. Chen, D. Frazer and V. Castranova, "Nanoparticle inhalation augments particle-dependent systematic microvascular dysfunction," Particle and Fibre Toxicology, vol. 5, no. 1, 2008.

[7] J. Yi and T. Nurkiewicz, "Nanoparticle Aerosol Generator". United States of America Patent US8881997 B2, 19 October 2010.

[8] "Toxic Substances Control Act," Environmental Protection Agency, 2002.

[9] M. Adachi, K. Okuyama, H. Masuda, S. Matsusaka and K. Higashitani, "Electrical Charge Control," in Powder Handbook, Taylor \& Francis Group, LLC, 2006, pp. 465-484.

[10] L. Robert and W. Ralph, "Nanotechnology," Scientific Discovery and the Future of Medicine, vol. 313, no. 2, pp. 135-136, 2015.

[11] A. International, "American Society for Testing and Materials (ASTM) International," Terminology for Nanotechnology, pp. E 2456-06, 2006.

[12] T. Nurkiewicz, D. Porter, A. Hubbs, S. Stone, B. Chen, D. Frazer, M. Boegehold and V. Castranova, "Pulmonary Nanoparticle Exposure Disrupts Systematic Microvascular Nitric Oxide Signaling," Toxicological Sciences, vol. 110, no. 1, pp. 191-203, 2009. 
[13] R. t. C. Requesters, "Particulate Matter," United States Government Accountability Office, Washington, D.C. , July 2006.

[14] T. R. Nurkiewicz, D. W. Porter, A. F. Hubbs, S. Stone, A. M. Moseley, J. L. Cumpston, A. G. Goodwill, S. J. Frisbee, P. L. B. R. W. Perrotta, J. C. Frisbee and M. A. F. D. G. e. a. Boegehold, "Pulmonary Particulate Matter and Systemic Microvascular Dysfunction," HEI, 2011.

[15] T. Kok, H. Driece, J. Hogervorst and J. J. Briede, "Toxicological assessment of ambient and traffic-related particulate matter: A review of recent studies," Mutation Research, vol. 613, pp. 103-122, 2006.

[16] W. C. Hinds, Aerosol Technology, 2nd ed., Wiley - Interscience, 1999.

[17] World Health Organization, "Hazard Prevention and Control in the Work Environment: Airborne Dust," 1999.

[18] M. Sanders, "Inhalation therapy: an historical review," Primary care respiratory journal, vol. 16, no. 2, pp. 71-81, 2007.

[19] F. P. Muchao and L. V. R. F. d. S. Filho, "Advances in inhalation therapy in pediatrics," Jornal de Pediatria, vol. 86, no. 5, pp. 367-376, 2010.

[20] N. El-Gendy and C. Berkland, "Combination Chemotherapeutic Dry Powder Aerosols via Controlled Nanoparticle Agglomeration," Pharmaceutical Research, vol. 26, no. 7, pp. 1752-1763, 2009.

[21] H. Yoshida, H. Masuda and K. Higashitani, Power Technology: Fundamentals of Particles, Powder Beds, and Particle Generation, CRC Press, 2006.

[22] Y. Cheng, E. Barr and H. Yeh, "A Venturi Disperser as a Dry Powder Generator for Inhalation Studies," Inhalation Toxicology, vol. 1, pp. 365-371, 1989.

[23] D. Hristozov and I. Malsch, "Hazards and Risks of Engineered Nanoparticles for the Environment and Human Health," Sustainability, pp. 1161-1194, 2009.

[24] E. O. J. O. Günter Oberdörster, "Nanotoxicology: An Emerging Discipline Evolving from Studies," Environmental Health Perspectives, vol. 113, no. 7, 2005.

[25] R. Utikar, N. Darmawan, M. Tade, Q. Li, G. Evans, M. Glenny and V. Pareek, "Hydrodynamic Simulation of Cyclone Separators," Intech, 2010. 
[26] P. Tapkir and D. Kamble, "Analysis Of Cyclone Separator Using Empirical Models And CFD For Variation Of Dimensions," International Journal of Research in Engineering \& Advanced Technology, vol. 2, no. 6, pp. 225-233, 2015.

[27] V. A. M. \&. B. A. O. Joshua M. Rocklage, "Study of Secondary Deposits in Multiple Round Nozzle Impactors," Aerosol Science and Technology, vol. 47, no. 10, pp. 1144-1151, 2013.

[28] TSE Systems, Cascade Impactors for aerosol assessment during inhalation studies, 2014.

[29] T.-J. Wang, Y. Jin, A. Tsutsumi, Z. Wang and Z. Cui, "Energy transfer mechanism in a vibrating fluidized bed," Chemical Engineering Journal, vol. 78, p. 115-123, 2000.

[30] M. C. F. a. J. T. F. Roger Valeri Daleffe, "Analysis of the effect of particle size distributions on the fluid dynamic behavior and segregation patterns of fluidized, vibrated and vibrofluidized beds," ASIA-PACIFIC JOURNAL OF CHEMICAL ENGINEERING, vol. 2, pp. 3-11, 2007.

[31] P. Tang, D. Fletcher, H. Chan and J. Raper, "Simple and cost-effective disperser for aerosol particle size management," Elsevier, vol. 187, pp. 27-36, 2008.

[32] W. McKinney, B. Chen, D. Schwegler-Berry and D. Frazer, "Computer-automated silica aerosol generator and animal inhalation exposure system," Inhalation Toxicology, vol. 25, no. 7, pp. 363$372,2013$.

[33] TSE Systems, Dust Generator Wright For Dust Aerosol Generation during Inhalation Studies, 2013.

[34] T. Systems, Dust Generator Bundschuh for Dust Aerosol Generation during Inhalation Studies, 2013.

[35] TSI Incorporated, Small-Scale Powder Disperser Model 3433, 2012.

[36] C.-J. Tsai, G.-Y. Lin, C.-N. Liu, C.-E. He and C.-W. Chen, "Characteristic of nanoparticles generated from different nano-powders by using different dispersion methods," Topical Collection on Nanotechnology, Occupational and Environmental Health, vol. 14, no. 777, 2012.

[37] TOPAS-GMBH, Dust Generator Series SAG 410, 2016.

[38] PALAS-GmbH, RBG Series Powder dispereser for extremely low and medium mass flows.

[39] T. Myojo, T. Oyabu, N. Kenichiro, C. Kadoya, I. Tanaka, M. Ono-Ogasawara, H. Sakae and T. Shirai, "Aerosol generation and measurement of multi-wall carbon nanotubes," Journal of Nanoparticle Research, vol. 11, no. 1, pp. 91-99, 2008. 
[40] T. Kasai, K. Gotoh, T. Nishizawa, T. Sasaki, T. Katagiri, Y. Umeda, T. Toya and S. Fukishima, "Development of a new multi-walled carbon nanotube (MWCNT) aerosol generation and exposure system, and confirmation of suitability for conduction a single-exposure inhalation study of MWCNT in rats," Nanotoxicology, vol. 8, no. 2, pp. 169-178, 2014.

[41] A. D. Ledbetter, P. M. Killough and G. F. Hudson, "A Low-Sample-Consumption Dey-Particulate Aerosol Generation for use in Nose-only Inhalation Exposures," Inhalation Toxicology, vol. 10, p. 239-251, 1998.

[42] L. B. Wichers, A. D. Ledbetter, J. K. McGee, R. B. Kellogg, W. H. R. III, J. P. Nolan, D. L. Costa and a. W. P. Watkinson, "A method for exposing rodents to resuspended particles using," Particle and Fibre Toxicology, vol. 3, no. 12, 2006.

[43] C. Chen, H. Bai, H. Chein and T. M. Chen, "Continuous Generation of TiO 2 Nanoparticles by an Atmospheric Pressure Plasma-Enhanced Process," Aerosol Science and Technology, vol. 41, no. 11, pp. 1018-1028, 2007.

[44] C. Tsai, M. Echevarria-Vega, G. Sotiriou, C. Santeufemio, D. Schmidt, P. Demokritou and M. Ellenbecker, "Evaluation of environmental filtration control of engineered nanoparticles using the Harvard Versatile Engineered Nanomaterial Generation System (VENGES)," Topical Collection on Nanotechnology, Occupational and Environmental Health, vol. 14, no. 812, 2012.

[45] J. Ho Ji, J. Hee Jung, I. Je Yu and S. Soo Kim, "Long-Term Stability Characteristics of Metal Nanoparticle Generator Using Small Ceramic Heater for Inhalation Toxicity Studies," Inhalation Toxicology, vol. 19, pp. 745-751, 2007.

[46] D. Daniher and J. Zhu, "Dry powder platform for pulmonary drug delivery," Elsevier, vol. 6, pp. 225-238, 2008.

[47] J. Sung, B. Pulliam and D. Edwards, "Nanoparticles for drug delivery to the lungs," Elsevier, vol. 25, no. 12, pp. 563-570, 2007.

[48] R. Palgrave and I. Parkin, "Aerosol Assisted Chemical Vapor Decomposition Using Nanoparticle Precursors: A Rout to Nanocomposite Thin Films," JACS Articles, vol. 128, pp. 1587-1597, 2006.

[49] M. Habibi, M. Nasr-Esfahani, G. Emtiazi and B. Hasseinkhani, "Nanostructure Thin Films of Titanium Dioxide Coated on Glass and Its Anti UV Effect for Living Organisms," Current Nanoscience, vol. 6, no. 3, pp. 324-329, 2010.

[50] TSI Incorporated, Aerosol Statistics Lognormal Distribtuions, 2012. 
[51] M. S. Phadke, Quality Engineering using Robust Design, Prentice Hall, Englewood Cliffs, New Jersey: AT\&T Bell Laboratories , 1989.

[52] TSI Incorporated, Scanning Mobility Particle Sizer Spectrometer (SMPS), 2012.

[53] G. Taguchi, S. Chowdhury and S. Taguchi, Robust Design, McGraw-Hill, 2000.

[54] K. Willeke, Generation of Aerosols and Facilities for Exposure Experiments, Ann Arbor: Ann Arbor Science Publishers, 1980.

[55] "Nanoparticles: What Hazards-What Risks?," Ministry of Ecology and Sustainable Development, Paris, 2006.

[56] I. Colbeck and L. Mihalis, Aerosol Science: Technology and Application, John Wiley \& Sons, 2014.

[57] M. Berger, "Ethical aspects of nanotechnology in medicine," nanowerk, 8 January 2008. [Online]. Available: www.nanowerk.com.

[58] P. A. Schulte and F. Salmanca-Buentello, "Ethical and Scientific Issues of Nanotechnology in the Workplace," Environmental Health Perspectives, vol. 115, no. 1, pp. 5-12, 2006.

[59] J. Byeon and J.-W. Kim, "Aerosol based fabrication of a Cu/polymer and its application for electromagnetic interference shielding," Elsevier, vol. 520, no. 2011, pp. 1048-1052, 2011.

[60] T. Lind, S. Danner and S. Guentay, "Monodisperse fine aerosol generation using fluidized bed," Elsevier, vol. 199, pp. 232-237, 2010.

[61] A. Noel, K. Maghni, Y. Cloutier, C. Dion, K. Wilkinson, S. Halle, R. Tardif and G. Truchon, "Effects of inhaled nano-TiO2 aerosols showing two distinct agglomeration states on rat lungs," Elsevier, vol. 214, pp. 109-119, 2012.

[62] D. To and R. Dave, "Deagglomeration of Nanoparticle Aggregates via Rapid Expansion of Supercritical or High-Pressure Suspensions," AIChE Journal, vol. 55, no. 11, pp. 2807-2826, 2009.

[63] K. Kho and K. Hadinoto, "Optimizing aerosolization efficiency of dry-powder aggregates of thermally-sensitive polymeric nanoparticles produced by spray-freeze-drying," Elsevier, no. 214, pp. 169-176, 2011. 
[64] S. D’Addio, J. Chan, P. Kwok, B. Benson, R. Prud'homme and H.-K. Chan, "Aerosol Delivery of Nanoparticles in Uniform Mannitol Carriers Formulated by Ultrasonic Spray Freeze Drying," Springer, vol. 30, pp. 2891-2901, 2013.

[65] S. Behara, D. Farkas, M. Hindle and P. W. Longest, "Development of a High Efficiency Dry Powder Inhaler: Effects of Capsule Chamber Design and Inhaler Surface Modifications," Pharmaceutical Research, vol. 31, pp. 360-372, 2014.

[66] H.-K. Chan, "Dry powder aerosol drug delivery-Opportunities for colloid and surface scientists," Elsevier, vol. 10, no. 91, pp. 50-55, 2006.

[67] P. W. Longest, L. Golshahi, S. Behara, G. Tian, D. Farkas and M. Hindle, "Efficient Nose-to-Lung (N2L) Aerosol Delivery with a Dry Powder Inhaler," Journal of Aerosol Medicine and Pulmonary Drug Delivery, vol. 28, no. 3, pp. 189-201, 2015.

[68] S. Meenach, K. Anderson, J. Z. Hilt, R. McGarry and H. Mansour, "High-Performing Dry Powder Inhalers of Paclitaxel DPPC/DPPG Lung Surfactant-Mimic Multifunctional Particles in Lung Cancer: Physicochemical Characterization, In Vitro Aerosol Dispersion, and Cellular Studies," American Association of Pharmaceutical Scientists, vol. 15, no. 6, pp. 1574-1587, 2014.

[69] G. Pilcer, N. Wauthoz and K. Amighi, "Lactose characteristics and the generation of the aerosol," Elsevier, vol. 64, pp. 233-256, 2012.

[70] E. Athanassiou, R. Grass and W. Stark, "Chemical Aerosol Engineering as a Novel Tool for Material Science: From Oxides to Salt and Metal Nanoparticles," Aerosol Science and Technology, vol. 44, pp. 161-172, 2010.

[71] N. Jennerjohn, A. Eiguren-Fernandez, S. Prikhodko, D. Fung, K. Hirakawa, J. Zavala-Mendez, W. Hinds and N. Kennedy, "Design, demonstration and performance of a versatile electrospray aerosol generator for nanomaterial research and applications," Nanotechnology, vol. 21, 2010.

[72] M. Miettinen, J. Riikonen, T. Tapper, U. Backman, J. Joutsensaari, A. Auvinen, V. Lehto and J. Jokiniemi, "Development of a highly controlled gasphase nanoparticle generator for inhalation exposure studies," Human \& Experimental Toxicology, vol. 28, pp. 413-419, 2009.

[73] A. Jaworek, "Micro- and nanoparticle production by electrospraying," Elsevier, vol. 176, pp. 1835, 2007.

[74] B. Chen, D. Schwegler-Berry, W. McKinney, S. Stone, J. Cumpston, S. Friend, D. Porter, V. Castranova and D. Frazer, "Multi-walled carbon nanotubes: sampling criteria and aerosol characterization," Inhalation Toxicology, vol. 24, no. 12, pp. 798-820, 2012. 
[75] J. Akedo, "Aerosol Deposition of Ceramic Thick Films at Room Temperature: Densification Mechanism of Ceramic Layers," Journal of the American Ceramic Society, vol. 89, no. 6, pp. 1834-1839, 2006.

[76] F. Iskandar, "Nanoparticle processing for optical applications - A review," Elsevier, vol. 20, pp. 283-292, 2009.

[77] P. W. Longest, Y.-J. Son, L. Holbrook and M. Hindle, "Aerodynamic Factors Responsible for the Deaggregation of Carrier-Free Drug Powders to Form Micrometer and Submicrometer Aerosols," Pharmacutical Research, vol. 30, pp. 1608-1627, 2013.

[78] B. v. Ravenzwaay, R. Landsiedel, E. Fabian, S. Burkhardt, V. Strauss and L. Ma-Hock, "Comparing fate and effects of three particles of different surface properties: Nano-TiO2, pigmentary TiO2 and quartz," Elsevier, vol. 186, pp. 152-159, 2009.

[79] C. Weiler, M. Wolkenhauer, M. Trunk and P. Langguth, "New model describing the total dispersion of dry powder agglomerates," Elsevier, vol. 203, pp. 248-253, 2010.

[80] S. Silva and M. Tavares, "Sustainable strategies for nano-in-micro particle engineering for pulmonary delivery," Journal of Nanoparticle Research, vol. 16, no. 2602, 2014.

[81] S. Karner and N. Urbanetz, "The impact of electrostatic charge in pharmaceutical powders with specific focus on inhalation-powders," Elsevier, vol. 42, pp. 428-445, 2011.

[82] L. Schmoll, "Occupational Nanoparticle Exposure," ProQuest LLC., Ann Arbor, 2008.

[83] Blaustein Atomizer (BLAM) Single-Jet Model (User Manual), CH Technologies (USA).

[84] C. Ruppert, T. Kuchenbuch, M. Boensch, S. Schmidt, U. Mathes, V. Hillebrand, I. Henneke, P. Markart, I. Relss, R. Schermuly, W. Seeger and A. Gunther, "Dry powder aerosolization of a recombinant surfactant protein-C- based surfactant for inhalative treatment of the acutely inflamed lung," Society of Critical Care Medicine and Lippincott Williams \& Wilkins, vol. 38, no. 7, pp. 1584-1591, 2010.

[85] J. Antony, Design of Experiments for Engineers and Scientists, Burlington, MA: ButlerworthHeinemann, 2003.

[86] D. C. Montgomery, Design and Analysis of Experiments 3rd ed, John Wiley \& Sons, 1991.

[87] P. Stapleton, V. Minarchick, J. Yi, K. Engels, C. McBride and T. Nurkiewicz, "Does the Barker Hypothesis apply to maternal engineered nanomaterial exposure and fetal microvascular function?," American Journal of Obstetrics and Gynecology, vol. PMDI: 23643573, 2013. 
[88] B. A. Wong, "Inhalation Exposure Systems: Design, Methods and Operation," Society of Toxicologic Pathology, vol. 35, p. 3-14, 2007. 


\section{APPENDIX A}

List of aerosol generators said to generate aerosols in the nano range:

- Write Dust Feed from TSE Systems

- Vilinus Dry Powder Aerosol Generator from CH Technologies

- Dust Generator Bundschuh from TSE Systems

- Dust Generator Budiman from TSE Systems

- Fluid Bed Aerosol Generator from Intox

- Venturi Dispenser from Intox

- Slide Action Powder Generator from Intox

- MG100 from Naneum

- NG100 from Naneum

- BEG Series Powder Dispersers from Palas

- RBG Series Powder Dispersers from Palas

- Fluidized Bed Generator 3400A from TSI Incorporated

- Small Scale Powder Disperser 3433 from TSI Incorporated

- Dust Feeder SAG 440 from Topas Gmbh

- Dust Disperser SAG 420 from Topas Gmbh

- Dust Generator SAG 410 from Topas Gmbh 
Test Sample Data Sheet:

SIGMA-ALDRICH

sigme-aldrichcom

3050 Spruce Street, Saint Louis, MO 63103, USA Website: www.sigmaaldrich.com

Email USA: techserv@sial.com

Outside USA: eurtechserv@sial.com

Product Name:

\section{Product Specification}

Silicon dioxide - nanopowder, 10-20 nm particle size (BET), $99.5 \%$ trace metals basis

$\begin{array}{lll}\text { Product Number: } & 637238 & \mathrm{SiO}_{2} \\ \text { CAS Number: } & 7631-86-9 & \\ \text { MDL: } & \text { MFCDO0011232 } \\ \text { Formula: } & \mathrm{O} 2 \mathrm{Si} & \\ \text { Formula Weight: } & 60.08 \mathrm{~g} / \mathrm{mol}\end{array}$

TEST

Specification

Appearance (Color)

White

Appearance (Form)

Particle Size

Powder

10-20 nm (BET)

Conforms

ICP Major Analysis

Confirmed

Confirms Silicon Component

Trace Metal Analysis

Purity

99.5\% Based On Trace Metals Analysis

$\leq 6000.0 \mathrm{ppm}$

Meets Requirements

Specification: PRD.0.ZQ5.10000026590

Sigma-Aldrich warrants, that at the time of the quality release or subsequent retest date this product conformed to the information contained in this publication. The current Specification sheet may be avallable at Sigma-Aldrich.com. For further inquiries, please contact Technical Service. Purchaser must determine the suitability of the product for its particular use. See reverse side of invoice or packing slip for additional terms and conditions of sale.

1 of 1 


\section{APPENDIX B}

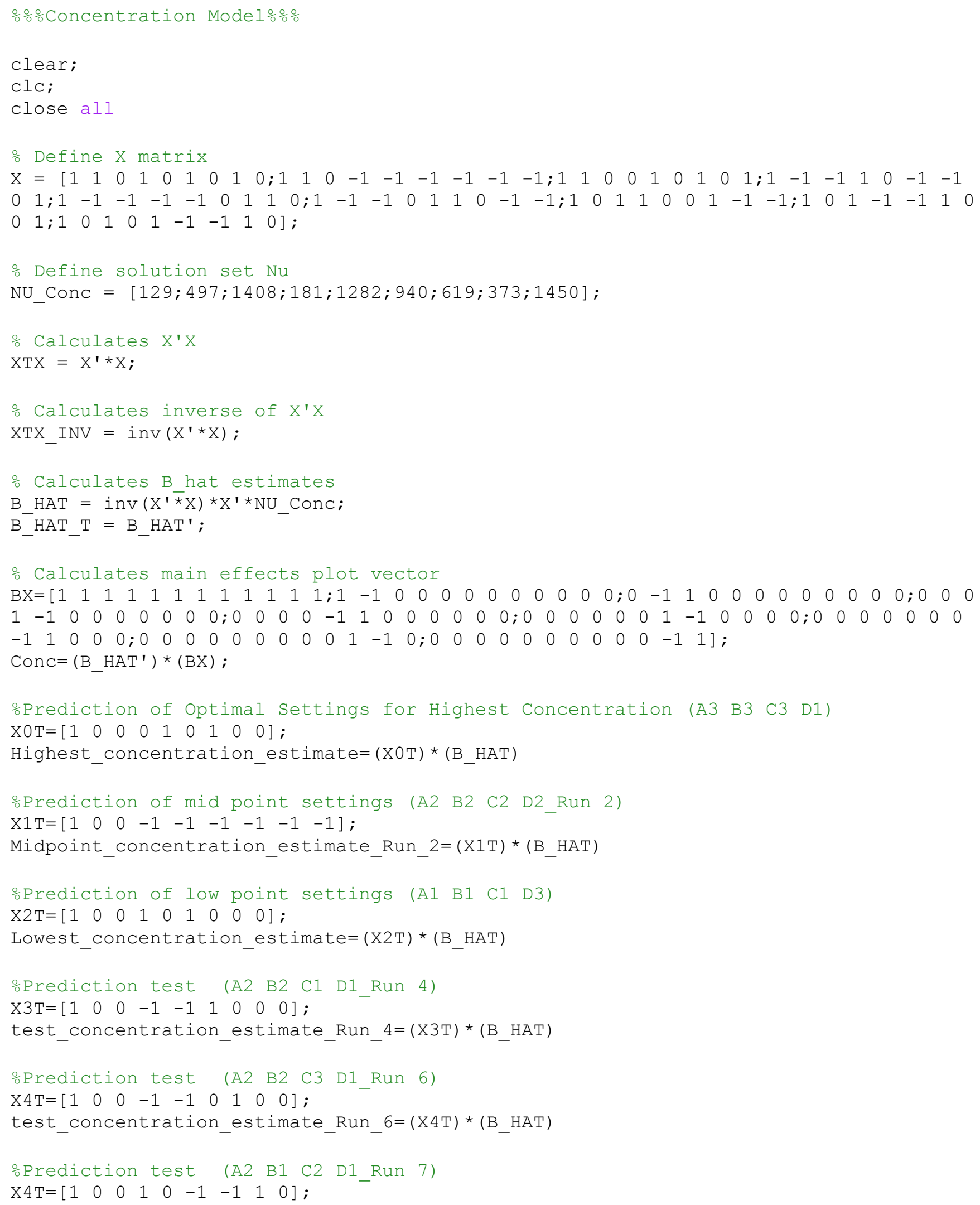




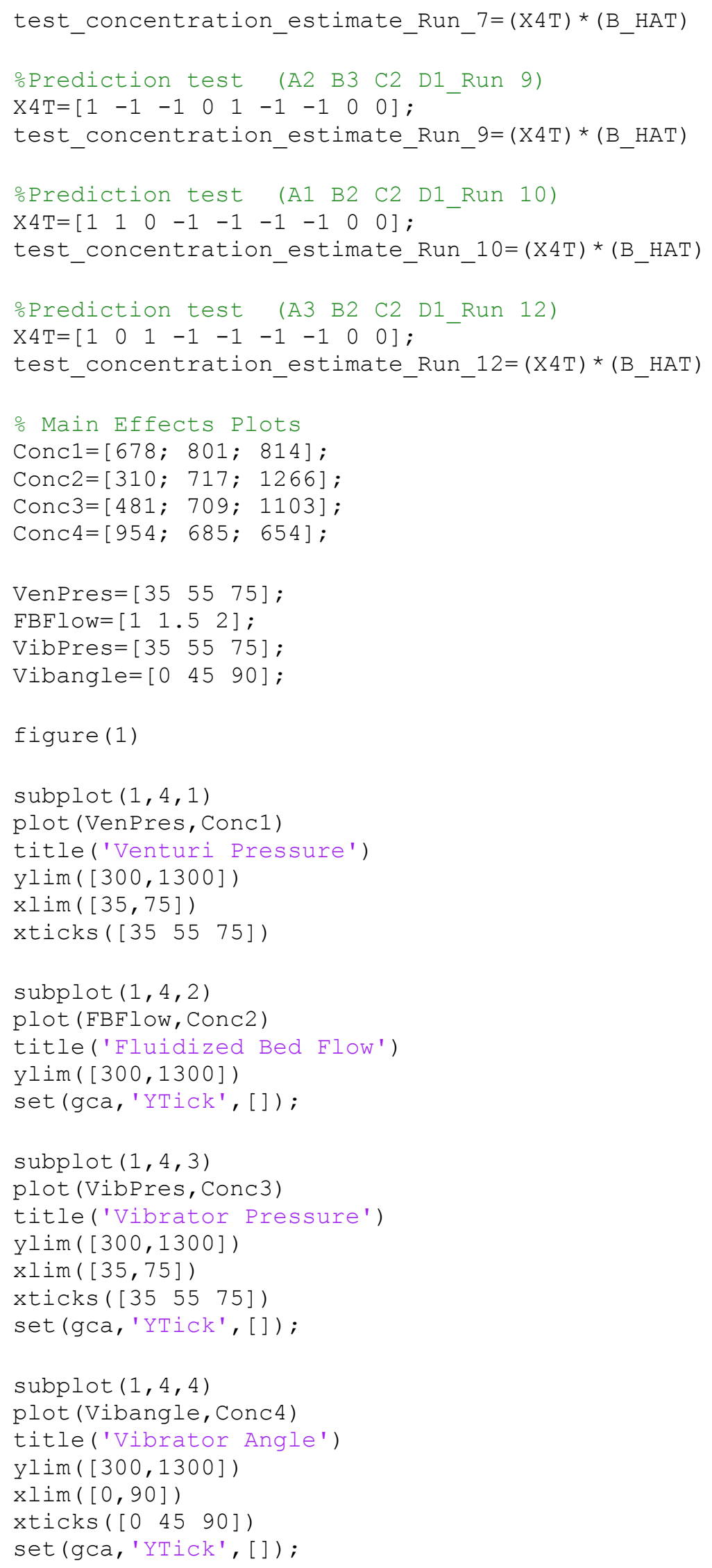




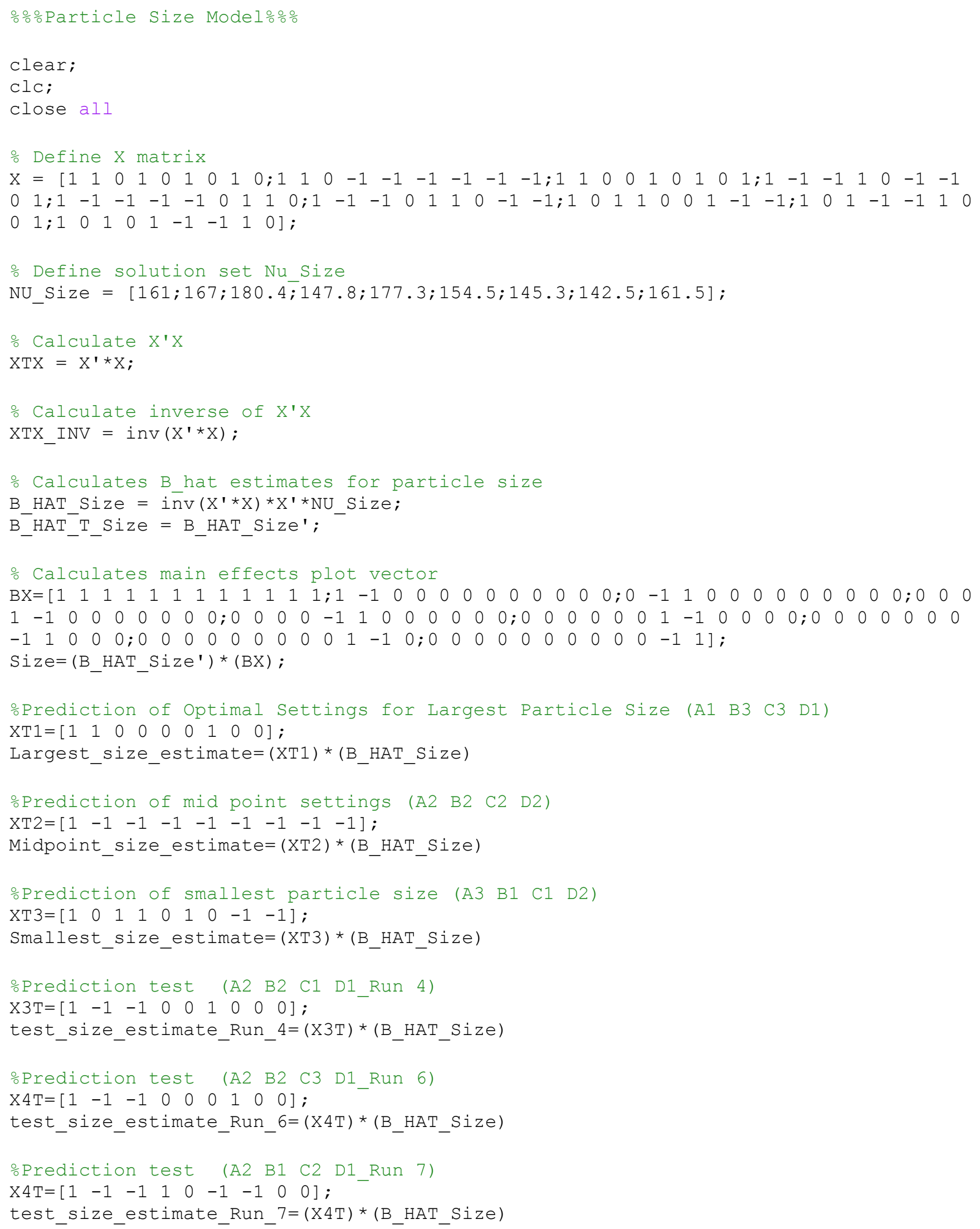




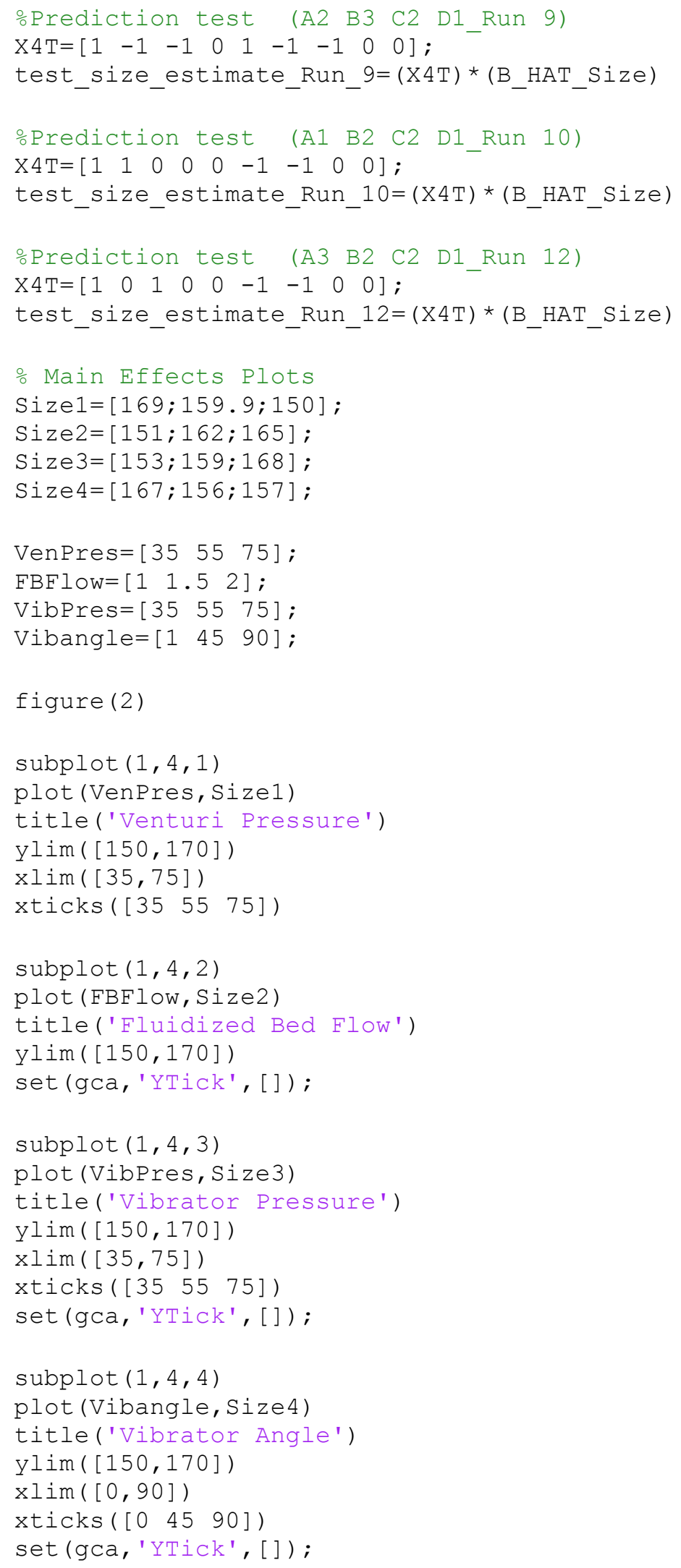




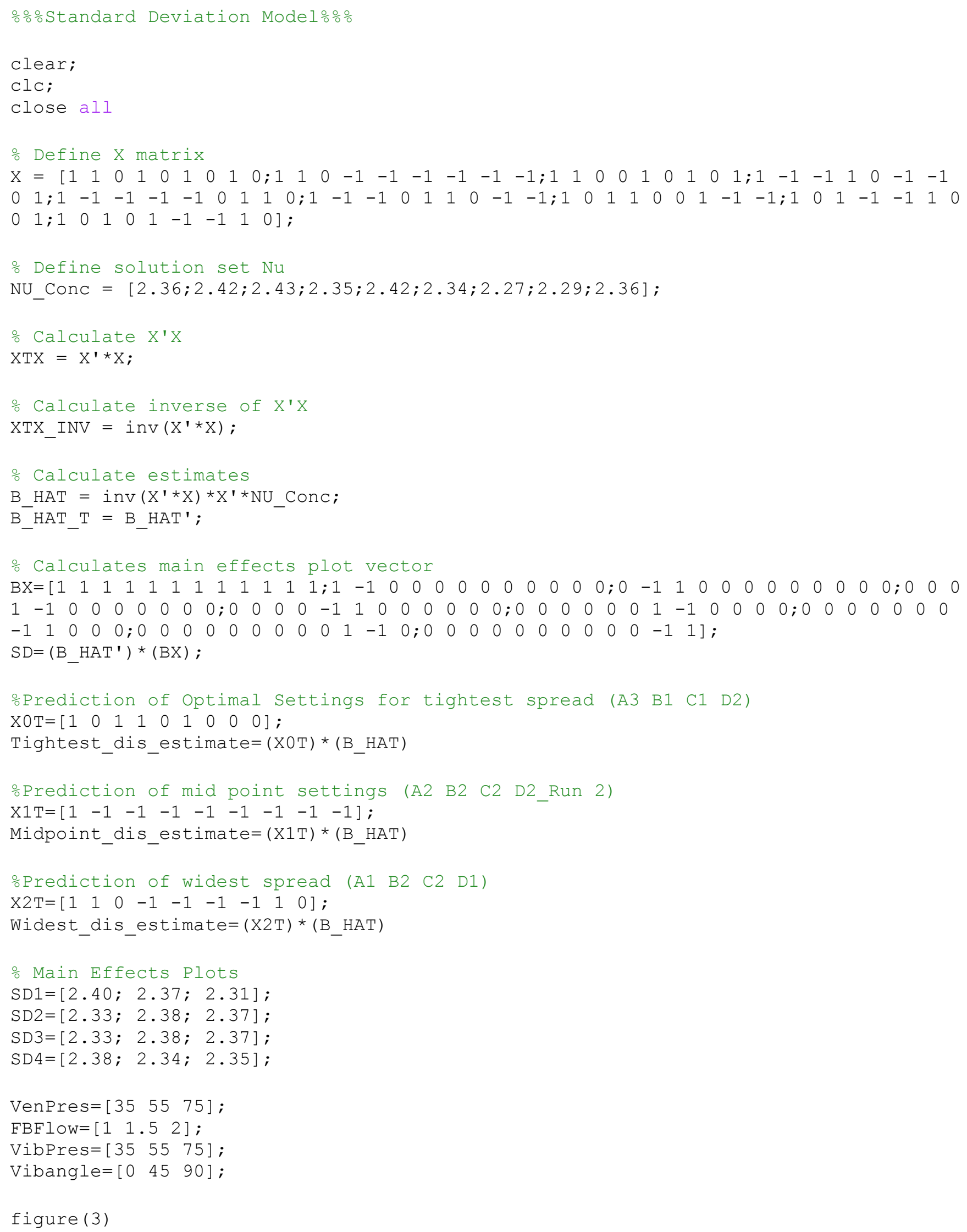




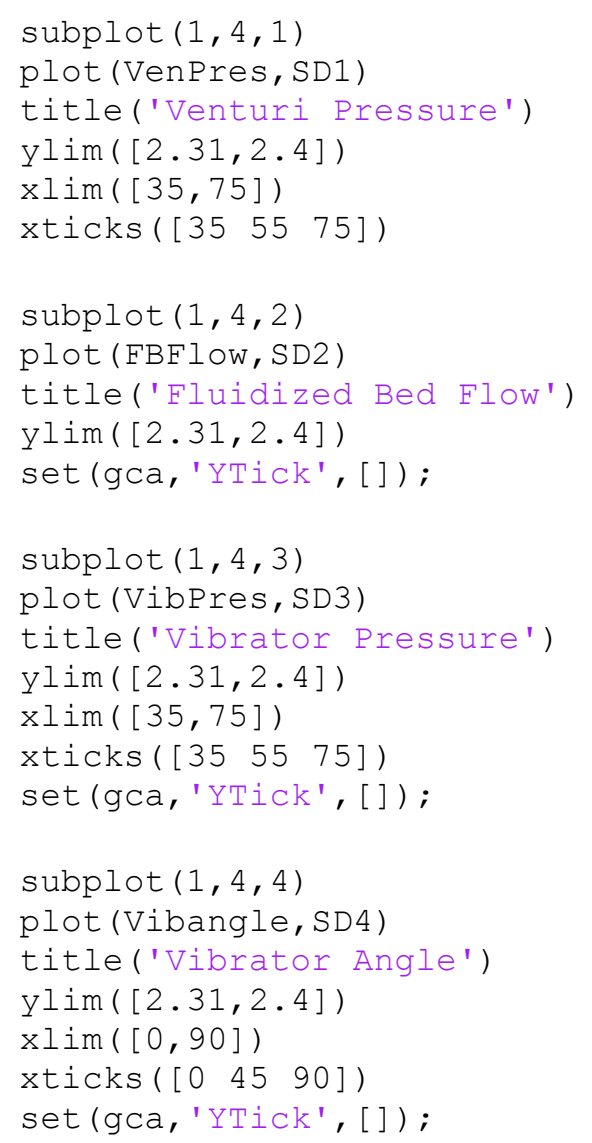

